\title{
XIII.
}

\section{Jahresbericht \\ über die Tätigkeit der Kgl. Universitäts-0hrenklinik \\ zu Halle a. S. vom 1. April 1907 bis 31. März 1908.}

\author{
Erstattet von I. Sehwartze.
}

Im Berichtsjahre 1907/08 wurden in der Kgl. UniversitätsOhrenklinik zu. Halle a. S. 3134 Patienten behandelt gegen 3282 Patienten im Vorjahre, wobei die aus dem vorigen Berichtsjahre in Behandlung verbliebenen nicht eingeschlossen sind.

In der stationären Klinik wurden aus dem Vorjahre übernommen 28 (13 männliche und 15 weibliche Kranke), neu aufgenommen wurden 305 Kranke (gegen 287 im Vorjahre), 200 männliche und 105 weibliche, so dab im ganzen 333 verpflegt wurden, 213 männliche und 120 weibliche. Es starben 18 $(5,4 \%), 12$ männliehe und 6 weibliche. Dieser höhere Prozentsatz der Todesfälle $(5,4 \%$ ) gegen das Vorjahr (wo auf 318 stationäre Kranke nur 10 Todesfälle $(3,5 \%)$ entfielen) erklärt sich durch den Umstand, daß uns neuerdings öfter als früher von Ärzten der Stadt und sogar von auswärtigen Krankenhäusern aus größeren Entfernungen Kranke überwiesen werden, die nach vergeblich gebliebenen Operationsversuchen bereits moribund eingeliefert wurden, oder doch in einem so hoffnungslosen $\mathrm{Zu}$ stande, dab uns ein weiterer operativer Kurversuch nicht mehr ratsam ersehien. In einzelnen Fällen wurde trotz der desperatesten Lage auf dringendes Verlangen der Angehörigen doch noch in extremis zu einer Operation geschritten, deren Erfolglosigkeit dann die prozentisehe Mortalitätsziffer ungünstig beinflubte.

Von den in der stationären Klinik behandelten Patienten wurden 280 entlassen, 172 männliche und 108 weibliche, so daß am 31. März 1908 ein Krankenbestand von 36 Kranken und 
zwar 23 männlichen und 13 weiblichen verblieb. Auf die Gesamtzahl der 333 stationär behandelten Kranken kamen 10172 Verpflegungstage, mithin durchschnittlich auf jeden Kranken 30,5 Tage. Der durehschnittliche tägliche Krankenbestand betrug 27,9. Kranke, überstieg also auch diesmal wie sehon seit langen Jahren die Zahl der etatsmälig vorhandenen 25 Betten. Der höchste tägliche Krankenbestand war am 28. März 08 mit 35 Kranken (gegen 36 im Vorjahre), der niedrigste am 21. August 07 mit 18 Kranken. Die durchschnittliche tägliche Aufnahme betrug etwa 0,9 Kranke, die höchste Zahl der an einem Tage aufgenommenen Kranken betrug 4, und zwar am 21. Ang. 1907.

Aus diesen Zahlen geht hervor, wie sehr die Klinik in den Zeiten stärkeren Krankenandranges überlegt war, und zwar handelte es sich dabei um Fälle schwerster Erkrankungen, die nur durch sofortigen operativen Eingriff aus der drobenden Lebensgefahr gerettet werden konnten. Infolgedessen war eine Abweisung dieser Patienten unmöglich. Auch die neben der stationären Klinik zur Verfügung stehenden 4 Filialen mit 47 Betten waren in den Zeiten stärkeren Krankenandranges voll belegt, so daß dann für längere Zeit selbst operative Fälle, die keine vitale Indikation zur Operation boten, zurïckgewiesen werden mußten. Mehrfach kam es auch vor, daß infolge der Überfuillung von Station und Filialen unbemittelte Kranke in Gasthäusern untergebracht werden mußten.

DaB derartige Zustände auf die Dauer unhaltbar sind, mub einleuchten, zumal eine sorgfältige Überwachung der an so auseinandergelegenen Orten untergebrachten Kranken nicht möglich ist. Infolgedessen $\mathrm{kam}$ es mehrfach vor, daß derartig untergebrachte Patienten die therapeutisehen Maßnahmen des behandelnden Arztes nicht befolgten und dadurch oft für Wochen die Heilung zum Nachteil von Patient und der die Verpflegung zahlenden Krankenkassen hinausgesehoben wurde. Mehrfach waren wir bei Kranken, die in Halle ansässig sind, gezwungen, infolge des andauernden Platzmangels auch größere Operationen ambulatorisch anszuführen. Auch der wiederholt hervorgehobene Mangel an Isolierräumen für Ohrenkranke mit ansteekenden Krankheiten (Scharlach, Diptherie, Syphilis etc.) machte sich weiter in der peinlichsten Weise bemerkbar, und nur infolge des bereitwilligen Entgegenkommens der Herren Direktoren der inneren und chirurgisehen Klinik waren wir in der Lage 
derartige Kranke durch Verlegung in die betreffenden Kliniken zu behandeln und falls notwendig, zu operieren.

Daß auch die für die Poliklinik bestimmten Räumlichkeiten in keiner Weise auch nur sehr mäßigen Ansprüchen in bezug auf Hygiene ete. entsprechen, ist bereits wiederholt hervorgehoben worden, zuletzt im vorjährigen Jahresbericht. (A.f. 0 . Band 71, S. 162).

Als Assistenten waren während des Berichtsjahres tätig: Dr. E. Dallman n ( $\dagger$ ), der vom Kgl. Kriegsministerium zur Klinik kommandierte Stabsarzt Dr. Is emer (im W. S. 07/08 als Privatdozent für Ohrenheilkunde habilitiert) und Dr. W. Küs tner.

Leider riß der unerbittliche Tod wieder eine Lücke in die Reihen der Mitarbeiter der Klinik. Am 6. November 1907 starb in Fürstenwalde a. Spree nach langem, schweren Krankenlager mein vortrefflicher erster Assistent Dr. Dallmann. Einen warmen Nachruf mit Würdigung seiner Verdienste um die Klinik habe ich ihm s. Z. an anderer Stelle gewidmet. (Arehiv Band 75 S. 166).

Am 1. Oktober rückte in eine etatsmäßige Assistentenstelle der bisher schon an der Klinik tätig gewesene Hilfsassistent Dr. Gmeinder. Als Volontär-Assistent war rom 1. Oktober ab Dr. Hausmann tätig.

Die Zahl der fur die Klinik inskribierten Zubörer betrug $18 \mathrm{im}$ Sommersemester 1908 (gegen 15 im Sommersemester 1907), 20 im Wintersemester 1908/09 (gegen 26 im Wintersemester 1907/08).

Im Berichtsjahr sind folgende Arbeiten aus der Kgl. Universitätsklinik hervorgegangen:

1. Dallmann und Isemer, Jabresbericht über die Tätigkeit der Kgl. Universităts-Obrenklinik zu Halle a. S. vom 1. April 1906 bis 31. März 1907 (Dieses Archiv Bd. 71, S. 161 ff.).

2. Fröse, Ein weiterer Beitrag zu den Erfahrungen bei der klinischen Behandlung von Mittelobreiterungen mit Staunngshyperămie nach Bier. Ibidem, Bd. 71 , Seite $1 \mathrm{ff}$.

3. Küstner, Über Tumoren des Akustikus und über die Möglichkeit ihrer Diagnose anf Grund der bisherigen Kasuistik. Jbidem, Bd, 72, S. $1 \mathrm{ff}$.

4. Schwartze, Historischer Rückblick auf die Entwicklung der Universitäts-Ohrenklinik Halle a. 8 . mit Statistik über die Krankenbewegnng und die Frequenz der Studierenden in derselben vom 15. Oktober 1863 bis1. April 1907. Zbidem, Bd. 72 , s. $11 \mathrm{ff}$.

5. Is emer, Zur Ätiologie des otitischen Kleinhirn-Abszesses, Ibidem, Bd. 74 (Festschrift). S. $244 \mathrm{ff}$.

6. Is emer, Die Bebandlung von Mittelohreiterungen mit Stauungshyperämie nach Bier (Habilitation schrift), bei C. Kämmerer u. Co. Hallea. S. 1907. 
Jahresbericht der Kgl. Universitäts-Ohrenklinik zu Halle a. S. 211

7. Is emer, Weitere klinische Erfahrungen über die Behandlung von akuten Mittelohreiterungen mit Stauungshyperămie nach Bier, dieses Archiv, Bd. 75, S. 95 ff.

Die Verhältnisse des Alters, der Heimat der Patienten, der Erkrankungen und der ausgeführten Operationen ergeben sich aus folgenden Tabellen:

I. Alterstabelle.

\begin{tabular}{c|c|c|c}
\hline $\begin{array}{c}\text { Altersklassen } \\
\text { Jahre }\end{array}$ & Männlich & Weiblich & Summa \\
\hline $0-2$ & 118 & 103 & 221 \\
$3-10$ & 522 & 458 & 980 \\
$12-20$ & 402 & 430 & 832 \\
$21-30$ & 245 & 140 & 385 \\
$31-40$ & 201 & 118 & 319 \\
$41-50$ & 96 & 83 & 179 \\
$51-60$ & 70 & 50 & 120 \\
$61-70$ & 43 & 39 & 82 \\
Unbekannt & 12 & 4 & 16 \\
\hline Summa & 1709 & 1425 & 3134
\end{tabular}

II. Heimatstabelle.

Halle a. S.

Provinz Sachsen . . . . . . . . . . 1220

. Hannover . . . . . . . . . . 5

,Westfalen . . . . . . . . , 2

, Hessen-Nassau . . . . . . . . 1

, Posen. . . . . . . . . . . 3

"Schlesien . . . . . . . . . . 4

"Brandenburg . . . . . . . . . 29

"OstpreuBen. . . . . . . . . . 2

Königreich Sacbsen . . . . . . . . . . 13

Großherzogtum Baden... . . . . . . . 3

Herzogtum Anbalt . . . . . . . . . , 80

, Sachsen Altenburg . . . . . . 3

, Sachsen Meiningen . . . . . . 2

"Braunsehweig. . . . . . . . 1

Furstentum Schwarzburg-Rudolstadt . . . . 2

, Reuß ältere Linie . . . . . . 2

" Reuß jungere Linie . . . . . . j

Freie und Hansastad Hamburg . . . . . 1

Österreich-Ungarn . . . . . . . . . . . . 1

Rheinprovinz . . : . . . . . .... 1

Unbekannt . . . . . . . . . . . . . 4 
III. Krankheitstabelle.

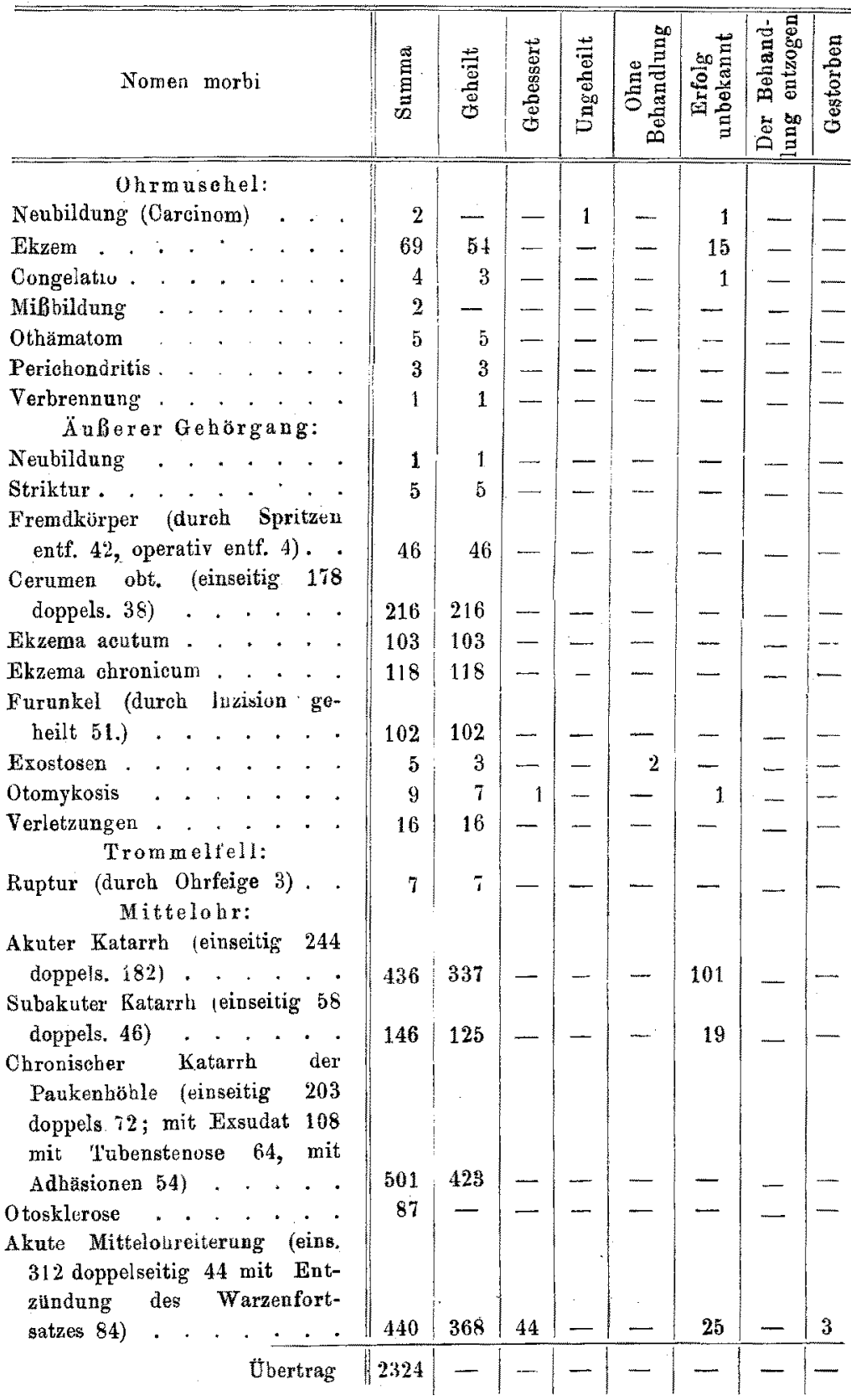




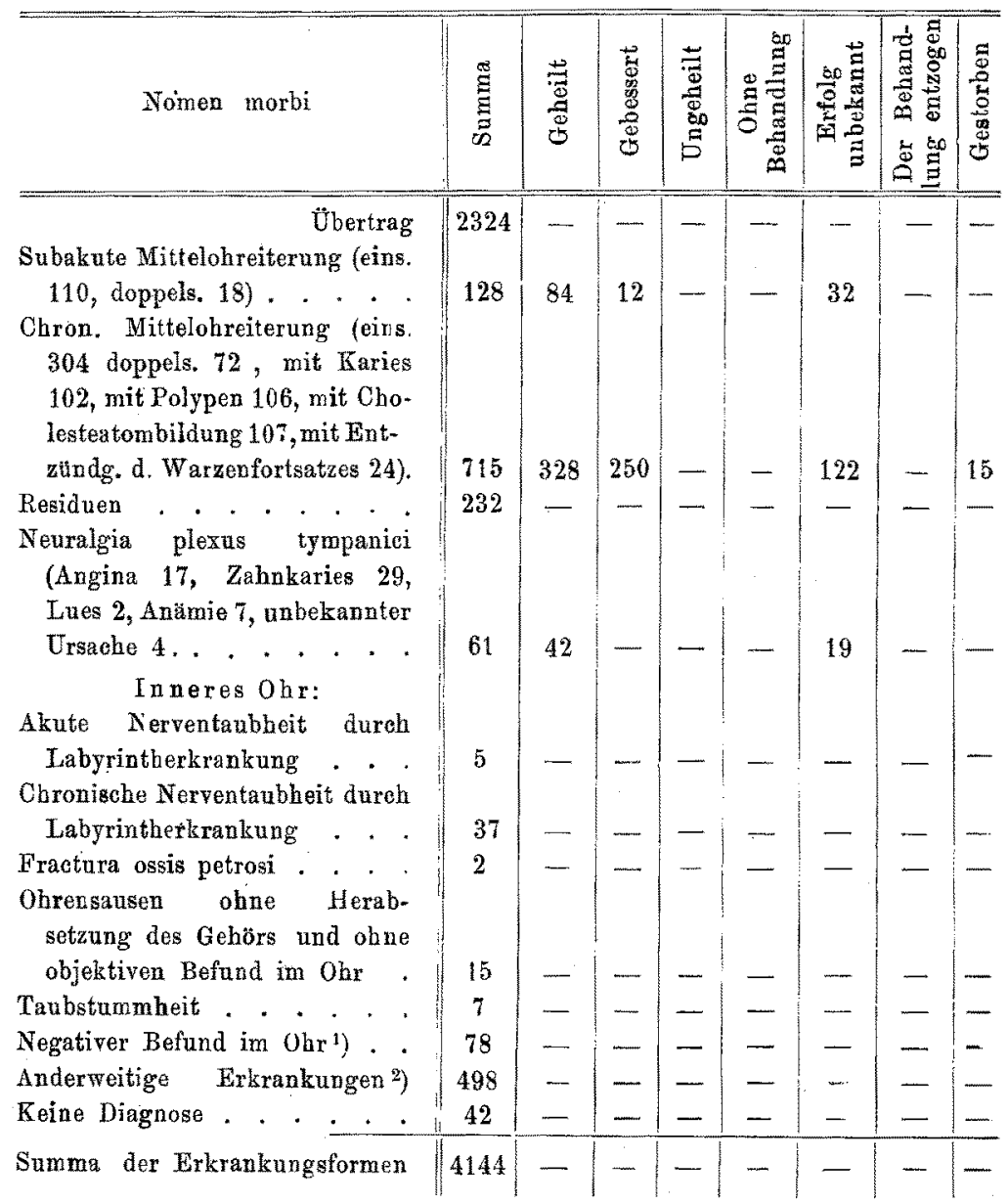

1) Betrifft meist Kranke, die von anderen Kliniken zur Feststellung des Ohrbefundes zugeschickt waren.

2) Betrifft vornehmlich Erkrankungen der Nase und ihrer Nebenhöhlen sowie des Nasenrachenraumes.

IV. Operationstabelle.

\begin{tabular}{|c|c|c|c|c|c|c|c|c|}
\hline Nomen operationis & 䙷 & 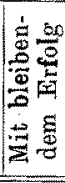 & 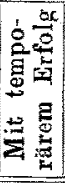 & 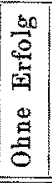 & 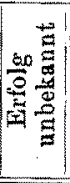 & 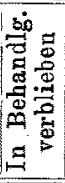 & 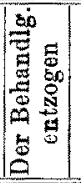 & 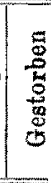 \\
\hline $\begin{array}{l}\text { Inzision des Gehörganges } \\
\text { Entfernung von Fremdkorpern fiurch } \\
\text { Spritze entfernt } 27 \text {; mit dem Zaufal- } \\
\text { schem Hebel 5) , . . . }\end{array}$ & 28 & 28 & - & - & - & - & - & - \\
\hline Ubertrag & 60 & 60 & - & -1 & ine & - & - & \\
\hline
\end{tabular}




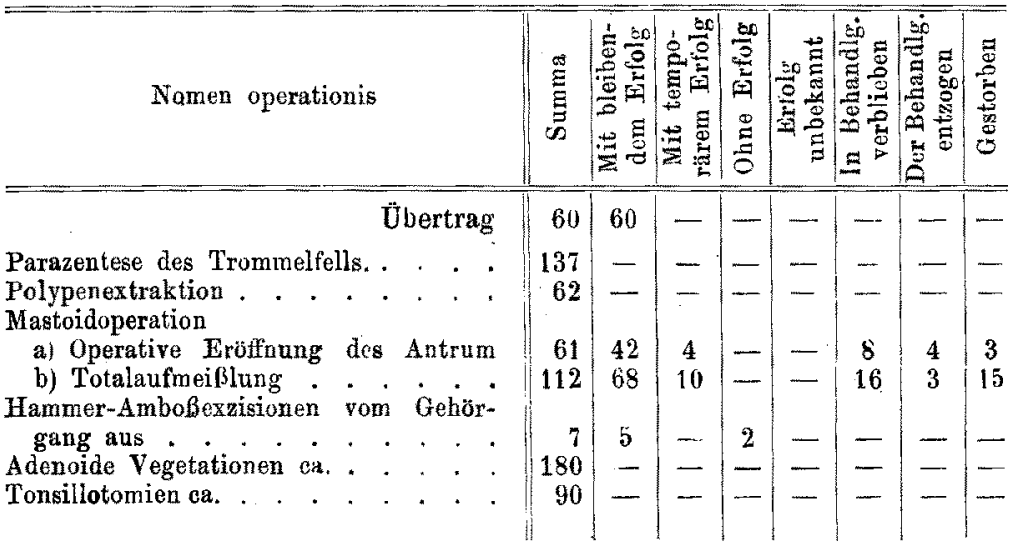

Die im Berichtsjahre in der Kinik beobachteten Todesfälle sind die folgenden 18, welche chronologisch nach dem Todesdatum geordnet sind.

\section{I.}

Emil Sehull, Tischler, $33 \mathrm{Jahr}$, aus Halle. Aufgenommen den 1. 4. 07, gestorben 1. 4. 07.

Anamnese: Der P., über den năhere anamnestische Anhaltspunkte fehlen, ist vor etwa vier Wochen außerhalb der Klinik anderweitig wegen akuter Mastoiditis operiert und danach wegen andauernder Schmerzen elektrisiert worden. Die ersten Wochen nach der Operation soll es dem Kranken gut gegangen sein. Vor ca. 14 Tagen aber haben sich heftige Genick- und Koptschmerzen eingestellt, zu deren sieh auch Erbrechen gesellte. Am 1. 4. 07 wurde der P, von dem behandelnden Arzte der Klinik moribund therwiesen. Status praesens vom 1. 4. 1907: bleicher, schlecht genăhrter Mann. Sensorium benommen. Pupillen gleichweit, verengt, reagieren noch auf Lichtreiz. Keine Lăhmungserscheinungen, auch nicht an den Augenwinkeln. Das Gebiet des Facialis ist intakt. Urin eiweißbaltig, aber zuckerfrei.

Der P. macht den Eindruck eines Moribunden; er wimmert laut und wirft sich unruhig hin und her. Nackengegend druckempfindlich.

T. $39,4^{\circ}$ (im Rectum), P. 104, klein und unregelmäBig.

Umgebung des rechten Ohres: Operationswunde fast vernarbt. Keine Druckemptindlichkeit in der Umgebung.

Rechter Gehörgang weit, frei von Sekret; Trommelfell gut zu übersehen, verdickt mit Gefäbinjektion.

Lumbalpunktion ergab eitrig-trüben Liquor unter erhöhtem Drucke. Von einer Operation wurde deshalb abgesehen. Im Ausstrich wie in Kultur des Liquors Streptokokken nachgewiesen (im hygienischen Institut).

Ord. Morphiuminjektion. Unter großer Unruhe erfolgt in Koma noch an demselben Tage abends $10 \%$ Uhr der Tod.

Auszug aus dem Sektionsprotokoll vom 2. April 1907:

Leptomeningitis purulenta des Gehirns und Riickenmarks, Pyocephalus internus, Hyperämie und Ödem des Gehirns. Trübe Schwellung des Herzmuskels. Pleuritis chronica adhaesiva beider- 
seits. Hyperämie, Ödem der Lungen beiderseits, frisehe Gangränherde im rechten Unterlappen, Fiebermilz. Parenehymatöse Degeneration der Leber. Trübe Schwellung und Hyperämie der Nieren.

Schläfenbeinsektion.

Hinter dem äußeren Gehörgange ist eine Knochenwunde, weit nach hinten ausgreifend, mit reichlichen, frischen Granulationen erfüllt. Das Antrum mastoideum selbst ist nur in Hirsekorngröße eröffnet. Am Tegmen antri ist der Knochen erweicht. Die Hirnsinus sind frei, ibre Wandungen glatt. Die Dura mater an der hinteren Fläche der Felsenbeinpyramide ist in der Ausdehnung vom Meat. audit. int. bis fast an den Sinus heran mißfarben, dureh Eiter abgehoben, der Knochen selbst weich, morseh, brïchig und zum Teil mit Granulationen durchsetz. Bei Eröffnung der Bogengänge findet sich, vor allem in del Ampulle des hinteren und oberen Bogenganges frische blutreiche Granulation aber kein Eiter. Der Meat. andit. int. ist ebenfalls frei von Eiter. In der Schnecke finden sich makroskopisch keine krankhaften Veränderungen. Das Trommelfell ist erhalten, aufgelockert, in der Paukenhöhle nur Spuren trüben Sekretes.

Epikrise: Der P. kam moribund in die Klinik, mit deutlichen Zeichen von Meningitis purulenta. Die Lumbalpunktion ergab eitrigtrübe Flüssigkeit und es wurde deshalb von einem weiteren operativen Eingriff von vornherein als nutzlos abgesehen. Wie die bakterielle Untersucbung ergab, handelte es sich in diesem Falle um Infektion mit Streptokokken. Bei größerer, kunstgerechter Freilegung des Antrum und Entfernung aller Krankheitsherde im Knochen hätte das Zerstörungswerk sich in der Richtung nach der Schädelhöhle nicht so leicht weiterverbreiten können. Jedenfalls kann man sich des Gedankens nicht erwehren, daß die anfängliche Besserung nach der Operation nur eine scheinbare war, und ein tieferer Krankheitsherd Gelegenheit fand, sich nach der Scbädelhöhle auszubreiten. Die Operation war nicht kunstgerecht ansgeführt.

\section{II.}

Ernst Barth, $39 \mathrm{Jahr}$ alt, Lohgerber aus Delitzsch. Aufgenommen am 15. 3. 1907, gestorben am 11. 4. 1907,

Cholesteatom. Kleinhirnabszeß mit Sinuspblebitis und Meningitis. Ist bereits von Dr. Isemer publiziert in Bd. 74, S. 244. 
III.

Margarete Baumann, Arbeiterskind aus Balle, 3 Jahr alt. Aufgenommen 25. 4. 1907, gestorben 28. 4. 1907.

Anamnese: $P$. war bereits in der hiesigen Kinderheilstătte vom Roten Kreuz ärztlich behandelt worden und wurde in die Klinik mit meningitischen symptomen und rechtsseitiger Facialislähmung eingeliefert. Letztere soll bereits $1 / 4 \mathrm{Jahr}$ bestanden haben. St. pr.: Das Kind war in leidlichem Ernährungs- und Kräftezustande. Nackengegend ist sehr druckempfindlich. Augen sind geschlossen. Befund: Die Umgebung des Ohres ist ohne Besonderheiten. Der rechte Gehörgang aber durch Senkung der hinteren Gehörgangswand verengt; bei Erweiterung sieht man, dab vom Eiter umspülte Granulationen den Bliek nach dem Trommelfell verlegen. Da P. soporös ist, ist Hörprüfung ausgeschloseen. T. $38,9^{\circ}$, P. 100-104.

Es wird zunächst die Lumbalpunktion gemacht, die blntig gefärbten Liquor ergab, der nicht unter erhöhtem Druck stand. Dann folgte die Totalaufmeißelung. Dabei äußerlich in den Weichteilen und Kortikalis keine Besonderheiten. An der hinteren knöchernen Gehörgangswand ein Durchbruch, aus welchem Granulationen wuchern. Breite Freilegung aller Mittelohrräume, in denen sich überall Granulationen und Eiter befinden. Die mediale Antrumwand zeigt geringe Karies; stärkere Granulationen sind in der Gegend unterbalb des Steigbugels, der nicht sichtbar ist. Von den beiden änßeren Ossiculis wird nichts gefunden.

Plastik, Tamponade, Verband.

Verlauf: 26. 4. 07. Das Fieher blieb zwischen 39 und $40^{\circ}$. Die bakteriologische Untersuchung des Liquor cerebrospinalis ergab im Ausstrich und in den Kulturen keine Bakterien. P. andanernd unruhig; kein Erbrechen.

27. 4. 07. Da P. die Verbandstoffe unter der Binde hervorgezupft hat, ist Verbandwechsel nötig. Große Unruhe, Wimmern und Stöhnen. Fieber wie tags zuvor. Kein Ërbrechen, geringe Nackensteifigkeit.

28. 4. 07. Fieber wie zuvor andauernd. Unter Anzeichen von großer Unruhe und Atemnot tritt nachmittags der Exitus ein.

Sektionsprotokoll.

Graziler Knochenbau mit Verdickung der Epiphysen an den langen Röhrenknochen. Haut über dem Abdomen grünlich verfärbt. Fettpolster der Brust und Bauchdecken gut entwickelt. Das fettarme Netz ist aufgerollt. Die Serosa der blassen Dârme ist spiegelnd. Kein fremder Inhalt im Abdomen. $Z$ werchfellstand beiderseits vierte Rippe. Die Knorpelknochengrenzen der Rippen sind verdickt. (Rhachitischer Rosenkranz). Lungen sinken zurück. Die rechte ist über der Spitze etwas verwachsen. Kein fremder Inhalt in den Pleurahöblen. Der fettarme Herzbentel liegt in Kleinbandtellergrổe vor. Innenfläche spiegelnd. Es entbălt einige Tropfen klaren Serums.

Cava superior sowie jugularis werden in situ präpariert und eröffnet. Es finden sich in ihnen Cruor, Speckgerinnsel und dunkeles, flüssiges Blut.

Herz entsprechend groß, gut kontrahiert. Rechtes Ostium für knapp zwei, linkes für einen Finger durchgăngig, Klappenapparat intakt. Herz. muskel blaß, weich, von diffus gelblichen Fecken in reichlicher Zahl durchsetzt. Aorta, Coronararterien ohne Befund.

Linke Lunge. Volumen und Gewicht erhöht. Aus dem Bronchus, dessen Schleimhaut geschwellt und injiziert ist, kommt anf Druck schaumig gelbliche Flüssigkeit, Pulmonalis frei, Pleura spiegelnd, graurötlich bis dunkelblau violett gefärbt. Lungengewebe, sehr blut- und saftreich, besonders im Unterlappen. In den abbängigen Partien des Unterlappens finden sich kleine bronchopneumonische Herde. Drüsen am Hilus sind vergrößert und zeigen auf dem Durchschnitt mehr oder minder ausgedehnte Verkäsungen. 
Rechte Lunge: Volumen und Gewicht wie links. Die Pleura zeigt Residuen von Verwachsungen. Rechte Lunge gleicht im wesentlichen der linken, nur finden sich keine pneumonischen Herde.

Hals - und Rachenorgane: Tonsillen etwas vergrößert, auf dem Durchschnitt blaß. In der rechten Tonsille in einer Lakune eitriges Sekret. Die Rachenmandel ist etwas vergrößert. Schleimhaut des Kehlkopfes und der Trachea ist injiziert und mit gelblichem Schleim bedeckt. Thyreoidea ohne Befund. Milz 9:6:2. Kapsel gespannt, blaurot, zart. Parenchym von guter Konsistenz, mittlerem Blutgehalt. Auf der Schnittfäche von blauroter Farbe, deutlicher Follikel- und undeutlicher Trabekelzeichnung. Leber $19: 11: 4,5$. Kapsel zart, gespannt, Parenchym blutreich, verfettet, Gallen blase ohne Befund, ebenso Magen, Pankreas. Nieren blutreich, trüb, geschwollen. Darm: Schleimhaut blaß, im unteren lleum finden sich mehrere ãltere, typische tuberkulöse Geschwüre. Mesenterialdrüsen vergrößert, sehr derb, zeigen auf dem Durchsehnitt ausgedehnte Verkäsungen, Harnblase ohne Befund.

Schädeldach dem Alter entsprechend, Diploë blutreich, Dura ziemlich fest mit dem Schädeldach verwachsen, sehr stark gespannt, im Sinus longitudinalis Cruor, Fibrin and dunkles, flüssiges Blut. Innenfläche der Dura trocken, zart. Gyri stark abgeplattet. W eiche Häute: Gefäße mäßig gefüllt, über der Konvexität keine subarachnoideale Flüssigkeit. Über dem Temporallappen sieht man dicken, gelbgrünen Eiter ím subarachnoidealen Raum, im Bereiche der Sulci auftretend, der nach der Basis zu reichlicher wird und im Bereiche der Fossae Sylvii und am Pons seine größte Menge erreicht. Nach Herausnahme des Gehirns quillt aus dem Wirbelkanal ebenfalls Eiter in reichlicher Menge hervor. Die Ventrikel sind erweitert und enthalten stark getrübtes Serum. Die Hirnsubstanz besonders die weiße ist anßerordentlich weich, fast zerfließend. Blutgehalt mittelstark, sonst keine Veränderungen am Gehirn. Im Bereiche der rechten Felsenbeinpyramide ist die Dura mater schmutzig, grünlich verfärbt. Sie läßt sich daselbst leicht vom Knochen abziehen und enthălt dort schmierig eitrigen Belag. Aus dem Por, acust. int, und aus Fissura, Glaseri rechts quillt schmieriger, gelblicher, ubelriechender Eiter hervor. Die Sinus der Basis enthalten Cruor, Fibrin und dunkles, flüssiges Blut, der Sinus cavernosus rechts jedoch einen eitrig zerfallenen Thrombus. Rü ckenmark: Dura stark gespannt, auch im subarachnoidealen Raume findet sich reichlich dicker, gelbgrünlicher Eiter. Rückenmarkssubstanz sehr weich und blab.

Diagnosis post mortem:

Meningitis purulenta cerebralis et spinalis. Eitrig zerfallener Thrombus im Sinus cavernosus dext. Beginnender Pyocephalus internus, hochgradiges Ödem des Gehirns. Pleuritis chronica adhaesiva rechts. Hyperämie, ödem der Lungen. Bronohitis catarualis. Verfettung des Herzmuskels, Fiebermilz, Verfettung der Leber, trübe Sehwellung der Nieren, tuberkulöse Geschwïre des Darmes. Verkäsung der mesenterialen, mediastinalen und bronchialen Lymphdrisen, Hyperplasie der Rachen. und Gaumentonsillen.

Schläfenbeinsektion: Die Dura ist bereits von der Felsenbeinpyramide entfernt. Die Knochenoberfläche ist miBfarben aber glatt. Im Meat. aud. int. steht schmieriger grünlicher Eiter in reichlicher Menge. In der schwärzlich verfärbten 
Operationshöhle ist der horizontale Bogengang gut erhalten sichtbar, der Facialiskanal liegt jedoch oberhalb des ovalen Fensters in grober Ausdehnung offen, der Nerv selbst ist innerhalb des Kanales in eitrige Schmiere gebettet und zwar bis uber das Ganglion genicul. hinaus, ist graugrün verfẩbt und erweicht bis zum Meat. audit. int. hin. Der periphere Teil der Nerven sieht gesund aus. Das Promontorium ist kariös, sieht schwärzlich verfärbt aus, zeigt nach vorn vom Foramen rotundum und ovale eine längliche Lücke. Das Foramen rotundum sowie das ovale Fenster stehen offen. Vom Steigbügel findet sich nur ein Rudiment, das etwa der Hälfte der Platte entspricht, von den beiden andern Gehörknöchelchen ist, wie schon im Operationsbericht gemeldet ist, nichts mehr vorhanden. Das Vestibulum ist mit mißfarbigem Eiter erfüllt; die Sebneckenwindungen und die Bogengänge sind frei von Eiter, enthalten klare Flitssigkeit, Tegmen antri und aditus ad antrum intakt, ebenso wie das Tegmen tympani.

Epikrise: Eine genauere Anamnese konnte nicht ermittelt werden. Man kann wohl nach dem Verlauf und der Autopsie mit einiger Sicherheit annehmen, daß es sich bei der kleinen P. um eine schon lange bestehende chronische Obreiterung auf tuberkulöser Basis handelte. Wahrseheinlieh hat die tuberkulöse Infektion ihre Eingangspforte im Intestinaltraktus gefunden, es waren verkäste Mesenterialdrüsen und vor allem tuberknlöse Darmgeschwüre vorhanden. Freilich könnte die Infektion auch durch die Atmungswege stattgefunden haben, da die Drüsen am Hilus gleichfalls vergrößert und verkäst waren, sonst war jedoeh mit Ausnahme alter pleuritiseher Residuen nichts $\mathrm{zu}$ finden, das auf Lungentuberkulose schließen liebe. Es wird die Verkäsung der Mediastinaldrüsen jedenfalls erst durch Verschleppung tuberkulösen Materials auf den Wegen der Lymphbahnen vom Verdaungstraktus aus erfolgt sein. Auf gleichem Wege wird auch die Obreiterung erfolgt sein, die wahrscheinlich auch tuberkulöser Natur war, was allerdings zwar nicht erwiesen ist, jedoch aus dem Verlauf und dem Befund bei der Operation anzunehmen ist. Sicherlich hat die Ohreiterung bereits sehr lange Zeit bestanden, wie lange ließ sich anamnestiseh nicht eruieren; es steht nur fest, dab die Facialislähmung schon ein viertel Jahr vor dem Tode bestanden hatte. Der Canalis Fallopii war kariös angenagt und der Nerv selbst eitrig infiltriert. Parallel dieser Zerstörung ist die Karies 
am Promontorium einhergegangen. Die Zerstörung der äußeren Ossicula liegt zeitlich weiter zurück, man hätte sonst noch bei der Operation oder Sektion Rudimente derselben finden müssen. Vom Steigbügel war noch ein Restchen da. Nach Zerstörung des runden und ovalen Fensters ist die Eiterung in das Vestibulum eingedrungen, hat die Bogengänge aber noch verschont. Von hier aus ist jedenfalls die Meningitis nicht erfolgt, denn nachzuweisen war es nicht, ob etwa der Aquaeductus vestibuli den Weg der Eiterung bezeichnete. Wohl aber zeigte der N. facialis von der Lüeke des Canalis facialis unterhalb des Bogenganges bis in den M. audit. int. eitrige Imbibition und vollständige Erweichung.

Da das Kind bereits vor der Operation somnolent war und bei der Einlieferung andere deutliche Zeichen ron Meningitis da waren, ist die Annahme, daß die Operation die eitrige Meningitis herbeigeführt oder in Verlaufe beschleunigt haben könne, mit Sicherheit auszuschließen.

Sehr auffallend ist, daß die bakteriologisehe Untersuchung des Liquor cerebrospinalis einen negativen Befund ergab, (hygienisches Institut) da doch bei der Sektion eine eitrige Meningitis des Wirbelkanales gefunden wurde, die nach Menge und Beschaffenheit des Eiters zu schließen schon mehrere Tage bestanden haben mubte. $\mathrm{Ob}$ der vor der Operation entnommene Liquor getribt war, konnte wegen der Beimengung von Blut niebt beurteilt werden.

\section{IV.}

Reinhold Brückenauer, 1 Jahr alt, Seiltänzerskind aus Kötschau bei Merseburg. Aufgenommen am 8. I. 1907, gestorben am 15. V. 1907.

Anamnese: Vor etwa 14 Tagen soll sich hinter dem rechten Ohr eine Geschwulst gezeigt haben, die von einem Arzte inzidiert wurde; seitdem wurde das Kind dem Arzte nicht wieder vorgestellt und wird heute in die Klinik gebracht. Genaneres kann uber die Vorgeschichte nicht mitge= teilt werden, da die vagabondierenden Eltern sich nicht um das Kind kümmern.

Status praesens vom 8.1. 1907. Blasses, krank aussehendes Kind in schlechtem Emährungszustand. Rechtsseitige Facialisparese. Über beiden Lungen verkärzter Schall und Diffuse bronchitische Geräusche, Temperatur 37,5 bei der Autnahme. Cmgebung des Ohres: Hinter dem rechten Ohre befindet sich eine Inzision, aus der etwas Eiter fließt.

Gehörgang- und Trommelfellbefund: Rechts: Gehörgang voll Eiter, hintere obere Gehörgangswand gesenkt, Einblick auf die Paukenhöhle dadurch verhindert. Links: Gehörgang gleichfalls voll Eiter, in der Tiefe Grannlationen, die das Trommelfell verdecken.

Hörprüfung nicht ausfuhrbar.

Therapie und Krankheitsverlauf: 
10. 1. 07 Typische Aufmeißelnng beiderseits.

Rechts: Schnitt durch die alte Inzision. Corticalis rauh, von grauschwarzer Farbe, nekrotisch. Im erweiterten Antrum Knochennekrose und freier Eiter. Lin $\mathrm{ks}$; Weichteile mäßig infiltriert, Corticalis in Erbsengröße mit Granulationen durchbrochen. Antrum und Aditus sebr groß. Im Antrum Eiter. Beiderseits Drain, Jodoformgazetamponade, Nabt, Verband. bis 38,8 .

20. 1. Ungestörter Wuudverlauf, Körpertemperatur stets erhöht, abends

24. 1. Auch auf der linken Seite stellt sich Facialislähmung ein, nachdem sich vorgestern ein Sequester durch den Gehörgang abgestoben hat.

23. 2. Das Kind muB täglich verbunden werden, da jedesmal beide Gebörgänge und Wundhöhlen mit grünlichem, aashaft stinkendem Eiter angefüllt sind, Beiderseits erscheinen die binteren Gehörgangswände und die sonst sichtbaren Teile der Schläfenbeine schwarz. Körpertemperatur immer erhöht; sie schwankt zwischen 38 und 39,5 . Schallverkürzung und bronchitische Rasselgeräusche über beiden Lungen, Hüsteln.

28. 3. Beim Ausspülen immer Knochensand im Spülwasser.

22. 4. Trotz täglicher Spülungen und täglichem Verbandwechsel zeigen die Operationswunden keine Neigung, sich zu schließen. Das Aussehen des Kindes greisenhaft. Appetit immer gut, trotz unverändert fortbestehendem Fieber. Andauernd Diarrhoe.

27. 4. Das Kind magert immer mebr ab; nach vorübergehender Verstopfung wieder Durchfälle. Andauerndes Hüsteln. Fieber, kleiner, beschleunigter Puls.

15. 5. 07. Unter zunehmender Herzschwâche tritt heute früh der Exitus ein.

\section{Sektionsprotokoll:}

Leiche von sehr reduziertem Ernährungszustand. Totenflecke und Totenstarre vorhanden, Muskulatur stark atrophisch, von blaß brauner Farbe.

K opf: Schädeldach ziemlich dünn, mäßig blutreich, Dura mit dem Schädel verwachsen, Imnenfläche glatt und glänzend. Weiche Hänte spiegelnd, subarachnoideale Flüssigkeit beträchtlich vermehrt. Piagefäße von mittlerer Füllung. Gefäße der Basis ohne Befund. In den Sinus flüssiges Blut, Cruor und Speckgerinsel. An der Hinterfäche der Schläfenbeinpyramiden in der Gegend des Porus acusticus internus finden sich in der Ausdehnung eines Markstückes kleine miliare weißlich gelbliche Knötchen. Hirnsubstanz weich, blaß, etwas ödematös, geringer Hydrocephalus internus; Ependym der Ventrikel glatt und glänzend. Klein hirn, Hirnstamm ohne Besonderheiten.

$Z$ werchfellstand rechts 4 . Interkostalraum, links 5 Rippe.

Fettarmes Netz herabgeschlagen, deckt die mäßig geblähten Därme, deren Serosa stellenweise injiziert ist und ringförmig angeordnete miliare Knötchen durchschimmern läßt. Kein fremder Inhalt im Ảbdomen.

Nach Herausnahme des Brustbeins sinken die Lungen ein wenig zurück. Rechte Lunge durch strangförmige leicht lösliche Verwachsungen der Thorax wand adhärent. Linke Lunge frei. In den Pleurahöhlen kein fremder Inhalt: Der Herzbentel liegt in 2-Markstückgröße frei und enthält zwei EBloffel klares Serum. Herz entsprechend grob, Klappenapparate intakt. Herzmuskel von blaBroter Farbe, mit gelblichen diffusen Fleckchen durchsetzt. Lin ke Lunge: Volumen und Gewicht erhöht. Aus dem Bronchus, dessen Schleimhaut blab ist, entleert sich auf Druck schaumig eitrige Flüssigkeit Pulmonatis frei, Plenra spiegelnd Oberlappen blut- und saftreich, von zahlreichen miliaren, z. T. zu kirschgroßen und größeren Komplexen konfluierenden Knötchen durchsetzt. Luftgehalt in diesen Partien aufgehoben. Unterlappen gleicht im wesentlichen dem Oberlappen, nur sind die miliaren Knötcben meist diffus verteilt und höchstens zu Kirscbkerngröße konfluiert.

Rechte Lunge: Volumen und Gewicht, Bronchus und Pulmonalis wie links; Pleura zeigt im Bereich des Unterlappen die Residuen der Verwachsung und fibrinöse Auflagerungen. Oberlappen in seiner oberen Hälfte pneumonisch infiltriert. Innerhalb der infiltrierten Partien miliare 
Knötchen, meist in Häufchen, wie im linken Oberlappen konfluiert. In der unteren Hälfte ein etwa pflaumengroßer im Zentrum erweichter Verkäsungsherd. Mittellappen und Unterlappen gleichen im wesentlichen dem Unterlappen links.

Leber entsprechend groß, Kapsel spiegelnd; Parenchym von mittlerem Blutgehalt und guter Konsistenz, stellenweise infiltriert. Gallenblase ohne Besonderheiten.

Milz nicht vergrößert, Kapsel stellenweise fibrös verdickt, Parenchym ziemlich derb, mit deutlicher Trabekel- und Follikelzeichnung.

Ni eren entsprechend groß, Fettkapsel spärlich, fibris zart. Oberfläche glatt. Rinde blaß, leicht überquellend, trüb, deutlich gegen die Pyramide abgesetzt.

Magen und Pankreas ohne Besonderheiten. Im Mesenterium zahlreiche, bis kirschgroße, meist verkäs te L y mphdrüsen.

Darm: Schleimhaut im allgemeinen blaß und ödematös. Im oberen Teile des Dünndarmes finden sich vereinzelte Geschwüre von typisch tuberkulösem Habitus, denen auf der Oberfiäche die vorhin beschriebenen Knötchen entsprechen. Im Ileum werden die Geschwüre zahlreicher, ringförmig; auch im Dickdarm finden sich zahlreiche Geschwüre letzterer Art.

Diagnosis post mostem: Hydrocephalus externus, Anaemie und Ödem des Gehirns. Tuberkelknötchen an der hinteren oberen Fläche der Schläfenbeinpyramiden. Tuberkulosis peribronchialis beider Lungen mit pneumonischer Infiltration des rechten Oberlappens. Pleuritis fibrosa et fibrinosa dextra, tuberkulöse Darmgeschwüre, Verkäsung der bronchialen und mesenterialen Lymphdrüsen. Fettige Degeneration des Herzmuskels und der Leber. 'Trübe Schwellung und Ödem der Rinde beider Nieren.

Epikrise: Das Kind ist nicht infolge des Ohrleidens, sondern an Miliartuberkulose gestorben.

Schon bei der Aufnahme des sehr heruntergekommenen Kindes in der Klinik wurde mit hoher Wabrscheinlichkeit das Vorhandensein einer allgemeinen tuberkulösen Erkrankung. diagnostiziert. Von der beiderseits vorgenommenen typischen Aufmeißelnng wurde deshalb nur eine vorïbergehende Besserung des Allgemeinbefindens erwartet. Aber selbst der erhoffte Temperaturabfall trat nicht ein, sondern die Körpertemperatur blieb dauernd - besonders abends - erhöht, die Lungen- und Darmsymptome der Tuberkulose wurden deutlicher und der Kräfteverfall machte trotz relativ guten Appetits von Tag zu Tag Fortschritte, bis nach mehrmonatlichem Krankenlager durch Herzschwäche der Tod eintrat.

Die Sektion bestätigte, daß es sich im vorliegenden Falle um eine ausgesprochene Miliartuberkulose handelte, die aller Wahrscheinlichkeit nach von den verkästen bronchialen oder mesenterialen Lymphdrïsen ausgegangen war. Von diesen primären tuberkulösen Krankheitsherden aus war wohl eine 
massenhafte Überschwemmung des Blutes und der Lymphbahnen erfolgt. Auf diesen Wegen waren die Bazillen in die Lungen, den Darm, die Dura (iiber den Sehläfenbeinpyramiden) und in die Paukenhöhle gelangt und hatten in letzterer zu ausgedehnter Zerstörung des Knochens und des Nervus facialis geführt, links etwas schleichender wie rechts.

Schläfenbeinsektion und mikroskopische Untersuchung wurden unterlassen, um die makroskopisch sehr anschaulichen Präparate in toto zur Demonstration zu erhalten.

V.

Melanie Stubenrauch, $23 / 4$ Jahr, ans Schmiedefeld in Thüringen, Vater Eisenbahnarbeiter. Aufgenommen 30. März 1907. Gestorben 20. Mai 1907.

Anamnese: 3 Monate vor der Aufnahme Masern, seit einem Monat Eiterung aus dem rechten Ohr bemerkt. Ob dieselbe schon im Anschluß an die Masern eingetreten ist, bleibt $z$ weifelhaft. Seit 14 Tagen ist Anschwellung vor dem rechten $\mathrm{Ohr}$, dann später auch hinter dem $\mathrm{Ohr}$ aufgetreten. Ob Fieber bestanden hat, wissen die Eltern nicht. Schwerhörigkeit ist nicht aufgefallen, weil das 2 weite $0 \mathrm{br}$ gesund war.

Stat. praesens: 30 . 3. 1907.

Blasses, wimmerndes Kind in mäßig gutem Ernährungszustand, Temp. $39,3^{\circ}$. Die rechte Obrmuschel steht senkrecht und nach vorn ab; hinter ihr eine gerötete, fluktuierende Geschwulst, die sehr druckempfindlich ist. Im rechten Gehörgang ein obturierender Polyp; kopiöser eitriger Ausfluß. Komplete Facialislähmung rechts.

Operation am Tage der Aufnahme.

30. 3.07. Totalaufmeibelung rechts. Der Weichteilschnitt spaltet einen großen subperiostalen AbszeB, aus dem 2 Eßlöffel Eiter von rahmiger Konsistenz entleert werden. Das Planum mast. ist vom Periost entblößt und zeigt zablreiche Blutpunkte. Es besteht ein Durchbruch der hinteren häutigen und zum T'eil der knöchernen Gehörgangswand. Ausschneidung der Abszeßmembran und einiger indurirler Drüsen. Entfernung des obturierenden Polypen im Gehörgange. Die Corticalis des Warzenfortsatzes war fest; die Zellen vor dem Antrum kariös, und wie das Antrum selbst mit Schleimeiter erfüllt; daneben zeigten sich im Antrum derbe fibröse Polypen ron gleicher Beschaffenheit wie der obturierende Gehörgangspolyp. Nach Wegnahme der Brücke zeigte sich auch die Paukenhöble mit auffallend derben fibrösen Massen erfüllt, so daß der Verdacht einer walignen Neubildung entstand. Sinus und Dura werden nicht freigelegt. Von Gehörknöchelchen nichts bemerkt. Bogengang normal weiß, abgeflacht; am Facialiskanal, soweit er sichtbar ist, keine Lücke bemerkbar. Plastik wegen fehlender Gebörgangshaut nicht möglich; Tamponade, Verband.

Verlauf. Die hohe Temp. $39,3^{\circ}$ vor der Operation ging bis zum năchsten Tage (31.3.) auf 37,4 herunter, war am 2. Tage p. $0.36,7$ und blieb vom 1.4.-3. 4. subnormal. Am 4. 4. mußte wegen lebbafter Klage über Schmerz im Ohr und Morgentemperatur von $37,7^{\circ}$ der Verband gewechselt werden. Die Wunde sah aber gut aus. Die Facialislähmung bestand unverändert. Am 13. und 14. 4. gab es zwei Tage lang hohe Temp., die wir auf eine leichte Angina zu beziehen geneigt waren. In der Wunde war schon rom 16. 4. ab eine stark wuchernde, leicht blutende Granulationsbildung aufgefallen, die den Verdacht einer malignen Neubildung (Sarkom?) erweckte. Die im pathoolgischem Institut kontrollierte Untersuchung einer Probexzision bestätigte indessen diesen Verdacht nicht. Eine am 17. 4. mit höherem Temperaturanstieg (bis $39,8^{\circ}$ abends) verbundene Entzündung des 
linken Fußgelenkes sprach für pyaemische Infektion, die zur Gewißheit wurde, als sich am 20.4. die Anzeichen von Lungenmetastasen hinzutraten bei andauernd hoher Temperatur $\left(39,7-40,1^{\circ}\right)$. Deshalb am 20. 4. Freilegung des Sinus sigmoideus und eines großen Teils des Sinus transversus. Die Sinuswand zeigte sich fibrös verdickt, der Sinus zeigt volle Rundung und ist leicht eindrückbar, prall elastisch. Nach Unterbindung der Vena jugularis, die normales Aussehen hat, wird der Sinus sigmoideus zuerst mit der Parazentesennadel probeweise inzidiert, und da kein Blut kam, mit dem Knopfmesser breit gespalten. Danach entleerte sich dünnflüssiger, jauchiger Eiter aus demselben. Der ganze Sinus fast bis zum Torkular wurde gespalten und entbält einen zum zum Teil schon eitrig zerfallenen Thrombus. Erst, nachdem beim Auslölöffeln der Thrombenmassen der Löffel bis weit nach dem Torcular Herophili vorgeschoben war, erfolgte stärkere Blutung, die durch Tamponade des Sinus mit Jodoformgaze gestillt wurde. Vom Bulbus her erfolgte überbaupt keine Blutung. Breite Exzision der lateralen Sinuswand. Verband. Abends nach dieser zweiten Operation am 20. 4. relatives Wohlbefinden bei Temp. $38,4^{\circ}$. Unter täglichem Verbandwechsel in den nächsten 14 Tagen Herabgehen der Temp. und allmäblige Verbesserung des Aussehens der Wunde und des Allgemeinbefindens. Am 4. Mai abends neuer Anstieg der Temp. auf 40,8 und Erbrechen, das sich zeitweise später wiederholte, besonders nach der Nahrungsaufnahme. Am folgenden Morgen wieder normale Temp. und beim Verbandwechsel ein gutes Aussehen der Wunde konstatiert; im obersten Teile des Sinus pulsierender Eiter sichtbar. In der letzten Lebenswoche traten die Lungensymptome (Metastasen, pneumonische Infiltration, und pleuritisches Exsudat) in den Vordergrund. Eine durch Atemnot veranlaßte Probepunktion des rechten Thorax blieb resultatlos, obwohl sie $4 \mathrm{mal}$ an verschiedenen Stellen versucht wurde. Trotzdem zeigte sich bei der Sektion, daß im Pleurasack ca. 200 Gramm eitrige Flüssigkeit vorhanden waren infolge Durchbruchs eines metastatischen Abszesses. Die Resultatlosigkeit der Probepunktion war bedingt durch schwartige Verdickungen der Pleura mit eitrig-fibrinösen Auflagerungen, wie der Sektionsbefund ergab. Am 17. Mai die ominöse Morgentemperatur von 40,1 bei öfterem Erbrechen; am 20. 5. Exitus unter Dyspnoe und Herzschwäche.

\section{Sektionsprotokoll.}

Leiche in sehr reduziertem Ernährungszustande, Totenstarre vorhanden, im Abdomen kein fremder Inhalt, Serosa der Därme blaß, spiegelnd. Zwerchfellstand rechts 4. Interkostalraum, links 4. Rippe. Bei der Eröffnung des Thorax sinken die Lungen nicht zurück, sie überdecken den Herzbeutel. Linke Lunge frej, kein fremder Inbalt in der linken Pleuraböhle, rechte Lunge der Thoraxwand leicht adbärent. In der rechten Pleurahöhle ca. $200 \mathrm{ccm}$ eitriger Flüssigkeit.

Herz: Im Herzbeutel, dessen Innenfläche glatt und glänzend ist, wenig klares Serum; Herz entsprechend groß, linker Ventrikel leidlich gut kontrahiert, Klappenapparat intakt, Muskel von blau-grauer Farbe, etwas träb, mit kleinen gelblichen Herden durchsetzt.

Linke Lunge: Etwas erhöhtes Volumen und Gewicht; aus dem Bronchus, dessen Schleimbaut blaß aussieht, entleert sich auf Druck schaumig gelbliche Flüssigkeit; Pulmonalis frei, Lungengewebe uberall nachgiebig, an den Rändern etwas gebläht; Saftgehalt überall vermehrt, Blutgebalt nur in den unteren Partien etwas erhöht, Luftgehalt überall vorhanden.

Rechte Lunge: Volumen und Gewicht stark erhöht; aus dem Bronchus entleert sich auf Druck dickeitrige Flüssigkeit; Pulmonalis frei. Pleura zeig über dem unteren Lappen schwartige Verdickungen mit eitrig fi brinösen A uflagerungen in erheblicher Stärke. Lungengewebe de Oberlappen ïberall nachgiebig, mit erhöhtem Saftgehalt. Der ganze Unterlappen ist pneumonisch infiltriert. Nabe dem unteren scharfen Rand befindet sich ein etwa erbsengroßer, im Zentrum erweichter, septischer Infarkt der nach der Pleura durchgebrochen ist; ein zweiter hämorrhagischer Infarkt an einer anderen Stelle des Unterlappens. 
Milz: $8: 5: 2$ Kapsel graublau, spiegelnd, Parenchym von leidlich guter Konsistenz. Follikel sehr deutlich, etwas vergrößert, Trabekelzeichnung undeutlich.

Leber: $16: 12: 4,5$. Oberfläche glatt, spiegelnd. Parenchym von guter Konsistenz mit deutlicher Lappenzeichnung $z$. $T$. verfettet.

Magen: Schleimhaut gut gefaltet, im Fundus etwas injiziert, daselbst auch mehrere kleine Blutungen.

Pankreas gut gekörnt, blaß, sonst ohne Besonderheiten.

Linke Niere: $7: 3: 3$ Fettkapsel spärlich, fibrös, leicht löslich, Oberfläche glatt, von blaßgrauer bis gelblicher Farbe. Rinde sehr blaß, trüb, von guter Konsistenz, undeutlich von den Pyramiden abgesetzt. Nierenbecken ohne Besonderheiten.

Rechte Niere: Etwas blutreicher, sonst wie die linke.

Blas e: Sehr stark mit klarem, wässerigem Urin gefüllt.

Schädeldach ziemlich dünn; Diploë vorhanden, von blaurötlicher Farbe. Außenfläche der Dura glatt und glänzend. Dura der linken Hemisphäre bläulich durchschimmernd, Innenfiäche der Dura glatt und glänzend. Weiche Häute über der rechten Hemisphäre spiegelnd, Piagefäße mittelstark gefüllt. Links sind die Subarachnoidealräume mit Blut gefülit, in der Pia betinden sich daselbst zahlreiche punktförmige Hämorrhagien. Der Sinus longitudinalis ist in seiner hinteren Hälfte vollkommen durch einen graugelblichen Thrombus ausgefüllt, der sich nach beiden Seiten verfolgen läßt und im rechten Sinus transversus eitrig zerfallen ist. Der rechte Sinus sigmoideus ist in einer Ausdehnung von $7 \mathrm{~cm}$ eröffnet.

Hirnsubstanz sebr weich, zerfließend; unter dem Ependym der Seitenventrikel und des Balkens überall zahlreiche punktförmige Blutungen. Während beide Hemisphären ebenfalls in ausgedehnter Weise mit kleinen Blutungen durchsetzt sind, ist das Kleinhirn frei von Blutungen und sehr blaB; desgleichen die Medulla oblongata. Über dem Scheitelhirn finden sich einige Venae cerebrales superiores thrombosiert.

Rechts Totalaufmeißelung; an der rechten Halsseite entsprechend der Vena jugularis befindet sich eine frische Narbe. Entlang der großen Halsgefäßie sind die Lymphdrüsen geschwellt und im Zustand akuter Entzündung.

Darm: Schleimhaut stellenweise injiziert.

Diagnosis post mortem: Totalaufmeißelung rechts, Operationsnarbe an der rechten Halsseite (geheilte Iugularisunterbindung) Blutungen in die Subarachnoidealräume links, Blutungen in der Pia über der linken Hemisphäre und in beiden Großhirnhemisphären. Thrombose des Sinus longitudinalis, transversus und sigmoideus; Anaemie und fettige Degeneration des Herzmuskels. Pleuritis fibrinosa et purulenta dextra. Septische Infarkte im rechten Unterlappen der Lunge, pneumonische Infiltration des rechtem Unterlappens; fettige Degeneration der Leber. Trübe Schwellung und parenchymatöse Degeneration der Rinde beider Nieren. Enteritis acuta, Lymphadenitis acuta cervicalis.

E pikrise. In diesem typischen Falle von Septicopyaemie mit stark remittierendem Fieber ohne Schüttelfröste bei ausgedehnter Thrombosierung im Sinus sigmoideus, transversus $\mathfrak{u}$. horizontalis kam die Ligatur der V. jugularis zu spät, um noeh die letalen Folgen der bereits vorhandenen Metastasen in den Lungen verhüten zu können. Das Vorkommen eitrig zerfallener Thromben 
wie hier, das ich im Kindesalter auch nach Scharlachotitis und Otitis mit Caries necrotica nach Diphtherie beobachtet habe, wurde früher als selten im Kindcsalter vorkommend angenommen. Ob es sich hier tatsächlich um die Folgen einer akuten Otitis media gehandelt hat, wie es nach der Anamnese erseheinen könnte, bleibt zweifelbaft. Wahrscheinlicher ist, daß es sich um eine Masernotitis handelte, die in den ersten 2 Monaten latent verlief und erst im 3. Monat akute, den Eltern auffällige Symptome herbeigefübrt hatte.

VI.

Richard Bogk aus Hackpfiffel, 27 Jahr, Ackerknecht, unverheiratet. Aufgenommen am 23. Mai 1907. Gestorben am 2. Juni 1907.

An amnese: Patient will mit Ausnahme einer Lungenentzündung stets gesund gewesen sein, keine Kinderkrankheiten durchgemacht haben. Ohne bekannte Ursache soll in der frühesten Kindheit das rechte Ohr erkrankt sein und seit jener Zeit fast ohne Unterbrechung geeitert haben. Das linke Ohr ist vor etwa 9 Jahren, nachdem eine Lungenentzündung kurz voraufgegangen war, erkrankt und hat seitdem, obne daß besondere Schmerzen im Ohr vorangingen, einen dünnflüssigen, nicht fötiden Ausfluß. Ohrensausen, Schwindel, Kopfschmerzen sind nicht vorhanden gewesen. Der P. merkte jedoch, daß seitdem - da das andere Ohr bereits krank war, seine Hörfăhigkeit stark beeinträchtigt war. Seit März d. J. also 8 Wochen vor der Aufnabme - traten heftige Schmerzen im linken Ohr und der linken Kopfseite ein; der AusfluB wurde stärker und stinkend. Ohrensausen stellte sich ein, Pat. ging deshalb zuerst zum Arzte, der Dämpfe von Kamillenthee angeordnet haben soll.

Vor etwa 10 Tagen (Anfang Mai d. J.) stellte sich das erste Mal Schwindel ein. 14 Tage zuvor hatte der Patient bereits die Arbeit niederlegen müssen, da vor allem beim Bücken sehr starke, stechende Schmerzen im Ohr eintraten. Der Schwindel wurde so stark, daß er „wie ein Betrunkener umherging." Kurz vor der Aufnahme ist der P. zweimal im Schwindel umgefallen; Erbrechen ist nie aufgetreten.

St atus praesens: Elend aussehender Mensch mit ängstlichem Gesichtsausdruck, in schlechtem Ernährungs- und Kräftezustand. Appetitlosigkeit, grau belegte Zunge.

Die Pupillen sind gleich weit, reagieren prompt auf Lichtreiz und Akkomodation; Nystagmus beim Blick nach rechts, beim Blick nach oben schwanken die Gegenstände hin und her. Schwindel objektiv nacbweisbar: Stehen mit geschlossenen Augen unmöglich, ebenso tritt beim Bücken starker Schwindel ein. Am Augenhintergruud sind die Venen beiderseits stark geschwollen; nasale Seite der Papillen odematös, etwas verwaschen. Klage über starke Kopfschmerzen in Stirn und linker Schädelseite. In der Umgebung des linken Ohres läßt sich der linke Processus mastoideus nicht so deutlich abtasten wie rechts, außerdem ist die Spitze und das Planum des Processus mastoideus auf Druck empfindlich.

Der linke Gehörgang ist von einem Polypen angefüllt, welcher von schmierigem, stinkenden Eiter umspült wird. Dér rechte Gehörgang ist weit, mit Eiter angefüllt; nach Austupfen sieht man im vorderen unteren Quadranten eine große nicht randständige Perforation, Hammergriff und Processus brevis deutlich sichtbar.

Hörprüfung. Flüstersprache wird links überhaupt nicht, Konversationssprache ad concham gehört. Stimmgabeln: C, vom Scheitel nach 
dem besseren, rechten Ohre gehört. Fis 4 links nur auf stărkeren Fingerkuppenanschlag hörbar, Rinne negativ.

Auf dem rechten Ohre wird Flüstersprache noch auf $50 \mathrm{~cm}$ gehört. $\mathrm{F}$ is $_{4}$ auf Kuppenanschlag, Rinne negativ. mäßig.

Temp. bei der Aufnahme $37,7^{\circ}$ (?) Puls 96 voll, kräftig aber nicht regel-

Therapie. Es wird nach dem Aufnahmebad Bettruhe, Calomel 0.3, Eisblase auf den Kopf verordnet.

24. 5. 08. Morgentemp. 39,4. P. 88. Kopfschmerzen wie zuvor, kein Erbrechen.

Operation: Es wird zunächst die Lumbalpunktion gemacht; dieselbe ergibt, daß der Liquor nicht unter erhöhtem Druck steht, aber deutlich getrübt ist. Im Ausstrichpräparat sind keine Bakterien nachzuweisen.

Totalaufmeifelung links: An den Weichteilen ist nichts Besonderes, der Knochen selbst hart und blutleer. Beim Ablösen der hinteren häutigen Gehörgangswand löst sich eine übererbsengroße Granulation, die zuvor den Gehörgang verlegt batte. In dem weiten Antrum schmierige, zum Teil zerfallene Granulationen, kein freier Eiter. Die Dura liegt in etwa Bohnengröße frei und ist mit derben Wucherungen bedeckt. Nach Wegnahme der Brücke und Freilegung sämtlicher Mittelohrräume liegt der horizontale Bogengang vor, derselbe ist aber nicht weiß und glänzend, sondern die zwei medialen Drittel sind zerstört, sehen schwärzlich aus, während das laterale Drittel gut erhalten erscheint. In der Paukenhöhle sind teils schmierig zerfallene, teils noch derbe Wucherungen sichtbar. Von den beiden äußeren Ossiculis ist nichts mehr vorhanden. Die Dura liegt nach Wegnahme der kariösen Umgebung etwa in Zehnpfennigstïckgröße frei. Der sinus wird freigelegt, sieht jedoch gesund aus. Plastik, deren Lappen aber nicht vernäht werden. Tamponade, Nähte, Verband.

Abends T. $39.5^{\circ}$.

25. 5.08. Die Nacht über hat P. nicht geschlafen, die Kopfschmerzen baben aufgebört. Obwohl bei der Operation sicher kein Facialisspasmus beobachtet war, zeigt sich beute eine leichte Facialisparese aller drei Äste. Nachts höchste T. 39,6 , morgens $38,9^{\circ}$ P. 80 . Abends 38,9, P. 72 . Das Resultat der bakteriologischen Untersuchung des Liquor cerebrospinalis ergab nur vermehrte Leukozyten, keine Bakterien (auch kulturell). Verbandwechsel, die Wunde sieht gut aus.

26. 5. 08 Es besteht wieder Klage über starke Kopfschmerzen. Weder Nackensteifigkeit noch Druckschmerz daselbst. Wiederholung der Lumbalpunktion; es werden ca. $40 \mathrm{~g}$ Liquor abgelassen. Derselbe ist von der gleichen Beschaffenheit wie zuvor, steht aber sehr unter starkem Drucke.

T. morgens $37,9^{\circ}$, P. 84 morgens, abends 39,0, P. 96,0 voll aber unregelmäßig.

27.5. 08. Nacht unruhig $38,5^{\circ}$, P. 80 , morgens $39,5^{\circ}$ P. 84 abends.

28.5. 08. Klage über Kopfschmerz; die mikroskopische und kulturelle Untersuchung des Liquor ergab das gleiche Resultat wie früher. Wegen Kopfdruckes nochmalige Lumbalpunktion von ca. 40 Gramm, trübe und unter starkem Druck stehend. Morgens 38,8 $8^{\circ}$ P. 80 , abends Temp. $39,6^{\circ}$, P. 80.

29. 5. 08. Temp. $38,6^{0}$ P. 72 morgens, abends T. $39,1^{\circ}$, P. 80 , keine wesentliche Änderung des Zustandes.

30. 5. 08. Temp 38, ${ }^{\circ}$, P. 80 Morgens, Temp. 39,50 P. 84.

31. 5. 08. Temp. $38,2^{\circ}$, P. 72 Morgens, Abends $38,0^{\circ}$ P. 84 .

Nacht war sehr unruhig, Pat. will aus dem Bett, Delirium, Flockenlesen. Pupillen mittelweit, reagieren gut auf Lichtreiz. Deutlicher Nystagmus horizontalis beim Blick nach rechts. Puls kräftig, doch unregelmäßig. Leib sehr gespannt. 2 EBlöffel Ol. ricini; Glyzerinklysma. Verbandwechsel.

1. 6. 08. Völlige Besommen heit. Delirien, große Unruhe Nachts. Morgens etwas ruhiger, P. murmelt vor sich hin. Flockenlesen. Leib stark gespannt. Kein Stuhl, kein Flatus, überall tympanitischer Schall. Öfter Aufstoßen, doch kein Erbrechen. Temp. Morgens $38,3^{\circ}$ P. 80, Abends $37.8^{\circ}$ $P$ uls 90 , zeitweise aussetzend. 
2. 6. 08 gegen Mitternacht tritt unter starker Unruhe Trachealrasseln e n, gegen 4 Ühr Morgens Exitus.

Sektionsprotokoll rom 3. Juni 1908:

Mittelgroße männliche Leiche von starkem Ḱnochenbau und mittlerem Ernährungszustand. Linkerseits Totalaufmeißelung gemacht. Wunde sieht etwas schmierig aus.

Sch ädeldach normal konfiguriert, sebr leicht, dünn. Diploë uur in geringer Menge vorhanden, graurot. Innenfläche des Schädeldaches zeigt abgesehen von den Eindrücken der Arterien und der Paccinionischen Granulatíonen keine Veränderungen. Schädeldach löst sich leicht. Gefäße der Oberfläche der Dura stark gefüllt, letztere stark gespannt, Innenfläche der Dura zart, trocken. Im Sinus longitudinalis Cruor, Speckgerinnsel und dunkelflüssiges Blut. Die Gefäße der weichen Hirnbäute, die zart sind, zeigen lebhafte Injektion. Gyri abgeglattet. Die Subarachnoideal-Räume über der Konvexität frei.

Bei der Herausnahme des Gehirns zeigt sich, daß sowohl im subarachnoidealen als auch im subduralen Raun der Basis und zwar besonders im Bereiche des Unterwurmes der Medulla, der Brücke, der fossa interpeduncularis, des Chiasma reichlich dicke grünlich-gelbliche Eitermassen sich befinden. In den Sinus der Basis findet sich nur dunkelflüssiges Blut und Cruor. Die Dura ist über dem linken Tegmen tympani eigentümlich schmutzig verfärbt. An zwei Stellen finden sich daselbst feine Öffnungen, durch welche man mit der Sonde, da das Tegmen tympani in größerer Ausdehnung fehlt, in das Mittelohr gelangt. Aus dem Porus acusticus internus links wie rechts fliebt dicker grünlich-gelblicher Eiter. Die austretenden Nervenstämme sind eitrig infiltriert. Die Ventrikel sind nur wenig erweitert, enthalten leicht getrübten Liquor. Das Ependym ist gut. Die Hirnsubstanz sehr weich, feucht, Blutpunkte an Zahl etwas vermehrt. Im übrigen finden sich am Gehirn keine besonderen Veränderungen.

Fettpolster der Brust und Bauchdecken mäßjig entwickelt. Muskulatur entsprechend entwickelt von fleischroter Farbe. Das fettarme Netz ist herabgeschlagen, bedeckt die geblähten Därme, deren Serosa stellenweise injziert aber allentbälben spiegelnd ist. Kein fremder Inhalt im Abdomen. Zwerchfellstand bds. 4. Kippe. Nach Herausnabme des Brustbeins sinken die Lungen nur wenig zurück, da sie durch ausgedehnte fibröse Strănge ziemlich fest mit der Brustwand verwachsen sind. Kein fremder Inbalt in den Pleurahöhlen. Der fettarme Herzbeutel liegt in klein Handtellergröße frei. Innenfläche spiegelnd; er enthält etwa einen Teelöffel klaren Serums. Die Cava superior und ihre Zuflußgebiete werden präpariert. Es findet sich in ihnen nur dunkelflüssiges Blut und Blutgerinnsel. Herz: entsprechend groß, mäßig gut kontrahiert. R. Ostium für gut drei, l. Ostium für knapp dre iFinger durchgängig Dünnflüssiges Blut, Cruor und etwas Speckgerinnsel in beiden Herzhöblen. Epicard zart, mäßig, fettreich. Auf der Rückseite finden sich unter ihm einige kleine Ekchymosen. Klappenapparat des Herzens intakt. Intima der Aorta, deren Wand gut elastisch ist, zeigt ebenso wie die Intima der Coronararterien spärliche sklerotische Einlagerungen. Herz muske) : weich, trüb, braunrot, von diffus graugelblichen Fleckchen durchsetzt. Linke Lunge: Volumen und Gewicht erhöht. Aus dem Bronchus, dessen Schleimhaut etwas injiziert ist, quillt auf Druck, schmutzrote schaumige Flüssigkeit, Pulmonalis frei. Pleura zeigt neben den Verwachsungen eine blaß graublaue, stellenweise violette Farbe. Oberlappen: Schnittfläche dunkelrot gefärbt. Der Blut- und Saftgehalt betrăchtlich erhöht, besonders in den hinteren Partien. Luftgehalt etwas reduziert, jedoch nirgends ganz aufgehoben. Unterl ap p en: zeigt noch stärkeren Blut- und Saftgehalt, aber auch hier ist der Luftgehalt zwar reduziert, doch überall vorbanden. Rechte Lunge: gleicht im wesentlichen der linken. Von der Thymusdrüse sind noch geringe Reste vorhanden. Hals-und Rachenorgane: Schleimhäute allenthalben blaß bis auf die Trachea, welche etwas injiziert ist. Tonsillen hypertrophisch, verengern den Racheneingang etwas. Thyreoidea ohne Befund. Milz: 13,5:7:4, Kapsel gespannt, im allgemeinen zart, graublau, Parenchym von mäßiger Konsistenz, mittlerem Blutgehalt, leidlich deut- 
licher Trabekel- und undeutlicber Follikelzeichnung. Leber: Kapsel ist über dem rechten Lappen mit dem Zwerchfell verwachsen, 23: $18: 7$ Kapsel, abgesehen von den Residuen der Verwachsungen zart. Organ ziemlich blutreich. Schnittfläche bräunlicb, gelblich gefleckt. Zeichnung undeutlich, Konsistenz des Parechyms herabgesetzt. Gallenblas e ohne besondern Hefund, ebenso die Harnblase. Hyperämie der Nieren, Enteritis follicularis mit Meteorismus.

Diagnosis post mortem: Totalaufmeißelung links. Mittelohreiterung auch rechts. Meningitis purulenta basalis, ausgehend vom linken Felsenbein. Hyperämie, Ödem des Gebirns. Pleuritis chronica adhaesiva beiderseits. Hyperämie, Ödem der Lungen. Parenchymatöse Degeneration des Herzmuskels. Hypertrophie der Tonsillen. Geringer Milztumor. Verfettung der Leber Hyperämie der Nieren. Enteritis follieularis.

Sektion des linken Schläfenbeins: Die Dura ist in der ganzen Ausdehnung der Felsenbeinpyramide grünlich, mißfarben. Die Paukenschleimhaut ist schmierig belegt, der Steigbügel, bis auf kleine Reste der Platte mit Schenkelrest zerstört, liegt lose im ovalen Fenster. Große, ovale Fistel mit zackigen Rändern im horizontalen Bogengang. Sämliche Bogengänge schwärzlich verfärbt, mit trübem Liquor angefüllt. Der Vorhof und die Schneoke sind mit dickem, gelben Eiter angefüllt, die Capula ist zum Teil zerstört. Im Porus acusticus internus ist gelber dicker Eiter. Der Nervus acusticus im ganzen Verlauf grünlich gelb verfärbt und mit Eiter durchsetzt. Der Nervus facialis ist, soweit er mit dem Nervus acusticus in Kontakt steht, von Eiter umgeben, der distale Teil erscheint jedoch von normaler Beschaffenheit.

Epikrise. Der Verstorbene ist schon mit ungïnstiger Prognose in die Klinik aufgenommen. Der starke Schwindel bis zum Umfallen, das Übelsein und der heftige Kopfschmerz, welcher bereits seit 14 Tagen Arbeitsunfähigkeit bedingt hatte, deuteten auf intrakranielle Komplikation chronischer Mittelohreiterung hin. Dazu kam der schlechte Allgemeinzustand. Die unmittelbar vor der Operation vorgenommene Lumbalpunktion wies noch bestimmter hin auf das Bestehen der Meningitis incipiens. Aber die unter erhöhtem Druok stehende und bereits getribte Lumbalflüssigkeit allein durfte bei dem fehlenden Nachweis von Bakterien keine Kontraindikation der Operation abgeben. Denn die bereits anderweitig veröffentlichten und auch einige in unserer Klinik beobachtete Fälle beweisen, daß trotzdem bei rechtzeitigem, operativen Eingreifen eine eben be- 
ginnende Meningitis mitunter noch zu einem glücklichen Verlauf kommen kann. Bei uns ist dieses allerdings noch nie bei Streptokokkeneiterung beobachtet worden, sondern nur bei Diplokokken. Anderseits mußte man sich sagen, daß der Pat. ohne Operation sicher verloren war. Hier ersehien uns also geboten, den Versuch mit der Operation noch zu machen, trotz ungünstigster Prognose.

Bei der Operation konnte nun auch bereits die Wegleitung für die Weiterverbreitung der chronischen Eiterung auf das Endocranium konstatiert werden. Das Tegmen antri war in größerer Ausdehnung kariös, die Dura selbst mit derben Granulationen bedeckt gefunden. Ferner war im horizontalen Bogengange eine größere Fistelöffnung mit schwärzlicher Umgebung welche der Eiterung nach dem Labyrinth und von hier nach dem Gehirn die Tür geöffnet haben konnte.

In der Tat ist anch, wie aus dem Sektionsbefund hervorgeht, die Dura über dem Tegmen antri bis zur Spitze der Felsenbeinpyramide und besonders über dem Meatus acusticus internus grünlich mißfarben. Und man kann mit einiger Sicherheit annehmen, daß durch beide genannten Eingangspforten sowobl durch Tegmen antri als durch das Labyrinth die Eiterung auf die weichen Hirnbäute fortgeschritten war. Denn im Labyrinth stand gelblicher eingedickter Eiter, der Nervus acusticus war eitrig infltriert und von dünnflüssigem Eiter umflossen. In seiner Gemeinschaft natürlich auch der Nervus facialis. Die Facialislähmung war nicht Folge der Operation, sondern natürliche Folge der fortschreitenden Eiterung. In der Dura mater über dem Tegmen antri wurden bei der Sektion, abgesehen von der grünlich mißfarbenen Beschaffenheit bereits zwei feine Perforationen gefunden, so daß hier die Dura mit dem Granulationswall keinen Schutz mehr gegen die Fortleitung der Eiterung gewähren konnte. Die unter Febris continua verlaufene Meningitis führte am 9. Tag post operationem zum Tode. Der Patient kam zu spät zur Operation; einige Monate früher operiert, hätte er vielleicht noch gerettet werden können.

\section{VII.}

Frieda Winkelmann, 6 Monat alt, Gärtnerskind, aus Helmsdorf, aufgenommen 12. 6. 1907, gestorben 15. 6. 1907. Zuerst in die Poliklinik gebracht am 4. Juni mit akuter Otitis media purulenta sinistra und einige Tage ambulatorisch be- 
handelt. Wegen Fieber mit cerebralen Symptomen in die Klinik aufgenommeu (Verdacht auf Meningitis tuberculosa) starb es nach 3 tägiger Beobachtung nach voraufgegangenen Konvulsionen.

Sektionsbefund: Hochgradige Anämie aller Organe. Anämie und Ödem des Gehirns. Bronchopneumonische Infiltrate im rechten Unterlappen der Lunge.

\section{VIII.}

Anton Klempzig, 26 Jahr. Saison-Landarbeiter aus Russland (von Domäne Packisch Domann bei Cossdorf, aufgenommen 4. Juli 1907, gestorben 4. Juli 1907.

Der P. wurde abends spät in die Klinik abgeliefert in fast bewußtlosem Zustande. Eine Verständigung mit ihm war nicht möglioh, weit er nicht deutseh versteht. Ü̉ber Entstehung und Verlauf seiner Krankheit war nichts bekannt, der Begleiter des Kranken weiß nichts weiter über ihn, als daß er wegen Ohrenleidens der Klinik tuberwiesen sei vom Krankenhause in Cottbus.

Stat. praesens vom 4. Juli 1907. P. ist ron starkem Knochenbau und mittlerem Ernährungszustande. Eine Verständigung mit ihm, auch mit Hilfe eines Dolmetschers ist unmöglich; er stößt nur unartikulierte Laute aus und ist sehr unruhig. Leicht ikterische Hautfärbung und Ödem an den Fußknöcheln. Beide Pupillen sind über mittelweit, reagieren nicht auf Lichteinfall. Gangränöser Fötor ex ore. T. 38,7. P. 68. Am oberen Lappen der linken Lunge ist gedämpfter Schall und leichtes Rasseln zu hören. Die Umgebung der Ohren ist ohne Befund. Der rechte Gehörgang ist stenosiert; aus demselben fließt dunkles Blut und aashaft stinkender Eiter.

Nach dem Reinigungsbade und der gründlichen Säuberung des P. wurde noch an demselben Abend 10 Uhr zur Totalaufmeibelung geschritten. Bei der Lumbalpunktion floß kein Liquor ab.

Bei der Aufmeißelung zeigten sich am Warzenfortsatz starke periostitisehe Verwachsungen; die Corticalis ungewöhnlich hart, der Knochen blutreich; an der hinteren Gehörgangswand ein linsengroßer Defekt. Beim Durchziehen des Bandes durch den äußéren Gehörgang kommt verfallene, stinkende CholesteatomMasse mit zum Vorschein. Nach wenigen Meißelschlägen zeigt sich eine walnußgroße mit zerfallenem Cholesteatom ausgefüllte Höhle, die hinten bis an den Sinus und vorne bis an die Dura 
reicht. Der Sinus wird in 10 Pfennigstückgröße, die Dura des Tegmen antri in Bohnengröße freigelegt. Fibrinöser Belag ?auf dem Sinus. An dem horizontalen Bogengang erscheint der vordere Teil schwarz und kariös zerfressen. Von den Ossiculis ist nichts zu finden. Glättung der Höhle, Plastik, Tamponade, Naht, Verband.

Etwa eine Viertelstunde nach Beendigung des Verbandes trat plötzlich Herzschwäche ein, die sich durch Aetherinjektionen, Sauerstoffinhalation und künstliche Athmung nicht beseitigen ließ.

\section{Sektionsbefund:}

Kräftiger Knochenbau, mittlerer Ernährungszustand. Totenflecke und Totenstarre vorhanden. Hantdecken leicht ikterisch Ödeme an den Knöcheln. Hinter dem rechten Ohre eine frische Operationswunde.

Medulla spinalis. Die weichen Häute des Rückenmarkes sind stellenweise diffus getrübt. Im subarachnoidealen Raum kein abnormer Inhalt. Die Gefäße sind stark gefüllt, besonders die Venen. Ruickenmark selbst von guter Konsistenz. Schnittfäche etwas feucht, leicht überquellend. Zeichnung deutlich. Blutgehalt der weißen Substanz ziemlich gering.

Schädeldach normal figuriert, Diploe mäBig blutreich. Innenfläche zeigt keine bemerkenswerten Veränderungen. Dura stark gespannt; Gefäße derselben gut gefüllt. Im Sinus longitudinalis Cruor und flüssiges Blut. Innenfäche der Dura ist zart und spiegelnd, die weichen Häute zart und durchscheinend; Subarachnoidealflüssigkeit nicht vermehrt, Gefäße der Pia ziemlich stark gefüllt.

Nach Herausnahme des Gehirns zeigt sich, daß der Porus acusticus rechts eitrig belegt und der Acusticus eitrig infiltriert und stark erweicht ist. Im Sinus sigmoideus reehts befindet sich ein gangränös zerfallener Thrombus, der sich fast bis zum Torcular fortsetzt. Die tibrigen Sinus der Basis sind frei. Die Dura wird von der Schädelbasis entfernt: Das Tegmen tympani zeigt einen etwa bohnengroßen Defekt; an entsprechender Stelle weist die Dura grau-rötliche Beläge auf. Die Außenseite des Sinus sigmoideus ist schmutzig grünlich verfärbt. An seinem Übergang in den Sinus transversus ist die Wand des Sinus gangränös zerfallen, ebenso ist an dieser Stelle der Knochen etwa in der gleichen Ausdehnung wie das Tegmen tympani zer- 
stört und man gelangt von hier aus in die große Operationswunde.

Gehirn: Die weichen Bäute und Gefäße der Basis zeigen im allgemeinen keine bemerkenswerten Veränderungen; nur im Bereich des Nervus acusticus und facialis sind die weichen Häute in Ausdehnung eines 5-Pfennigstitekes verfärbt und eitrig infiltriert. Der vordere Absehnitt der Unterfläche der linken Kleinhirnhemisphäre ist grau-bläulich verfärbt. Bei der Palpation glaubt man hier Fluktuation zu fühlen. Ein Abszeß findet sich jedoch nicht. Schnitte durch das Kleinhirn zeigen ziemlich reichliches Ödem und erhöhten Blutgehalt der Substanz. Pons und Medulla ohne Besonderheiten.

Großhirn: An der Unterfläche des rechten Occipitallappens befindet sich in Ausdehnung von zwei Fingern die gleiche graublänliche Verfärbung wie am Kleinhirn. Die Substanz des Großhirns ist sehr weich, ödematös und sehr blutreich, sonst zeigt sie keine bemerkenswerten Veränderungen.

Fettpolster der Brust- und Bauchdecken mäBig entwickelt. Muskulatur derselben etwas blaß. Das fettarme Netz ist herabgeschlagen und deckt die geblähten Därme, deren Serosa spiegelnd und glatt ist. Kein fremder Inhalt im Abdomen. Zwerchfellstand: Oberer Rand der vierten, links oberer Rand der fünften Rippe. Nach Herausnahme des Brustbeins sinken die Lnngen nur wenig zurück, sie sind durch ausgedehnte fibröse Stränge mit der Brustwand verwachsen. In der rechten Pleurahöhle dickflüssiger, aashaft stinkender Inbalt.

Der Herzbeutel liegt in Kleinhandtellergröße vor. Innenhaut spiegelnd, Inhait ca. $20 \mathrm{ccm}$ klares Serum. Die Cava superior und Zuflußgefäße werden präpariert. Dabei zeigt sich, daß die rechte Jugularis stellenweise schmutzig verfärbt und das umgebende Bindegewebe infiltriert ist. In der Jugularis findet sich ein adbärenter teils grangränös zerfallener, vom Bulbus bis zur Höhe des Schlüsselbeins reichender Thrombus. Die übrigen Venen intakt.

B erz entsprechend groß, dürftig kontrahiert, rechtes Ostium für vier, linkes für drei Finger durchgängig; Cruor, Fibrin und dunkles Blut in beiden Herzhöhlen. Epicard fettreich, leicht diffus getrübt, Klappenapparat intakt. Klappensegel zeigt leicht gelbliche Verfärbung (cf. Ikterus der Haut). Rechter und linker Ventrikel etwas dilatiert, Herzmuskel weich, tritb, graubraunrot, 
von sebr feinen weißlichen Fleckohen durchsetzt. Aorta braunrot, ohne Besonderheiten.

Linke Lunge: Volumen und Gewicht erhöht. Aus dem Bronchus, dessen Schleimhaut dunkelbraun infiltriert ist, dringt schmutzig-bräunlich aussehender Schaum. Pulmonalis frei. Die Pleura zeigt ausgedehnte Verwachsungen; sie ist schmutzig grünlich-gelblich verfärbt, an einer Stelle auf der Vorderseite des Oberlappens ist sie eingerissen. Durchsehnitte dieser Stelle zeigen, daß sich hier ein kleinapfelgroßer, mit schmierigem Inhalt gefärbter Gangränherd befindet. Im Oberlappen befinden sich noch mehrere derartige Gangränherde. Im übrigen ist der Oberlappen blut- und saftreich. Der Unterlappen zeigt sich noch blut- und saftreicher und enthält einen in der eitrigen Einsehmelzung begriffenen Infarkt.

Die rechte Lunge gleicht im wesentlichen der linken.

Hals- und Rachenorgane, abgesehen von einer entzündlichen Schwellung der laryngotrachealen Lymphdrüsen, ohne Besonderheiten. Milz: 15:11:5. Kapsel gespannt, blau-violett gefärbt, zart. Parenehym braunrot, fast breiiger Konsistenz und nahezu aufgehobener Zeichnung.

Leber: $30: 21: 9$. Kapsel zart, spiegelnd. Parenchym sehr weich, brüchig, blutreich, grau-bräunlich-rötlich, trüb, ohne Zeichnung auf der Schnittfläche. In der Gallenblase zähflüssige schwarzgrüne Galle.

Magen: Klein, enthält gallig gefärbte, schleimige Flüssigkeit. Schleimbaut gallig inbibiert, sonst ohne Besonderheiten.

Pankreas, Mesenterium ohne Besonderheiten.

Blase: Schleimhaut nicht ikterisch, klarer, dunkelgelber Urin.

Nieren blut- und saftreich, Schnittfäche trüb und undeutlich gezeichnet, Nebennieren ohne Besonderheiten.

Darm: Schleimbaut ödematös. Der obere Dünndarm sowie das Colon ascendens stellenweise lebhaft injiziert. Follikel und Peyersche Plaques schiefarig pigmentiert.

Stammteil der Aorta ohne Besonderheiten.

Diag nosis postmortem: Ikterus. Nekrose in der knöchernen Wand des Sinus sigmoideus reehts. Gangränös zerfallener Thrombus im Sinus sigmoideus und transversus rechts, sowie in der rechten Vena jugularis. Hyperämie, Ödem des Gehirns. Eitrige Infiltration des Acusticus rechts. Dilatation des Herzens, trübe Sehwellung der Muskulatur, Myoearditis chronica fibrosa cordis. Pleuritis chronica adhaesiva beiderseits, jauchige Pleuritis 
rechts, Hyperämie der Lungen, Gangränherde (metastatisehe) in beiden Lungen. Laryngo-tracheobronchitis. Parenchymatöse Degeneration der Leber und Nieren. Chronischer Darmkatarrh.

Sektion des Schläfenbeins: Das Tegmen tympani ist kariös und zeigt eine bohnengroße öffnung. Die Wand des Antrum mast. und der Aditus ad antrum ist glatt wie ausgedrechselt. Der Nervus facialis liegt unterhalb des horizontalen Bogenganges frei. Unter dem Facialiskanal hindurch geht ein schwärzlich aussehender Fistelgang nach der Paukenhöhle. Stapes fehlt. Orales und rundes Fenster stehen offen, enthalten schwärzlichen Detritus. Der horizontale Bogengang ist in seinem vorderen Teile kariös zerfressen, mit offenem Lumen, enthält schwärzliche, schmierige Eitermassen. Vestibulum mit gleichem Inhalt angefüllt. Auch in der Schnecke grünliche, schmierige Flüssigkeit. Im oberen und hinteren Bogengange blutig gefärbte trübe Flüssigkeit. Facialis und Acusticus im Meatus. audit. internus grünlich verfärbt.

Epikrise.Zerfallenes Cholesteatom mit Gangrän der Sinuswand und Thrombophlebitis.Pyämie; zirknmscripte basale Meningitis purulenta am Austritt des N. acustico-facialis. Totalaufmeißelung zu spät. Eine halbe Stunde post operationem Exitus durch Herzschwäche. Alle Versuche, dieselbe zu bekämpfen blieben vergeblich. Die Operation wäre unterblieben, wenn dieLumbalpunktion nicht resultatlos verlaufen wäre.

IX.

Emma Bürkner, $18 \mathrm{Jahr}$ alt, Landarbeiterin aus Sehrenz beiStumsdorf, Aufgenommen 11. VII. 1907, gestorben 14. VII. 1907.

P. ist mit benommenemSensorium am 9. VII. vom Arzt an die UniversitätsFrauenklinik überwiesen wegen „eklamptischer Krämpfe“", die sich zu Hause zweimal wiederholt hätten. Im Urin seien nur Spuren von Eiweiß dagewesen, doch könnten diese auch durch das hohe Fieber (T. 39, $8^{\circ}$ ) herbeigeführt sein. Auf Ersuchen der Franenklinik wird die P. dort von uns untersucht und auf Grund von Cholesteatom-Verdacht mit intrakranieller Komplikation in die Obrenklinik verlegt. Anamnestisch ist von der benommenen Kranken nichts zu eruieren.

Status praesens vom 11. 7. 1907. Starkes, kräftig entwickeltes Mädchen, im 6. Monat schwanger, ist derartig benommen, daß sie nur undeutlich und sinnwidrig antwortet. T. $38,1, P$. 76 . Die Pupillen sind gleich weit, reagieren prompt auf Lichtreiz und bei Akkommodation.

Augenhintergrund normal. Keine Augenmuskellähmung, kein Nystagmus. Auf Schwindel nicht zu präfen. Úrin enthălt geringe Menge von Eiweiß, keinen Zucker.

Umgebung des Ohres ohne Befund außer geringer Druckempindlichkeit am linken Proc. mast.

Im linken Gehörgang aashaft stinkender, schmieriger Eiter. Nach dessen Entfernung sieht man den größten Teil des Trommelfells mit dem 
Hammer erhalten. Hinter dem Hammergriff im hinteren oberen Quadranten ist eine randstăndige Perforation, aus der eine Granulation hervorragt, neben welcher jauchiger Eiter von oben herabrinnt.

Hörpr üfung bei der Benommenheit der P. nicht ausführbar.

Verlauf. Am 12. 7. 07 Lumbalpunktion. Dieselbe ergibt klaren sterilen ${ }^{1}$ ) Liquor, langsam aussickernd. Mikroskopisch ohne vermehrte Leuḱozyten und ohne rote Blutïörperchen. Sogleich hinterher die Totala ufmeißelung links.

Starke periostitische Verwachsungen, Corticalis sonst ohne Besonder. heiten. Knochen an sich hart und blutleer; aus dem eröffneten Antrum fließt dünnflüssige, stinkende Jaucbe, die von zerfallenem Cholesteatom herrührt. Nach der Spitze zu erstreckt sich eine haselnußgroße Höhle, die gleichfalls mit sehwärzlicher zerfallener Cholesteatommasse angefüllt ist. Der Grund der Höhle ist glatt wie ansgedrechselt. Die Bänder der Höhle sind schwarz verfärbt. Nach Glättung des Facialissporns wird eine über hirsekorngroße Fistel im vorderen Teil des horizontalen Bogengangs bemerkt; Lumen der Fistel deutlich erkennbar als zackig zerfressen. Am Tegmen antri wird die Dura in Halblinsengröße freigelegt; dieselbe sieht gesund aus. Von den Ossiculis ist der Hammer intakt, der AmboB an beiden Schenkeln kariös, der Steigbügel nicht sichtbar, an seiner Stelle finden sich größere Granulationen, die unberührt bleiben. Der Sinus wird nicht freigelegt. Plastik, Tamponade, Naht, Verband.

Am Tage nach der Operation (13.7.07) weniger benommen nach ruhig durchschlafener Nacht.

14. 7. 07. P. hat in der Nacht vom 13. zum 14. deliriert, wurde aber gegen Morgen klar und sprach mit der Wärterin vernünftig. Bei der ärztlichen Frühvisite fiel auf, daß sie anf die verschiedensten Fragen stereotyp dieselbe Antwort gab: „Ja, 19 Jahre". Die Somnolenz steigerte sich schnell zum Coma, in welchem ohne Konvulsionen der Tod erfolgte.

Die klinische Diagnose war gestellt auf linksseitigen Schläfenlappenabszeß, mit Durchbruch in den Seitenventrikel.

Anatomische Diagnosis post mortem.

Totalaufmeißelung links. Meningitis purulenta basalis cerebri et medullaris. Älterer Hirnabszeß im linken Temporal- bezw. Occipitallappen mit Perforation in den Subduralraum und linken Seitenventrikel, Ödem des Gehirns, Dilatatio cordis. Myocarditis fibrosa cordis. Pleuritis chronica adhaesiva. Hyperaemia pulmonum. Tracheitis, Bronchitis, Bronehiolitis. Struma colloides. Milztumor. Parenchymatöse Degeneration der Leber. Hyperämie der Nieren, Gastroenteritis acuta, Cholecystitis acuta. Gravidität 7. Monat.

\section{Sektionsprotokoll.}

Mittelgroße wbl. Leiche von kräftigem Knochenbau in gutem Ernährungszustand. Totenflecke und -Starre vorbanden. Hautdecken "etwas bräunlich gefärbt, die Mammae sind groß; es läßt sich reichlich ausgebildete Drüsensubstauz fühlen. Auf Druck quillt reichlich Colostrum aus den Brustwarzen hervor. Warzenhöfe und Linea alba reichlich pigmentiert.

Rücken mark. Dura mäßig gespannt, Innenfläche zart, weiche Häute stark injiziert. Im subaracbnoidealen Raum Flüssigkeit vermehrt. Im Aus-

1) Die im Hygienischen Institut angestellte kuiturelle Untersuchung er-
kein Wachstum. gab kein Wachstum. 
strich werden Diplokokken nachgewiesen. Rückenmarksubstanz blaß, feucht, weich. Weiße Substanz quillt stark über, sonst keine Verânderung.

Schädeldach normal konfiguriert, Diploë graurot. Innenfläche mit der Dura mäßig fest verwachsen, zeigt Eindrücke der Duralgefäße sowie Pacchion. Granulat. Auf der Innenfläche des linken Stirnbeins nahe der Kranznaht findet sich eine pfefferkorngroße Eostose. Dura stark gespannt. Im sin. longitudinalis flüssiges Blut, Cruor und Fibrin. Innenfläche der Dura zart, etwas trocken. Die Gyri sind abgeplattet, Sulci etwas verstrichen, Arterien der Pia mäßig gefüllt, stärker die Venen. Im subarachn. Raum über der Konvexität keine bemerkenswerten. Veränderungen

Basis des Gehirns: Weiche Häute auf der Unterfläche des Kleinhirns und des linken Occipital- uud Temporallappens eitrig infiltriert. Der linke Temporal- bezw. Occipitallappen ist graugxünlich verfärbt und fluktuiert bei der Palpation im größten Bereich. Dura, die die linke Felsenbeinpyramide überkleidet, ist mit dicken. grünlich-gelblichen Eiterbelägen bedeckt. Über dem Tegmen ist die Dura ganz morsch, teilweise zerstört, teilweise abgehoben.

Es wird ein Horizontalschnitt durch die ganze linke Großhirnhemisphäre gelegt. In dem vorderen Teil des Occipitalhirns findet sich ein bis ins Temporalhirn sich erstreckender Abszeß von Hühnereigröße, der eine deutliche Abszeßmembran aufweist und mit grünlich-gelblichem übelriechenden Eiter erfültt ist. Das den Abszeß umgebende Gewebe ist schmutzig-gelblich verfärbt und halbflüssig. Der Abszeß ist einmal nach außen hin perforiert und zwar im Bereiche des äußeren Randes des Occipitallappens Außerdem hat ein Durchbruch in den Seitenventrikel stattgefunden. Die Ventrikel sind infolgedessen mit trüber grünlich-gelblich gefärbter Flüssigkeit gefüllt. Hirnsubstanz im übrigen sehr feucht, weich, mäßig blutreich.

Fettpolster der Brust- und Bauchdecken reich entwickelt. Muskulatur entsprechend, etwas blaß. Das mäßig fettreiche Netz herabgeschlagen, bedeckt die Serosa der Därme, die glatt und glänzend ist.

Der Uterus, der sich sehr weich anfühlt, überragt die Symph. mit seinem Fundus um $18 \mathrm{~cm}$. Zwerchfellstand beiderseits 3. Rippe. Bei Herausnahme des Brustbiins sinken die Lungen zurück, sie sind durch spärlich fibröse Stränge mit der Brustwand verwachsen. Herzbeutel liegt in Handtellergröße vor. Seine Innenflăche spiegelnd. Herz größer als die Faust der Leiche, sehr schlaff. Beide Ostien für 3 Finger durchgăngig. Cruor, Fibrin, und flüssiges Blut in beiden Herzhöhlen. Arterielle Klappen schließen. Epicard wäßig fettreick, beide Ventrikel dilatiert. Herzmuskel weich, blaßßötlich, trüb und von kleinen sehnigen Einlagerungen durchsetzt. Endocard; Aorta, Coronararterie obne Befund.

Linke Lunge: Volumen reduziert, Gewicht erhöht. Aus dem Bronchus, dessen Schleimhaut geschwollen und injiziert ist, dringt auf Druck gelbliche schaumigo Flüssigkeit in reichlicher Menge. Pulmonalis frei. Die graurötliche bis blauviolett verfärbte Pleura zeigt die Residuen der Verwachsungen. Im übrigen glänzend. Oberlappen nachgiebig und knisternd. Schnittfläche glatt, graurot gefärbt. Blut- und Saftgehalt vermehrt. Luftgehalt reduziert, nirgends aufgehoben. Unterlappen etwas blutreicher, aus dem Querschnitt der Bronchien treten auf Druck Eiterpfröpfchen hervor.

Rechte Iunge gleicht im wesentlichen der linken. Schleimhaut des Rachens blaß, Tonsillen zerklüftet. In einzelnen Lakunen Sekretpfröpfe, Schleimhaut des Kehlkopfes und Tracbea injiziert und mit Schleim bedeckt. Schilddrüse vergrößert, von weicher Konsistenz. Colloid vermehrt.

Milz 15:81/2:31/2. Kapsel hart, gespannt, blauviolett, Organ von weicher Konsistenz. Von Schnittfäche läBt sich Pulpa von braunroter Farbe abstreichen. Follikel vergrößert, verwaschen konturiert.

Leber 28:21:10. Kapsel gespannt, zart, rötlich-gelblich gefärbt, Parenchym weich, brüchig, blutreich, trübgelblich bräunliah gefärbt, undentlich gezeichnet. 
Magen kollabiert, enthält geringe Mengen Speisereste, Schleimhaut geschwellt und besonders auf der Höhe der Falten im Fundus dunkelrot injiziert, stellenweise durchblutet.

Pankreas weich, gekörnt, graurötlich. gelbe Galle.

Gallenblase, Schleimhaut geschwellt, injiziert, enthält trübe, gold-

Linke Niere. Fettkapsel entsprechend, fibröse leicht abziehbar $11: 41 / 2: 3$. Oberfiäche glatt, rot, gute Konsistenz des Organs, reichlicher Blutgehalt. Rinde nicht verbreitert, graurot, gut gezeichnet, gegen die dunkelrote Pyramide gut abgesetzt.j

Rechte Niere gleicht der linken, Nebennieren ohne Befund.

Uterus und Scheide werden an der Hinterwand eröffnet; im Uterus ein $37 \mathrm{~cm}$ langer männlicher Fötus.

Darm. Schleimbaut geschwellt, bes. auf der Höhe der Falten lebhaft injiziert uud reichlich durchblutet.

Die Herausnahme des Schläfenbeins zur genauen Untersuchung ist aus äußeren Gründen nicht möglich gewesen.

Epikrise: Die P. kam in sehwer krankem Zustande in die Klinik. Es war zunäebt die Frage, ob die schweren Erseheinungen vielleicht nicht doch mit der Schwangersehaft in Zusammenhang zu bringen wären. Die Untersuchnng des Urins, das Fehlen von ödemen ete. beseitigte den $\mathrm{Zweifel} \mathrm{und} \mathrm{da}$ eine sehwere Ohrenerkrankung vorhanden war - Cholesteatom mit Granulationwucherungen aus dem Atticus und aashaft stinkendes Sekret - war es geboten, die P. zu operieren, obgleich sie bereits soporös war. Bei der Operation wurde es manifest, daß die cerebralen Erscheinungen otogener Natur waren. Es fand sich eine hirsekorngrobe Fistel, im horizontalen Bogengang. Ferner war das Tegmen antri in Linsengröße kariös, sodaß die Dura nach Entfernung des kariösen Knochens freilag; letztere sah jedoch, soweit eine genauere Betrachtung bei der Operation möglich war, gesund aus. Die Operierte erholte sich nur seheinbar für kurze Zeit, Schläfrigkeit und Benommenbeit des Sensoriums hielten an; P. sprach wirre Worte und gab am letzten Tage anf alle Fragen dieselbe stereotype Antwort: „ja, 19 Jahr". Es wurde aus diesem Symptom im Verein mit dem übrigen Befund und dem Krankheitsverlauf die Diagnose: „Linksseitiger Schläfenlappenabszeß" gestellt. Leider verbot der Zustand der Patientin, die Trepanation auf dem linken Schläfenlappen auszuführen. Die Kranke war bereits so schwach, daß sie eine zweite Narkose uieht mehr überstanden bätte; zudem aber ließen auch die wiederholt aufgetretenen Krämpfe schon mit Gewißheit vermuten, daß bereits ein Durchbrueh des Abszesses in den linken Seitenventrikel erfolgt sei, was auch der Sektionsbefund bestätigte. 
Der Abszeß war vermutlich vom Tegmen antri aus induziert. Wenn auch die Dura, wie auf Grund des Operationsbefundes angenommen wurde, gesund gewesen wäre, hätte sich doch ein AbszeB im Großhirn von dem kariösen Tegmen antri aus entwickeln können, selbst hinter einem Wall von gesunder Hirnsubstanz. In unserem Falle bat nun entweder das Aussehen der Dura getäuscht, oder es ist später ein Durchbruch nach der Richtung des Tegmen tympani hin erfolgt und bat die Dura derartig verändert, daß der Zustand, wie er bei der Sektion geschildert ist, eintrat. Es heibt dort „die Dura über dem Tegmen antri ist ganz morscb, teilweise zerstört" ; es ist unwahrseheinlich, daß der Abszeß vom Labyrinth aus induziert ist. Einmal war die Dura der binteren Pyramidenfläche ganz intakt; ferner müßte eine eitrige Labyrinthentzündung mit ibren schweren Erscheinungen voraufgegangen sein. Genauere anamnestische Angaben fehlen uns allerdings, aber vermutlich ist der erste Teil der Schwangersehaft gut verlanfen; bei der ersten gröberen Störung (Krämpfe) hat der behandelnde Arzt die Kranke der Franenklinik zugesandt in der Annahme, daß es sich um Eklampsie handele. Wären zuvor schon bedrohliche Erscheinungen, wie sie eine Labyrintbentziundung mit sich bringt, aufgetreten, so wäre ärztliche Hilfe früher in Ánspruch genommen worden. Daß andernfalls der Abszeß wie aus der derben Abszeßmembran hervorgeht, schon längere Zeit bestanden haben muß, obne schwere Erscheinungen zu zeitigen, kann nicht wundernehmen, denn Hirnabszesse sind oft ohne besondere Besehwerden zu verursachen bis kurz vor dem Exitus latent geblieben. Stauungspapille war bei diesem großen Abszeß nicht vorhanden.

$$
\text { X. }
$$

Emma Stephan, Arbeiterskind, 8 Jahr, aus Förderstedt. Aufgenommen 10. Juli 07, gestorben 16. Juli 07.

Anamnese: Nach Angabe des Vaters soll das Kind mit Ausnahme der Kinderkrankheiten stets gesund gewesen sein. Vor etwa einem halben Jahre soll das Kind in einen Keller drei Meter tief hinabgefallen sein, scheinbar ohne Schaden zu nehmen. Es babe keine sicbtbare Kopfverletzung gehabt, habe nicht erbrocben, und sei nicht bewußtlos gewesen. Seit einem Vierteljabr eitere das r echte Ohr angeblich nach Erkältung (Bad im Dorfteiche) nach voraufgegangenen heftigen Schmerzen im Ohr. Seit etwa 2-3 Wochen mache das Kind einen schwerkranken Eindruck. Es habe viel über Kopfscbmerzen geklagt, sei auch schläfrig und benommen. Seit 8 bis 10 Tagen ist dem Vater aufgefallen, daß die $P$. viel mit den Händen herum hantiere, an der Bettdecke gezupft habe und das Hemd habe zerreißen wollen. Erbrechen jst nicht dagewesen. Mangelbafte Nahrungsaufnahme und angebaltener Stuhlgang. 
Status praesens vom 10. Juli 1907 : Ziemlich kräftiges, gut genährtes Kind mit gerötetem Gesicht, wenig belegter Zunge. Keine Lähmungen, keine Parästhesien. Minische Muskeln gut innerviert. Sensorium benommen, schläfrig. Aufschreien bei jeder Berührung; undeutliches Flockenlesen. Pupillen gleich, mittelweit, reagieren prompt auf Lichtreiz. Kein Nystagmus, keine Augenmuskellähmung. Augenhintergrund bis auf starke Venenfüllung ohne Besonderheit. Reflexe normal. Leib nicht eingesunken, weich. Urin eiweiß- und zuckerfrei. T. $38,1^{\circ}$ P. . 72 unregelmäßìg klein.

-Die Umgebung des rechten Ohres stark druckempfindlich, auf dem Planum und an der Spitze des Proc. mast.; links ohne Besonderheiten. Der rechte Gehörgang ist voll stinkenden Eiters; nach Abtupfen sieht man Granulationen, die den Blick auf das Trommelfell verlegen. Linker Gehörgang und Trommelfell ohne Befund.

Gehörprüfung wegen der Benommenheit unmöglich.

11. 7. 07. Früh Temp. 39,10, P. 88. Nachts Unruhe. Durch Lumbalpunktion 30 Gramm unter starkem Druck stehender, völlig klarer Liqu or abgelassen.

Totalaufmeißelung rechts: Weichteile und Cortikalis von normalem Aussehen. Hyperämie des Knochens, in Antrum und Paukenhöhle, spärliche Mengen Eiter und einige Granulation in der Paukenhöhle, sonst keine krankhaften Verănderungen. Hammer und Amboß gesund. Plastik, primäre Naht. Verband, Temp. abends 39,2 .

12. 7. 0 \%. Nacht sehr unruhig. Öfters lautes Aufschreien. $39,4^{0}, 39,8^{0}$, Sensorium andauernd benommen.

13. 7. 07. Große Unrube, Aufschreien, deutliches Flockenlesen. Nahrungsaufnahme unmöglich. Urin unter sich gelassen. Temp. $39,3^{\circ}-40,1^{\circ}$.

14. 7. 8. Nochmalige Lumbalpunktion mit Entleerung von 30 Gramm, Liquor, der jetzt leicht getrübt ist, aber unter geringerem Druck steht als zuvor. Keine Nackensteifigkeit. Kein Erbrechen. Temp. 39,4 $4^{\circ} 40,0^{\circ}$.

16. 7. 05. Kurz nach Mitternacht im Coma Exitus.

Die Untersuchung der Lumbalfüssigkeit im Hygienischen Insttut, ergab beidemale im Austrich keine Meningokokken und keine Tuberkelbazillen, sondern nur vermehrte Leukozyten. Auch kulturell wurden keine verdächtigen Bakterien nachgewiesen. Einzelne gewachsene weiße Kolonien (Stapbylococcus albus) wurden auf Verunreinigung bezogen.

Sektionsbefund: Rednzierter Ernährungszustand. Totenstarre und Flecke vorhanden, Hautdecken blaß. Im Subduralraum des Rückenmarks findet sich eine wenig klare, gelbliche Flüssigkeit. Innenfläche der Dura daselbst glatt, weiche Häute ohne Befund. Graue und weiße Substanz des Rückenmarks zeigen normale Verhältnisse. Schädeldach: von mittler Dicke, sehr blutreich, Diploë vorhanden. Außen- und Innenfläche der Dura glänzend. Gefäße derselben stark gefüllt. Dura Innenfläche feucht. Weiche Bäute an der Konvexität zart, glänzend. Subaracbnoideale Flüssigkeit nicht getrübt. Die Gyri sind leicht abgeplattet. An der Basis in der Gegend des Chiasma sind die weichen Häute in Markstückgröße verdickt, zeigen gelblich sulziges Aussehen. Dort sieht man auch vereinzelte weiße Knötchen, Gehirnsubstanz sehr weich, feucht, blaß. Im übrigen nichts Besonderes. Die Sinus der Basis enthalten reichlich flüssiges Blut und etwas Cruor. Rechte Lunge ist durch strangförmige, leicht lösliche Verwachsungen der Brustwand adhärent. Linke $L$ unge von normalem Volumen und Gewicht. Aus dem Bronchus, dessen Schleimhaut injiziert ist entleert sich auf Druck blutig schaumige Flüssigkeit. Pulmonalis frei Pleura ïberall spiegelnd. Oberlappen von gelblich rötlicher Farbe. Unterlappen bläulich. Unter der Pleura, besonders des Unterlappens kleine, zahlreiche Hämorrhagien. Oberlappen überall nachgiebig, Schnittfäche von roter Farbe, blut- und saftreich, an der Spitze findet sich ein hanfkorngroßer Käseherd; in dessen Umgebung zablreiche kleine Miliartuberkel. In der Nachbarscbaft des eben erwähnten Herdes findet sich peribronchial angeordnet ebenfalls eine größere Anzahl miliarer Tuberkelknötchen. Unterlappen von stark erböhtem Blut- und Saft- 
gehalt, Luftgehalt in kleinen Partien aufgehobev. Schnittfläche stellenweis ziemlich derb von dunkelroter bis braunroter Farbe. Rechte Lunge Volumen, Gewicht, Bronchus. Pulmonalis, Pleura wie links. Pleura zeigt über dem Oberlappen Residuen von Verwachsungen, sonst spiegelnd. Im Oberlappen finden sich an der Spitze zahlreiche miliare Tuberkelknötchen, stellenweise ein kirscbgrober Herd. Im übrigen gleicht der Oberlappen dem linken. Darmkanal ohne Befund.

Diagnosis post 'mortem: [Hyperämie der Hirnhäute Basilarmeningitis, Hydrocephalus internus, Cerebromalacie, Plenritis chronica fibrinosa adbaesiva dextra, Tuberkulosis peribronehialis in beiden Lungenspitzen.

Die Sehläfenbeinsektion ergab normale Verhältnisse also keine Anhaltspunkte dafür daß die Meningitis mit dem Ohrenleiden in ursächlichem Zusammenhange war.

Epikrise: Die P. wurde in schwerkrankem Zustande zugesandt und die Diagnose der bereits eingetretenen Meningitis war gesichert. Unsicher blieb jedoch die Ätiologie. Der Befund des rechten Ohres die profuse Eiterung und die Granulationen in der Tiefe konnten auf otogene Gehirnhautentzündung hinweisen. Da nun die erste Lumbalpunltion eine zwar unter erhöhtem Druck stehende, jedoch wasserhelle Flüssigkeit ergab, wurde doch noch bei dem anscheinend hoffnunglosen Falle zur Operation geschritten. Letztere erwies jedoch, und die Autopsie bestätigte das, daß es sich nicht um otogene, sondern um eine tuberkulöse Meningitis handelte, die ihren Ausgangspunkt in der Tuberkulose der Atmungsorgane hatte.

$\mathrm{XI}$.

Paul Stieber, 12 Jahre alt, Gärtnerssohn aus Passendorf. Aufgenommen 26. Mai 07, gestorben 7. Aug. 1907.

Der Junge wurde zuerst am 22. Mai 1907 in der Poliklinik vorgestellt wegen chronischer Eiterung rechts, seit 1 Jahr nach Scharlach, jetzt mit entzündlicher Stenose des Gehörgangs verbunden. Da heftiger Fieber und Schmerz bestand hinter und vor dem Ohr seit 8 Tagen (Temp. 37,50) wurde sofortige Aufnahme in die Klinik empfohlen. Dieselbe erfolgte aber erst am 26. Mai, nacbdem sich inzwischen die Schmerzen im Ohr und Kopf bis zum Unerträglichen gesteigert hatten.

Status praesens vom 26. Mai 1907. Blasser, schlecht genährter Knabe von grazilem Knochenbau. Puls regelmäßig, 76, Temp. 36,8. Pupillen gleich weit, reagieren prompt bei Lichteinfall und Akkomodation; kein Nystagmus. Urin ohne Eiweiß und Zucker. 
Umgebung des Ohres. Die Gegend hinter dem rechten Ohre ist ödematös geschwollen. Die Insertionslinie der Ohrmuschel verstrichen. Fluktuation nicht deutlich nachweisbar. Druek auf den Tragus empfindlich.

Gehörgang und Trommelfellbefund. Rechts sehlitzförmige Stenose des Gehörgangs. In der Tiefe hinter der Stenose kleine Granulationen siehtbar. Fötide Sekretion. Links Trïbung des Trommelfells, normaler Gehörgang.

Hörprüfung. Flüstersprache rechts nur direkt ins $\mathrm{Ohr}$ links $1,5 \mathrm{~m}$. Fis 4 rechts bei Nagelansehlag, links normal. $\mathrm{C}$ vom Seheitel uber die Mittellinie hinans nach rechts lateralisirt. Operation am Tage der Aufnahme.

26. 5. 07. T otalaufmeißelung rechts. Weichteile stark infiltriert, unter dem Periost entleeren sich einige Tropfen Eiter. Aus drei Durehbrüchen des Knochens. im Warzenfortsatz am äußeren Rande des Gehörgangs quillt pulsierend Eiter hervor Warzenfortsatz bis zur Spitze eitrig durehsetzt; Resektion der Spitze. In sämtlichen Mittelohrräumen zerfallenes Cholesteatom, das zu ansgedehnten Zerstörungen der hinteren Pyramidenfläche geführt hat. Extraduraler Abszeß der hinteren Schädelgrube Dura hier mit dickem mißfarbenen Granulationspolster bedeckt; Sinuswand fibrös verdiekt. Die beiden äußeren Ossicula fehlten. Ein Cholesteatomausläufer reichte bis an die Steigbügelgegend. Spaltung, Plastik ete.

Am 1. 6. Erster Verbandweehsel. Wunde sieht gut ans beginnende Granulationsbildung; nur die Dura der hintern Schädelgrube noch etwas mißfarben.

Beim zweiten Verbandweehsel am 3. 6. hat sich diese Stelle der Dura bereits deutlich gereinigt, aber der Pat. klagt über Kopfsehmerz in der Stirn.

Nach gut durchschlafener Nacht erneute Klage ibber diesen Kopfsehmerz. Kein Sehwindel, keine Übelkeit, kein Nystagmus. Ophthalmiskopiseh wird links leichtes Ödem der Papille konstatiert, Temp. und P. normal (72).

In der Nacht vom 5. zum 6. Juni wurde P. sehr unruhig und klagte viel über Stirnkopfschmerz. Gegen morgen trat beim Aufrichten im Bett Erbrechen bei nüchternem Magen ein. Temp. 36,7 0. P. 56. Völlig freies Sensorium. Keine Druckempfindliehkeit im Nacken. Motilität und Sensibilität der Ex- 
tremitäten erhalten. Sehnenreflexe normal. Da die andauernden heftigen Kopfsehmerzen, die Pulsverlangsamung bei subnormaler Temperatur, das zerebrale Erbrechen für intrakranielle Drucksteigerung sprachen, wurde sogleich (6.6.1907) zur zweiten Operation geschritten. Bei der Lumbalpunktion entleerte sich leicht gelblich getrübter Liquor unter erhöhtem Druck. Nach breiter Freilegung der Dura der mittleren Schädelgrube zeigte sich die Dura von gesundem Aussehen; sie wölbte sich aber stärker vor als normal. Trepanation auf den Schläfenlappen von außen. Auch hier die Dura sehr stark gespannt. Nach Inzision derselben prolabiert das Cerebrum ungewöhnlich stark. Durch tiefe Inzisionen mit dem Skalpell in den Schläfenlappen nach allen Richtungen hin entleert sich aber kein Eiter. Deshalb wurde sofort hinterber auf das Kleinhirn von außen trepaniert. T-Schnitt zur Freilegung der Schädelbasis. Hierbei starke Blutung aus dem Emissarium mastoidenm. Die Dura mater über dem Kleinhirn zeigte sich nicht so stark gespannt, wie itber dem Schläfenlappen. Dureh Einstich in das freigelegte Kleinhirn mit dem Skalpell wird zunächst kein Eiter zutage gefördert. Erst nach Eingehen in den Schnitt mit der Kornzange und Spreizen derselben entleerte sich von vorn - oben ungefähr ein Teelöffel voll gelben, dickflüssigen, leicht fötiden Eiters. Drain in die Abszeßhöhle. Verband. Gleich nach vollendetem Verbande trat bedrohliche Herzsehwäche ein mit kaum noch fühlbaren Puls. Subkutane Ätherinjektion besserte den Puls nicht viel, deshalb Kochsalzinfusion. Gegen Abend hatte sich danach der Puls wieder gehoben, und war sogar ziemlich kräftig und regelmäßig, 58, Temp. abends 37,1 o. P. verweigerte jede Nahrungsaufnahme und wurde schlafsüchtig. Nur hin und wieder beklagte er sich über Fortdaner der starken Kopfschmerzen. In der folgenden Nacht vom 6. zum 7. Juni schlief er ganz ruhig, schrie aber mehrmals auf über Kopfschmerzen. Die Atmung war regelmäßig, 20,0 .

7. 6. morgens Temp. 37,1, P. 64. Vollständige Benommenheit. Hat weder Urin noch Kot unter sich gelassen. Abends Temp. 40,3, Puls 84. In der Lumbalflüssigkeit waren weder mikroskopiseh noch kulturell Bakterien nachgewiesen (im Hygienischen Institut). In der ersten Hälfte der folgenden Nacht schlief $P$. ruhig bei einem regelmäßigen $P$. zwischen $\$ 6$ und 92 und T. zwischen 40,3 und $40,6^{\circ}$. Gegen $3 \mathrm{Uhr}$ morgens lautes Aufstöhnen mit plötzlichem Atmungsstillstand. Exitus. 


\section{Sektionsprotokoll:}

Leiche von grazilem Knochenbau, mittlerem Ernährungszustande. Totenflecke und Totenstarre vorhanden. Hautdecken im allgemeinen blaßs.

Hinter dem rechten Ohre findet sich eine etwas ältere, von einer Totalaufmeißelung herrïhrende, mit Granulationen besetzte und mit eitrigem Sekret belegte Operationswunde. Über und vor dem rechten Ohre eine ca. zweimarkstäckgroße Trepanationsöffnung im Bereiche des Temporallappens, durch welche reichlich weiche, stark durchblutete Hirnmasse prolabiert ist. Hinter und etwas oberhalb vom rechten Processus mastoideus findet sich eine zweite ca. zehnpfennigstückgroße Trepanationsöffinung, durch welche ein mittelstarkes Drainrohr in die Schädelhöhle führt, etwa in der Richtung auf den äußeren Rand der Kleinhirnhemisphäre. Das Drain ist mit einigen Nähten an der Kopf'schwarte fixiert. Aus dem Drain fließt etwas sch mutzig-blutiges Sekret.

Schădeldach normal konfiguriert, mäßig fest mit der Dura verwachseu, sonst ohne Besonderheiten.

Die Dura ist gespannt, im Bereiche der abhängigen Partien der rechten Hemisphäre leicht blutig inbibiert. Im Sinus longitudinalis Cruor, Fibrin, dunkelflüssiges Blut. Innenfläche der Dura trocken, ohne Auflagerungen. Die weichen Häute sind zart, über der rechten Hemisphäre leicht blutig inbibiert, besonders über den abbängigen Partien. Subarachnoideale Flässigkeit hicht in nennenswerter Menge vorhanden. Piagefäße mittelstark gefüllt. Nirgends Eiter im subarachnoidealen Raume, auch nicht an der Basis des Gehirns. Gefäße und weiche Häute daselbst ohne Besonderbeiten. Entsprechend den Trepanationsöffnungen finden sich Defekte im Gehirn rechterseits. Das Loch im Temporallappen ist sehr unregelmäBig fetzig gestaltet, die Hirnsubstanz in der Umgebung ist erweicht, stark durchblutet, jedoch nicht eitrig infiltriert.

Das Loch in der rechten Kleinhirnhemisphäre ist nur wenig weiter als das Drainrohr, ziemlich scharf begrenzt; die den Wundrand bildende Hirnsubstanz ist etwas erweicht, durchblutet, schmutzigrötlich verfärbt und stellenweise etwas eitrig inflitriert. Das Loch führt in eine etwa haselnußgroße, vorwiegend in der Marksubstanz gelegene Abzeßhöble, in welche das Drain hineinreicht. Die Wandungen der Höhle sind frisch erweicht und durchblutet. Bei der weiteren Sektion der rechten Kleinhirnhemisphäre gelangt man in eine etwas nach vorn und unten von der ersten gelegene zw eite, mit dickem grünlich-gelblichem Eiter gefüllte, etwa gleichgroße, mit der ersten durch einen Kanal in Verbindung stehende Abszeßhöhle. deren Wand eine dentliche Membranbildung aufweist. Der 4. Ventrikel ist unverändert. Er enthält leicht getrübten Liquor. Die Großhirnventrikel sind etwas erweitert, enthalten ebenfalls vermehrten, leicht getrübten Liquor. Abgesehen von starkem Ödem und den beschriebenen Veränderungen im rechten Temporallappen und der rechten Kleinhirnhemisphäre finden sich keine Veränderungen der Hirnsubstanz. Die Dura über dem rechten Tegmen tympani ist blutig inbibiert. Im Sinus sigmoideus rechts tindet sich ein kleiner, grauroter, adhärenter Thrombus. Die übrigen Sinus ohne Besonderheiten.

Fettpolster der Brustbauchdecken entsprechend entwickelt. Muskulatur daselbst blaß. Im Abdomen kein fremder Inhalt. Därme leicht gebläht, Serosa spiegelnd. Zwerchfellstand beiderseits 4. Rippe.

Lungen: Sinken zurück, nur links über dem Unterlappen an zirkumskripter Stelle mit der Brustwand verklebt. Pleurahöhlen frei.

Herz ohne bemerkenswerten Befund.

Linke Lunge: Schwer und roluminös. Aus dem Bronchus, dessen Schleimhaut etwas gerötet ist, dringt auf Druck schaumige Flüssigkeit (gelblich); Pulmonalis frei. Pleura im allgemeinen spiegelnd, grau-blau-rot, Mitten über dem Unterlappen ist die Oberfläche leicht buckelig vorgewölbt, etwa in der Ausdehnung eines Zweimarkstückes. In diesem Bereich ist die Pleura mit bereits in Organisation begriffenen Fibrinbelägen bedeckt; auf Druck fluktuiert die. Stelle etwas. Beim Finschneiden zeigt sich etwa $1 / 2 \mathrm{~cm}$ unter 
der Pleura ein ca. haselnußgroßer, halbverflüssigter käsiger Herd, der von einer breiten hāmorrhagischen Zone umgeben ist. Eine reaktive Bindegewebswucherung in der Umgebung des Herdes ist nicht zu konstatieren. Der Prozeß wurde, da sich sonst nirgends irgendwelche tuberkulöse Prozesse in der Leiche fanden, für einen hämatogen (vom $\mathrm{Ohr}$ her) entstandenen $\mathbf{A b}$ szeß gehalten. Die mikroskopische Cntersuchung ergab jedoch daß es sich um einen eitrig eingeschmolzenen käsigen, tuberkulösen Herd handelt. Im übrigen ist das Lungengewebe sehr blut- und saftreich, besonders im Unterlappen. Der Luftgehalt ist reduziert, jedoch nicht aufgehoben.

Rechte Lunge gleicht der linken, entbält jedoch keinen Käseherd.

Hals- und Rachenorgane: Ábgeseben von mäßiger Hyperplasie des adenoiden Gewebes sind Rachen- und Nasenrachenraum ohne bemerkenswerte Veränderungen.

Milz: Etwas vergrößert, von guter Konsistenz. Kapsel zart, gespannt. Schnittfläche zeigt starke Hyperplasie und Follikel, deren Grenzen verwaschen sind.

L eber: Verfettet, sonst ohne Besonderheiten.

Magen: Pankreas, Nebennieren ohne Besonderheiten.

Nieren: Blutreich, Parenchym etwas trüb, undeutlich gezeichnet. Blase ohne Besonderbeiten.

Darm: Schleimhaut stellenweise stark injiziert, auch geschwellt. Die Follikel und Plaques sind geschwellt.

Diagnosis post mortem: Totalaufmeißelung rechts, Trepanationsöffnungen im Bereiche des rechten Temporallappens und der rechten Kleinhirnhälfte. Hirnprolaps aus dem Trepanationsloch über dem rechten Temporallappen. Thrombus im rechten Sinus sigmoideus. Drainierter Abzeß der rechten Kleinhirnhemisphäre. Hydrocephalus internus (leicht getrübt) Ödem des Gehirns. (Keine Meningitis) Hyperämie, ödem der Lungen. Tuberkulöser Herd im linken Unterlappen. Hyperplasie der Milzfollikel. Verfettung der Leber. Hyperämie, trübe Schwellung der Nieren. Enteritis follicularis.

Sektion des Sehäfenbeins: Im Sinus sigmoideus am Emissarium mastoideum ein etwas über erbsengroßer, gutartiger Thrombus. Sonst die Sinus mit frischem Blut und Blutgerinnsel gefüllt. Im Bulbus venae jugularis kein Thrombus. Dura der hintern Schädelgrube mit dicken Granulationen besetzt und die entsprechende Innenfläche der Dura verfärbt. Am Tegmen tympani und an der medialen Wand der Paukenhöhle keine Arrosion des Knochens. Stapes in situ. Labyrinth makroskopisch intakt, auch der Aquaeductus vestibuli.

Epikrise. Im vorliegenden Falle handelt es sich um einen. 12 jährigen, schwächlichen Knaben, der an einer veralteten, ohne Zweifel seit frühester Kindheit bestehenden rechtseitigen Ohreiterung litt. Die vor einem Jahre überstandene Seharlacherkrankung, die in der Anamnese als Ursache der Ohreiterung 
angegeben wird, war wohl nur die Veranlassung einer akuten Exacerbation. Der Krankheitsbefund im Ohre, wie er sich im vorliegenden Falle bei der Operation zeigte, kann kaum durch einen Prozeß herbeigeführt sejn, der nur ein Jahr lang bestanden hat. Zudem ist es ja doch eine allgemeine Erfahrung und zwar nicht nur in den unteren Volkssehichten, daß Mittelohreiterungen sehr häufig keine Beachtung finden und daß erst durch ein zufällig hinzutretendes Leiden eine Exacerbation herbeigeführt und dadurch die Aufmerksamkeit auf das schon lange bestehende Ohrenleiden gelenkt wird. So auch in diesem Falle.

Bei der ersten Untersuchung des Patienten am 22. August wurde eine fötide Eiterung des rechten Ohres mit entzündlicher Stenose des Gehörganges neben Granulationswucherungen aus der Paukenhöhle festgestellt. Die Gegend vor und hinter dem Ohr war geschwollen und sehr druckempfindlich. Heftige Schmerzen vor und hinter dem Ohr, verbunden mit Fieber, hatten den Patienten in die Klinik getrieben. Trotz der dringlicben Mahnung zur sofortigen Aufnahme kam der Patient erst 4 Tage später und sollen sich in diesen Tagen die Ohrschmerzen bis zum Unerträglichen gesteigert haben. Sofort nach der Aufnahme wurde die Operation (Totalaufmeibelung) ausgeführt und ein zerfallenes Cholesteatom mit ausgedehnter Kno.chenzerstörung im Warzenfortsatz und mit Bildung eines extraduralen Abszesses in der hinteren Schädelgrube gefunden. Nach der Operation trat wesentliche Besserung des Allgemeinzustandes ein. Die Wunde hatte beim ersten Verbandwechsel ein gutes Aussehen, auch die anfänglich mißfarbene Stelle der Dura begann sich zu reinigen und mit frisch rot aussehendem Granulationspolster zu bedecken. Da trat etwa eine Woche nach der Aufmeißelung. eine Verschlimmerung des Zustandes ein. Die Stirnkopfschmerzen wurden heftiger, die ophthalmoskopische Untersuchung zeigte ein leichtes Ödem beider Papillen. Stärkere Unruhe und einmaliges Erbrechen bei nüchternem Magen setzten ein. Dabei blieb aber das Sensorium stets klar und die Temperatur subnormal. Die andauernden Kopfschmerzen, das zerebrale Erbrechen, die Pulsverlangsamung bei subnormaler Temperatur sprachen fiir intrakranielle Drucksteigerung durch einen Hirnabszeß. Durch die am 6. August ausgeführte Lumbalpunktion wurde leicht getrübter Liquor unter erhöhtem Druck entleert. Gleich darauf folgte die Trepanation, und zwar zunächst vergeblich auf den Schläfenlappen und dann mit Erfolg auf das 
Kleinhirn. Der Schläfenlappen war als wahrscheinlicher Sitz des Abszesses vermutet worden, weil das Labyrinth intakt war und die Kopfsohmerzen stets in die Sehläfengegend und Stirngegend lokalisiert wurden. Über den Hinterkopf war nicht geklagt worden. Verdächtig für eine Fortleitung der Eiterung aus den Mittelohrräumen in das Kleinhirn war allerdings das bei der Totalaufmeißelung gefundene mißfarbige Granulationspolster auf der Dura der binteren Sehädelgrube. Durch Einstich in das von außen freigelegte Kleinhirn mit dem Skalpell wurde zunächst keine Eiterentleerung erzielt; erst nach Eingehen in den Schnitt mit der Kornzange entleerte sich ungefäbr ein Tee. löffel voll gelben dickflüssigen, leicht fötiden Eiters. Trotz dieser Eiterentleerung trat eine Verschlimmerung des Zustandes ein. Die Kopfschmerzen wurden heftiger, das Sensorium trübte sich und am nächsten Tage erfolgte der Tod unter plötzlichem Stillstand der Atmung. Die Sektion ergab als Ursache dieser Lähmung des Atmungszentrums das Vorhandensein eines zweiten Abszesses im Kleinhirn, der nicht von dem Messer getroffen und deshalb nicht entleert war. Dieser zweite Abszeß stand mit dem entleerten Abszeß durch einen engen Kanal in Zusammenhang und zeigte als Anzeichen seines längeren Bestehens eine deutliche Membranbildung.

\section{XII.}

Germer Otto, 38 7ahre alt, Grubensattler aus Frose. Aufgenommen am 31. Oktober 1907, gestorben am 12. November 1907.

Anamnese. P. bringt ein Schreiben seines Kassenarztes in Vorlage wonach P. seit ca. 18. Oktober in Behandlung ist und sofort an einen Ohrenarzt uberwiesen wurde. Wegen allgemeiner rheumatischer Beschwerden konnte er erst am 22. Oktober wieder zu dem Ohrenarzt gehen. Da. eine Besserung im subjektiven Befinden eintrat, konnte sich P. nicht zur Überweisung in die Klinik entschließen trotz dringlicher Ermahnung seines Kassenarztes. Als am 31. Oktober eine wesentliche Verschlecbterung eingetreten war (beschleunigter Puls, Pupillenstarre bei weiter rechter Pupille), lehnte der Kassenarzt jede weitere Behandlung ab, wenn P. sich nicht zur Aufnahme in die Klinik entschließen könne.

Status praesens. Mittelgroßer, kräftig gebauter, schwer krank aussehender Mann mit blasser Gesichtsfarbe. Er klagt über heftige rechtsseitige Kopfschmerzen, Übelkeit und unsicheres Gefühl beim Geben. Temperatur $37,7^{\circ}$, Puls 100 .

Umgebung des Ohres ohne Besonderheiten. Gehörgang und Trommelfellbefund rechts: Gehörgang-Trommelfellgrenze hinten oben verstrichen, Gehörgangs wand etwas gesenkt. Totaldefekt des Trommelfells bis auf einen kleinen V-förmigen Rest um eine angelötetes Hammer-Rudiment. Hinten oben Krater, Labyrinthwand epidermisiert. Sekretion mäßig, sehr fötid. Links ohne Besonderheiten. 
Hörprüfung. Flüstersprache: Rechts nur sehr lautes Flüstern ad concham. Links $2 \mathrm{~m}$. Rinne rechts negativ. $C_{1}$ nach rechts lateralisiert, Fis 4 rechts auf Nagelanstrich.

Therapie: Totalaufmeißelung rechts am 1. November. Weichteile und Corticalis 0. B. Beim ersten Meißelschlag zur Fortnahme des Planums quillt stinkender Eiter aus der Tiefe. Breite Freilegung aller Mittelohrräume. Im Antrum, Aditus und Kuppelraum zerfallenes Cholesteatom. Ausgedehnte Nekrose im Antrum, Sinus sigmoideus in etwa Bohnengröße freiliegend; das Tegmen antri zum Teil durch Caries zerstört. Aus dem Defekt im Tegmen antri quillt rahmiger Eiter von einem extraduralen Abszeb her. Fortnahme des ganzen Tegmen und eines Teiles der Schuppe zur weiten Freilegung des extraduralen Abszesses. Die Dura sieht gelblich grün verfärbt aus, an einer kleinen Stelle bereits nekrostisch. Die Sinuswand zeigt dünnes Granulationspolster. Weitere Freilegung des Sinus bis seine Wand gesundes Aussehen zeigt. Ussicula: Ambol fehlt, Hammerrest nicht gesichtet. Plastik, Verband.

Temp. betrug kurz vor der Operation $39,4^{\circ}$. Temp abends nach der Operation $38,0^{\circ}$. Im Laufe der Nacht vom 31. 10. auf 1. 11.: $37,2^{0}$, $37,8^{\circ}, 37,7^{\circ}$.

2. November. P. hat nur wenig geschlafen; viel über Durst geklagt. Gegen Morgen Frösteln an den Beinen.

Temp. im Laufe der folgenden Nacht: $38,6^{\circ}, 39,0^{\circ}, 38,4^{\circ}, 38,0^{\circ}, 38,4^{\circ}$, $38,1^{\circ}$; früh 7 Uhr: $37,9^{\circ}$. Puls 112 , Respiration 21 . P. füblt' sich leichter, hat keine Schmerzen. Er spricht auffallend viel und wiederbolt sich immer. - Klystier wegen angehaltenen Stubles.

10 Ubr. P. nimmt nichts zu sich als einen Zwieback und etwas Bouillon, nachdem er die wenige am Morgen genossene Milch wieder ausgebrochen. Sclerae zeigen leicht subikterische Färbung. T. mittags $38,8^{\circ}$; gegen 5 Uhr nachmittags Schüttelfrost von ca 20 Minuten obne nachfolgenden Schweiß. T. abends: $39,5^{\circ}$. Kein Husten.

3. November: $P$. hat die Nacht von gestern auf heute gut geschlafen. Keine besonderen Klagen, außer Durst. heute auch das Gesicht subikterisch. T. im Laufe der Nacht (von 8 bis 6 Uhr): $40,0^{\circ}, 38,9^{\circ}, 38,0^{\circ}, 37,0^{\circ}, 38,0^{\circ}$ $38,0^{\circ}$, früh 8 Uhr: $38,2^{\circ}$.

Lungen und Atmung ohne besonderen Befund, P. 11 h: 120, Respiration 21. Abends $7 \mathrm{Uhr}$ : Pat. hat jetzt eine gute Stunde geschlafen und vermag, allerdings ganz kurz vorber erwacht, sich nicht über die Zeit zu orientieren. Er hălt den eben getanen Schlaf für die zurückgelegte Nacht und meint, es könne zwischen 2 und 4 Uhr morgens sein und "der Montag müsse bald losgehen". Er erkennt and benennt jedoch alle" ihm rorgehaltenen Gegenstande richtig und fragt nach der Pulszabl, um sie mit der vormittägigen zu vergleichen. T. $39,5^{\circ}$, Puls 120 , Respiration 20.

4. Nov ember. P. hat sehr gut geschlafen, wachte nur beim Messen der T. auf. Morgens spontan Stubl. Sputum o. B. T. im Laufe der Nacht: $39,3^{\circ}, 38,4^{\circ}, 38,6^{\circ}, 38,2^{\circ}, 38,0^{\circ}$, früh 8 Uhr: $37,8^{\circ}$, Puls $109, \mathbf{R}$. 26 , Mittag nur 3 Löffel Suppe genommen, lehnt weiteres Essen ab. 2 Uhr: eine Tasse Kaffee und etwas Zwieback. T. 40,6. Nach dem Messen schläft P. ein, kommt während des Schlafes in Schweiß; wacht kurz vor 4 Uhr auf. Zwischen 5 und 6 Uhr schläft $P$. noch einmal ein; während des Schlates e n derartiger Schweißausbruch, daß das Hemd durchnäßt ist. $P$. wird trocken gerieben, schläft darnach gleich wieder weiter bis gegen 7 Uhr. R. im Schlaf 18, nach dem Erwachen 24-26. Puls 94, T. 38,50. P. ist über seine Zimmergenossen orientiert.

5. November. P. hat gut geschlafen. Klagt beim Erwachen über Schmerzen beim Atmen auf der Brust rechts hinten unten. Objektiv nichts nachweisbar. Sputum ohne Besonderheiten. T. im Laufe der Nacht: $38,4^{\circ}, 38,8^{\circ}, 39,0^{\circ}, 39,2^{\circ}, 38,3^{\circ}, 37,9^{\circ}, 39,6^{\circ}$. T. 8 Uhr früh $39,6^{\circ}$. P. 106, 108, R. 26. Nachmittags 5 Uhr Verbandwechsel. In der Schwarte auf dem Sinus zeigen sich mehrere frische kleine Granulationen. Bei Kompression der Jugularis schwillt der Sinus nur ganz wenig an. Punktion mit der
Pravaz-Spritze ergibt flüssiges Blut.

Archiv f. Ohrenheilkunde. Bd. 78. 
Der freigelegte Durabezirk, der sich jetzt in einen Prolaps von der Größe einer starken Haselnuß verwandelt hat, zeigt nur noch in seiner unteren Hälfte Dura, oben ist das Cerebrum frei, mit Pia überkleidet. Der gesamte Prolaps ist graugrün. Leichte Ausfüllung der Operationsböhle mit Jodoformgaze. Verband. T. abends 6 Uhr: $40,0^{\circ}, 8 \mathrm{Chr}$; T. $38,4^{0}$, P. $108, R, 32$.

6. November. P. hat geschlafen. T. im Laufe der Nacht: $38,4^{\circ}$, $38,8^{\circ}, 39,0^{\circ}, 39,2^{\circ}, 38,3^{\circ}, 37,9^{\circ}$; früh 8 Uhr $39,3^{\circ}$. P. 96, R. 28 . T. mittags 2 Uhr $40,0^{\circ}$. Abends T, $38,9^{\circ} ;$ P. 108, R. 40 . P. hat seine Tagesrationen heute ganz aufgezehrt. Mittags 2 Uhr Schüttelfrost, darnach $40,4^{\circ}$. Kein Husten. Sputum ohne Besonderheiten. T. abends $38,9^{\circ}$, P. 108, R. 40.

7. N ovember. Dämpfung, handtellergroß, rechts hinten unten. Atemgeräusch und Stimmfremitus abgeschwächt. T. früh $39,4^{\circ}$. P. und $R$. unverändert.

Sinusoperation: Nach Unterbindung der Jugularis Freilegung des Sinus bis zum oberen Knie. Sinuswand nach oben gesund. Eröffnung des Sinus mit Parazentesennadel und Knopfmesser. Von oben her reichliche freie Blutung mit 'Tamponade gestillt, von unten ber wird mit dem Knielöffel ein schmaler, etwa kleinbohnengroßer, roter Thrombus herausgeholt. Verband. Probepunktion an der Dämpfungsstelle ergibt beim dritten Einstich $1-2 \mathrm{~cm}$ seröse, bernsteingelbe Flüssigkeit. T. abends $39,1^{\circ}$, P. 112 , R. 40 .

8. November. P. fühlt sich wohl, hat leidlich geschlafen. T. $39,4^{\circ}$, P. 112, R. 40 . Atembeschwerden angeblich geringer. $T$, abends 39,10 . P. erbält Digitalisinfus mit Coffeïn.

11. November. Abends Verbandwechsel. Beim Abnehmen der komprimierenden Gazestücke mäßige Blutung aus der unteren Sinusgegend bezw. dem Sinus petrosus inferior. Tamponade. Der obere Sinustampon vom 7. bleibt noch liegen. Die vom Wundsekret durchtränkten Partien desselben werden abgeschnitten.

Lungen befund: Dämpfungszone rechts hinten unten unverändert. Über der brettharten Dämpfung bronchiales Atmen, dazwischen hellklingendes Knisterrasseln, etwas weiter unten Lederknarren. Rechts vorne und seitlich Dämpfung, Giemen und Knisterrasseln. T. früh $39,4^{\circ}$, mittags $40,1^{\circ}$, abends $39,5^{\circ}$, abends 7 Uhr 37,7 . P. and R. wie seither.

12. November. P. hat leidlich gut geschlafen. Er spricht jetzt nicht mehr, winkt den Kaffee ab, antwortet nur zögernd, aber richtig, ist sehr blaß und collabirt. P. 140, R. 44. T. im Laufe der Nacht: $38,0^{\circ}, 37,0^{\circ}$, $37,5^{\circ}, 38,2^{\circ}, 38,0^{\circ}$, früh 8 Uhr $37,9^{\circ}$. P. reagiert mittags nicht mehr auf Anruf. T. $39,5^{\circ}, 40,6^{\circ}$. Exitus 12 . Norember nachmittags $5 \mathrm{Uhr}$.

\section{Sektionsprotokoll.}

Mittelgroße männliche Leiche von kräftigem Knochenbau und gutem Ernährungszustand, leichte Ödeme der unteren Extremitäten. Hautdecken blaß mit leicht gelblichem Anflug. Auch Sklera leicht gelblich gefärbt. Totenstarre und -Flecke vorhanden. Hinter dem rechten Ohr Totalaufmeißelungswunde mit schmierigem Belag. Am inneren Rande des Sternocleido eine $4 \mathrm{~cm}$ lange, Jeicht belegte tamponierte Operationswunde (Cnterbindung der Jugularis int.).

Schädeldach mittelschwer, symmetrisch, Diploë vorhanden, blaßgrau-rot. Innenfläche ohne Befund, Dura mit der Schädeldecke nur wenig verwachsen, ziemlich gespannt; sie weist einen mittleren Blutgehalt auf. Sinus longitudinalis enthält flüssiges Blut und Cruor. Innenfläche der Dura zart und glänzend, Gyri leicht abgeplattet, besonders rechts. Die weichen: Häute zart, subarachnoideale Flüssigkeit nicht vermehrt. Gefäße der Pia ziemlich reichlich gefüllt.

Das Gehirn und zwar der hintere Abschnitt des Temporallappens ist mit der Dura bezw. dem Schädel verlötet. Nach Lösung der Verlötungen zeigt sich, daß an dieser Stelle, welche einem ursprünglich schon vorhandenen oder durch Operation entstandenen Defekt entspricht, die Dura völlig zer- 
stört, bezw. schmierig verfärbt und eiterig infiltriert ist, und daß von hier aus sich ein Abszeß in die Hirnsubstanz fortsetzt, über dessen Größe sich vor der Hand nichts Bestimmtes sagen lăßt. Jedenfalls ist dieser Herd an der Grenze durch Verwachsungen gegen die Umgebung abgeschlossen. Die Dura ist in der Umgebung dieses Herdes injiziert. Im Sinus sigmoideus links Cruor und flüssiges Blut; im Sinus' sigmoideus rechts ein größtenteils schmierig verflüssigter Thrombus, der im Beginn des Sinus transversus eine festere Konsistenz und Aussehen annimmt und sich bis zum Confluens sinuum fortsetzt. Der Thrombus jst der Wand adhărent, auch in Transversus finden sich kleine adhärente grau-rote Thromben.

Fettpolster der Brust- und Bauchdecken gut entwickelt. Muskulatur daselbst krăftig, gut fleischrot. Das fettreiche Netz aufgerollt. Därme, deren Serosa glatt und glänzend ist, sind nicht gebläht. Kein fremder Inhalt im Abdomen, Zwerchfellstand rechts 6. Rippe, links 5. Interkostalraum.

Nach Herausnahme des Brustbeins sinkt die linke $L$ unge nicht zurück, da sie durch ausgedehnte fibröse Stränge mit der Brustwand ver wachsen ist. Kein fremder Inhalt im Pleuraraum. Rechte Lunge ist mit der Brustwand verklebt bezw, yerwachsen. Im Pleuraraum ca $1000 \mathrm{ccm}$. einer blutig-serösen, trüben, mit Fibrinflocken vermischten Flüssigkeit.

Der mäßig fettreiche Herzbeutel liegt in Handtellergröße vor. Er enthält ca. $230 \mathrm{ccm}$ einer gelben, nicht fadenziehenden klaren Flüssigkeit. Seine Innenfäche spiegelt. Herz entsprechend groß, leidlich kontrahiert. Rechtes Ostium für 3 , linkes für 2 Finger durchgängig. Reichlich flüssiges Blut, Cruor und Fibrin im Herzen. Arterielle Klappen schlußfähig, Epicard zart, glänzend, mäßig fettreich, Klappenapparat des rechten Herzens intakt. Mitralis ohne Befund, auf den Segeln der Aortaklappe finden sich kleine abstreifbare Blutgerinnsel, Aorta zeigt ebenso wie die Coronararterien weiße Placques.

Herzmuskel braunrot, mäßig trüb, von kleinen sehnigen Streifen durchsetzt.

Linke Lunge: Volumen und Gewicht erhöht. Aus dem Bronchus dessen Schleimhant geschwellt ist, entleert sich reichlich schäumige Flüssigkeit. Pulmonalis frei. Pleura zeigt die Residuen der Verwachsungen. Oberlappen blut- und saftreich, an einzelnen Stellen beginnende pneumonische Infiltration, Luftgehalt nirgends aufgehoben, Unterlappen noch blutreicher, Bronchopneumonische Herdchen enthaltend. Drüsen am Hilus schieferig induziert.

Rechte Lunge: Volumen des Oberlappens erböht; Mittel- und Unterlappen reduziert. Gewicht der ganzen Lunge erhöht. Der Oberlappen entspricht dem linken, nur sind die hinteren Partien kompressionsatelektatisch. Beide zeigen ausgebreitete atelektatische Herde. Im unteren Rande des Unterlappens findet sich ein durch Metastasen entstandener über haselnußgroßer gangränöser Herd, über dem die Pleura schmierig verfărbt ist. Über diesem Herd findet sich in einer Abkapselung dieses Pleuraraumes ein übel riechendes Exsudat. Im Ựbrigen ist die Pleura mit teilweise in Organisation begriffenen dicken Fibrinbelägen bedeckt.

Hals- und Rachenorgane: Die Vena jugularis rechts sowie ihr Übergang in die Cava wird herauspräparat; in der Mitte des Halses dopnelt unterbunden. Das Gewebe daselbst infiltriert, teilweise auch schmutzig verfärbt. Im peripheren Abschnitt des Gefäloes, dessen Innenfläche schmutzigblutig verfärbt ist, findet sich reichliches schmutziges Blutgerinnsel.

Schleimhaut des Rachens, des Kehlkopfes und der Trachea ist injiziert. Die rechte Plica ary-epiglottica ist ödematös. Tonsillen etwas geschwellt, auf dem Durchschnitt blutreich, M ilz: 18:11:4/2. Kapsel gespannt, blauviolett. Nahe dem vorderen Rand in Haselnußgröße ein bläulich-grünlich verfärbter Bezirk. Beim Einschneiden zeigt sich an dieser Stelle im Parenchym ein haselnußgroßer gangränöser Zerfallsherd, der scharf gegen die Umgebung abgesetzt ist, sonst Milz breiig, weich, Schnittfläche von braunroter Farbe und undeutlicher Trabekelzeichnung.

Leber: 28:22:81/2. Kapsel gespannt, zart. Parenchym blutreich, sebr brüchig, trüb, gelblich-bläulich. Ziemlich deutliche Läppchenzeichnung. 
Gall enblase enthălt bräunlich gelbe Galle.

Magen: Etwas gebläht, enthält geringe Mengen Flüssigkeit. Schleimhaut des Duodenums gallig imbibiert. Pankreas 0 . B.

In den Venenstämmen des Abdomens postmortale Gerinnsel.

Blase normal. Linke Nebenniere: Zentral erweicht.

Linke Niere: Fettkapsel reichlich, fibröse leicht löslich. Oberfläche der Niere glatt graugelblichrötlich, stellenweise Venensternzeichnung. $11 \frac{1 / 2}{5}: 4$. Organ von leidlich guter Konsistenz, reichlichem Blutgehalt, Rinde trüb, nicht verbreitert, graurötlich, obne deutliche Zeichnung, gegen die Pyramiden gut abgesetzt. Rechte Niere wie linke. Stammteil der A orta o. B. Darmschleimhaut ödematös, stellenweise etwas injiziert.

Diagnosis post mortem: Septikopyämie. Wunde von Totalaufmeißelung rechts. Abszeß im rechten Temporallappen. Jauchige Thrombose des Sinus sigmoideus rechts. Thrombose des Sinus transversus beiderseits. - Unterbindung der rechten Vena jugularis. Infiltration der Gefälsscheide. Ödem der rechten Plica ary-epiglottica, Laryngitis, Pharyngitis. Pleuritis chronica adhaesiva beiderseits. Pleuritis serofibrinosa. Hyperämie, Ödem beider Lungen, mit bronchopneumonischen Herden. Gangränös zerfallener Infarkt im rechten Unterlappen. KompressionsAtelektase in der rechten Lunge. Braune Atrophie des Herzens. Myocarditis fibrosa chronica. Blutgerinnsel auf den Aortenklappen, beginnende Endocarditis. Splenitis acuta, gangränös zerfallener Milzinfarkt. Parenchymatöse Degeneration der Leber und der Nieren. Gastromalacia acida, Ödem der Darmschleimhaut mit stellenweiser Injektion.

Sektion des Schläfenbeines.

Steigbügel in situ. Rundes Fenster mit Membran erhalten. Labyrinth intakt. Tegmen antri fehlt in ganzer Ausdehnung. Entsprechend dem Defekt im Tegmen antri ist die Dura grünlich, schwartig, in der Mitte des Defektes etwa in Erbsengröße nekrotiseh, sonst im Bereich des extraduralen Raumes mit derben kleinen Granulationen bedeckt. Superficielle Caries des Knochens in den (angrenzenden) Randpartien des Defektes.

Sulcuswand breit bis ans obere Knie fortgenommen. Sinuswand verdickt, oben guter Thrombus. Innenwand des Sinus schmierig belegt. Im Bulbus Cruorgerinnsel, sonst frei. Die übrigen Sinus frei.

\section{Epikrise.}

Der abends ankommende P. zeigte eine große Hinfälligkeit. Die Klagen tuber den seit zwei Wochen bestehenden heftigen Kopfschmerz auf der ohrkranken Seite ließen im Zusammenhalt mit dem Ohrbefund - Cholesteatom, Retentionserscheinungen - 
einen Extraduralabszeß, der toxische Puls eine Beteiligung des Sinus vermuten. Die Temperatur von 37,7 bot kein Kriterium.

Unmittelbar vor der am am nächsten Tage vorgenommenen Totalaufmeißelung schnellt die Temperatur auf 39,4 in die Höhe und vervollständigt das Bild.

Das bei der Operation aufgedeckte Cholesteatom hatte unter Zerstörung des Tegmen antri zunächst einen Extralduralabszeß verursacht, der seinerseits nach Nekrotisierung der Dura per contiguitatem einen Rindenabszeß im Schläfenlappen induzierte. Beide Abszesse blieben bis in die letzte Zeit, als Kopfschmerzen und zerebrale Drucksymptome auftraten, latent. Der Rindenabszeß, vom Volumen einer Haselnuß, hatte eine Abszeßmembran und war gegen die Umgebung durch Verwachsungen abgesetzt, sodaß auf langes Bestehen desselben geschätzt werden kann. Der extradurale Abszeß war ebenfalls nach dem Mittelohr dureh Granulationen abgeschlossen. Im weiteren Verlauf wurde dann eine Sinusphlebitis durch das Cholesteatom verursacht. Wir machten als das Fieber andauernd hoch blieb und sichere Zeichen von Metastasenbildung (Schüttelfrost, Dämpfung) aufgetreten waren, die Jugularisunterbindung und Sinusoperation ohne Erfolg. Es mag scheinen, daß wir zu lange gewartet haben, indes ist es wahrscheinlich, daß schon eine geraume Zeit die Metastasierung bestand, wofür der Sektionsbefund spricht. Andererseits spricht die Febris continua, der Ikterus und die Euphorie mehr für Sepsis.

\section{XIII.}

Rettig Friedrich, 37 Jahre alt, Kesselschmied aus Burg bei Magdeburg. Aufgenommen am 13. Dezember 1907, gestorben am 18. Dezember 1907.

Anamnese: P. hat vor vier Jahren Milzbrand durchgemacht. Die jetzige Erkrankung begann vor acht Tagen. P. fühlte sich damals bereits am Morgen sehr matt, gegen Abend trat noch Schwindel ein und Kopfschmerz, die seitber zunahmen. Über sein Ohrleiden kann der benommene P., der nur selten antwortet, keine Angaben machen. Potatorium negiert.

Status praesens: Großer, kräftiger Mann von guter Gesichtsfarbe. Lunge und Herz ohne Besonderheiten. Urin frei von Eiweiß und Zucker. T. abends bei der Aufnahme 39,1, P. 96-100.

Patellarreflex erböht, Nackensteifigkeit nicht vorhandon.

Augenbefund: Augenhintergrund beiderseits vollkommen normal, anch keine Augenmuskelstörungen.

Umgebung des Ohres ohne Besonderheiten.

Gehörgang und Trommelfellbefund: Gehörgang beiderseits weit. Rechts eine kleinhanfkorn-große Perforation vor dem Hammergriff, nirgends randständig. Unten hinten und vorne Verkalkung. Im Gehörgang schmierigtrockenes Sekret in Spuren, leicht fötid. 
Links: Der gleiche Befund bezüglich der Perforation, hinten oben eine narbige Einziehung. Beiderseits keine Fistel tber dem proc. brevis.

Hörprûfung: Flüstersprache rechts ad concham, links $10 \mathrm{~cm}$. Rinne beiderseits negativ, fis 4 rechts auf Nagelanschlag, links auf Kuppenanschlag.

Krankbeitsverlauf: 14. Dezember, P. war die Nacht über unruhig und verwirrt, ging im Hemd aus dem Zimmer. Gegen Morgen auf Augenblicke klar. Urinieren und Defäktion spontan. T. früh: 38,8, P. 96-104

Lumbalpunktion: Ergab ca $40 \mathrm{ccm}$ klaren Liquors. Entnahme von Blutproben zur Widalschen Reaktion. Nachricht des Hygienischen in stitutes: Widal negativ.

P. nimmt gegen Abend etwas kalte Milch. T. abends: 39,2, P. 100.

15. Dezember. $P$. war die Nacht über sehr unruhig; er sprang wiederholt aus dem Bett. lief im Zimmer umher, suchte nach dem Kloset, fand dann sein Zimmer nicht mehr und war nur schwer zur Ruhe zu bringen. Schläft gegen zwet $\mathrm{Uhr}$ ein. Die T. überstieg im Laufe der Nacht nicht 38,9 . T. früh $38,7, P$. über 100 . $R, 30$, Cheyne-Stokes angedentet.

Griff in die Nackenmuskulatur, welche leicht kontrahiert ist, schmerzhaft. Sehnenhẗpfen im rechten Vorderarm. P. apathisch. Nahrungsaufnabme beschränkt sich nur auf etwas Milch.

Nachmittag wieder große Unruhe. P. will sich anziehen, kommt aber nicht in die Kleider. Beim Urinieren außer Bett läßt er den Urin zuerst in die Flasche, dann auf den Boden. Flockenlesen und Schreibebewegungen mit der rechten Hand. Der rechte Arm überhaupt unruhiger wie der linke. Klonische Zuckungen in der Oberarm- und Vorderarmmuskulatur.

T. abends: 38,9, P. $6^{1 / 2}$ Uhr $92-96$, R. 40,36 . P. $7^{1 / 2}$ Uhr 84.

Nachtrag zum 15. Dezember. R. 30. Cheyne-Stokes. Morphiuminjektion 0,01 .

Mitteilung des Hygienischen Instituts über die Untersuchung des Liquors der Lumbalpunktion vom 14. Dezember:

Ausstrich: Vereinzelte rote Blutkörperchen, keine Bakterien.

Kultur: a) Blut auf Drigalski-Conradi-Agrar und in Bouillon steril.

b) Cerebrospinalflüssigkeit in Bouillon und anf Agar steril. Auf Placenta-Serumagarplatten vereinzelte grampositive Kokken, die auch als Verunreinigung angesehen werden müssen.

16. Dezember. P. war ruhiger. Greift öfter nach dem Kopf. Hat seit gestern mittag nichts zu sich genommen. T. im Laufe der Nacht 38,9 bis 38,3 . T. früh: 38,6, P. 96, R. 30 . Déviation conjugée.

Da P. seit gestern abend $6 \mathrm{Uhr}$ nicht mehr uriniert hat, soll er katherisiert werden. Beim Einführen des Katheters erwacht P. aus seinem Sopor, wehrt sich und will selbst Wasser lassen. Er steht mit Unterstützung auf und uriniert, gibt auch kurze Antworten, verfăllt jedoch nach kurzem wieder in seinen Sopor.

Um 11 Uhr $\mathrm{zweite}$ Lumbalpunktion. FJüssi gkeit leicht getrübt mit einem Stich ins grünliche.

P. hat danach ruhig gelegen bis $1 / 25 \mathrm{Uhr}$ abends. Erneute Unruhe, will wieder aus dem Bett. 0,01 Morph. subkutan.

T. abends: 38,7, P. unregelmäßig 96, 88, 92. Ausgesprochener CheyneStokescher Atmungstyp.

Das rechte Lid geschlossen, das linke balb offen, linker Bulbus nach oben rotiert. Die linke Nasolabialfalte leicht verstrichen, der Mund etwas nach rechts verzogen. Diese Veränderung wurde schon bei der Morgenvisite konstatiert. Flockenlesen.

17. Dezember. P. bekam, da er wieder sehr unruhig wurde, 1/22 Uhr morgens noch einmal Morphium subiutan. T. im Laufe der Nach́t zwischen , 6 und 38,2 .

T. früh; 38,6, P. $128,120,116,124$.

P. kommt im Laufe des Vormittags etwas zur Besinnung, blickt die Umgebung an, bejaht, ob er trinken will, und es gelingt, ihm ca. 1/4 Liter Milch einzuflößen. Antwortet nicht weiter. T. abends: 38,8 P. 100, 89 (wegen der motorischen Unruhe nur schwer zu zăhlen). R. 40. 
Dem P. konnte im Laufe des Tages nocb mehreremale Milch eingeflößt werden. Nachmittags 2 Uhr und abends 9 Uhr den Urin unter sich gelassen.

Nachts 11 Uhr 0,01 Morphium subkutan.

18. Dezember. P. war die Nacht über |rubiger, redete unverständliches Zeug vor sich hin.

T. im Laufe der Nacht: $8^{\text {h }} 38,0,10^{\text {h }} 38,1,12^{\text {h }} 37,5,2$ h $37,2,4^{\text {h }} 36, \bar{T}$, 6h 38,6 . T. früh $8 \mathrm{~h}: 38,6$, P. 148.

R. unter Beibehaltung des Cheyne-Stokeschen Typs beschleunigter, $52,48,48$. Um 9 Uhr wieder Urin unter sich gelassen.

Fupillen von mittlerer Weite, beiderseits gleich, keine Augenmuskelstörungen. Linkes Auge weit offen, Lid wird nicht bewegt. Linke Nasolabialfalte ist jetzt deutlich verstrichen, Mundwinkel nach der rechten seite hin verzogen. Motorische Unruhe, wie seither, in beiden Armen, Flockenlesen, Muskelzuckungen, Flexionskrämpfe.

Gegen $1 / 21$ Uhr Mittag wird R. angestrengter und frequenter, P. kaum $\mathrm{zu}$ fühlen. P. erhält 0,02 Morphium subkutan.

Exitus $21 / 2$ Uhr mittags.

18. Dezember. Mitteilung des Hygienischen Instituts über den Liquor der zweiten Lumbalpunktion vom 16. Dezember:

Im Ausstrich keine 'Tuberkelbazillen, ziemlich zahlreiche Lenkosyten, keine deutlichen Bakterien. Kultur: Placentaserumagar zur Festztellung auf Meningokokken. Keine Meningokokken, dagegen zahlreiche Kokken, Sfaphylokokken (grampositiv), von denen nicht gesagt werden kann, ob es sich um Verunreinigungen handelt.

\section{Sektions protokoll.}

Sehr kräftiger Körper, starkes Schädeldach, löst sich sehr schwer, symmetrisch, wenig Diploe, diese leicht injiziert. Dura im Längsspalt sehr verdickt, Injektion mäßig, vielleicht etwas gespannt, Im Sinus longitudinalis ziemlich viel frisches Cruorgerinnsel, die Innenfläche der Dura etwas matt, rechts mehr wie links. Die Arachnoidera von vermindertem Glanz, zart. Kein Hydrops meningeus. Die kleineren wie die großen Blutgefäße sehr stark injiziert. Oberfläche der Gyri stark abgeplattet. Links einige Blutungen in der Umgebung der stark gefüllten Gefäße. Arach. noidea hinter dem Chiasma leicht getrübt, aber in den Subarachnoidealräumen keine Flüssigkeit. Die basalen Gefäße ohne nennenswerte Veränderungen. Die Fossa Sylvii der linken Seite frei, Balken etwas nach oben gedrłackt. Im linken Ventrikel klare blutig gefärbte Flüssigkeit, etwas vermehrt. Ependym soweit glatt, nur das Ependym über dem linken Streifenhügel zeigt an einigen Stellen etwas über hirsekorngroße weiße derbe Verdickungen. Ventrikelflüssigkeit rechts wie links. Ependym rechts glatt, Seitenventrikel leicht erweitert. Plexus chorioideus stark injiziert, Rautengrube nicht erweitert. Ependym glatt. Hirn von guter Ernährung, feucht, auf dem Durchschnitt zahlreiche Blutpunkte. Grane Rinde etwas blah, aber doch von rosa Schimmer. Die Masse des Gehirns wird in einigen Iuängsschnitten und zahlreichen Querschnitten weiter zerlegt. Auch die Zentralganglien etwas blaß. Brücke und verlängertes Mark 0. B. Die Sinus der Basis enthalten reichlich flüssiges Blut und Gerinnsel. Basale Dura o. B., glatt glänzend, ohne Eiterung.

Fettpolster der Brust- und Bauchdecken reichlich vorhanden. Zwerchfellstand rechts oberer Rand der vierten Rippe, links vierter Interkostalraum. Bei der Eröffnung des 'Thorax sinken die Lungen nur wenig zurück. Herzbeutel liegt in der Ausdehnung eines kleinen Handtellers vor. Beide Lungen frei. Im Herzbeutel ca. ein Teelöffel voll klaren Serums. Herz etwas veryrößert. Epikard glatt und glänzend. Rechter Vorhof stark ausgedehnt. Enthält flüssiges Blut und Cruor. Ostium rechts für drei Finger durchgängig, links für zwei Finger. Klappen scharfrandig, zart. Mitralis zeigt unbedeutende Verdickungen am Rande, sonst zart. Herzmuskel $2,2 \mathrm{~cm}$ im linken Ventrikel. Kranzarterie intakt. 
Linke Lunge: Volumen erhöht, Gewicht nicht erhöht. Pleura glatt, aus dem Bronchus entleert sich etwas schaumige Flüssigkeit. Schleimhaut des Bronchus etwas injiziert. Oberlappen hyperämisch, lufthaltig, ebenso Unterlappen.

Rechte Lunge: Unterlappen schwarzrot, sonst wie links.

Tonsillen nicht vergrößert. Kein Glottisödem. Schleimbaut des Kehlkopfes und der Trachea injiziert.

Leber- und Gallenblase etwas hyperämisch, und ödematōs, sonst o. B.

Magen wenig gefaltet, chronische hämorrhagische Gastritis.

Niere: Hyperämi sch, etwas ödematös.

Bla se: 0 . B.

Darm : o B.

Tuberkulose des linken Nebenhodens und Samenstranges.

Diagnosis post mortem: Hirndruck. Hyperämieder weichen Substanzund der weichen Häute Bronchítis. Hyperämie der Lungen und Ödem. Atelektasedes rechten Unterlappens. Hyperămie und Ödem der Leber und Nieren. Chronische Gastritis. Tuberkulose des linken Nebenhodens und Samenstranges.

Sektion der Schläfenbeine. Beiderseits Gehörknöchelchen in situ intakt. Pauke blaß, Tubengegend etwas feucht. Am tegmen tympani et antri keine Tapete oder Granulation. Antrum frei, desgl. alle Sinus. Nirgends Debiszenzen. Labyrinth intakt.

Epikrise. Wir hielten uns in diesem Falle schon bei der ersten Untersuchung berecbtigt, den otologischen Befund ron dem Bild der schweren Allgemeinerkrankung, als nicht im Kausalnexus stehend, abzusondern. Abgeseben von dem Feblen aller entzündlichen Erscheinungen wiesen die völlige Reizlosigkeit des Trommelfelles und Gehörganges, sowie die Lage und Beschaffenheit der Perforation nicht auf eine otogene Ursache. Auch war die Gegend über dem proc. brevis völlig einwandfrei. Die bestehende Herabsetzung der Hörfähigkeit ist bei einem Kesselschmied weiter nichts Auf. fallendes.

Wir nahmen bei dem Patienten, trotzdem sich Anhaltspunkte für Tuberkulose nicht ergaben zunächst beginnende tuberkulöse Meningitis an, durcb die Sektion wurde der kryptogenetische Herd manifest.

\section{XIV.}

Hermann Werner, Bergmann, 20 Jahre alt aus Kochstedt. Aufgenommen am 3. 12. 07, gestorben am 24. 12. 07.

Anamnese: Patient soll im 6. oder 7. Jahre Diphtherie überstanden haben, von sonstigen Krankeiten ist nichts beliannt. Im Anschluß an jene Krankbeit ist ein Ohrenleiden nicht beobacbtet. Erst einige Jahre später Schmerzen und Eiterausfluß rechts; Ausspülungen. Im 12. Lebensjahre muBte der Kranke wegen des Ohrenlejdens ärztliche Hilfe in Anspruch nehmen, weil er es vor Schmerzen nicht mehr ausbalten konnte. Es wurde ärztlicherseits sein Ohrpolyp damais konstatiert, der entfernt worden sein soll. Nach ein paar Jahren wurde P. wiederum ărztlicb behandelt mit Obreinträufelungen.

Ende September 1907 erkrankte P. plötzlich schwer. Bis zum 28. September batte er noch seine volle Arbeit als Bergmann im Schacht verrichten können. Am 29. Sept. fühlte er sich jedoch so matt, daß er zu Bett bleiben mulite. Am Abend traten starke reiliende Schmerzen im rechten Obr and nach der Schläfe zu auf. Dabei habe Fieber bestanden. Nach etwa achttăgigem Krankenlager traten allabendlich Schüttelfröste ein von 8-10 Minuten langer Dauer, nach dem Frostanfall meist Schweißausbruch.

Diese Schüttelfröste wiederholten sich ungefähr 8 Tage lang tăglich. 14 Tage nach Beginn der jetzigen Erkrankung trat auch Erbrechen auf, das sich mehrfach in einer Woche zeigte. Nach Auffassung des Patienten seien nur schwere Speisen daran Schuld gewesen, da er ein starker Esser gewesen 
und der Appetit stets gut geblieben sei. Schwindel bestand außer einem leichten Anfall am 30. Sept. nachmittags nicht. Husten, Seitenstechen oder Auswurf, Schmerzhaftigkeit im Genick oder der Wirbelsäule, Gelenkschmerzen traten während seiner Erkrankung, die auch vom Arzt als schwere Influenza angesehen wurde, nicht auf. Die Besinnung blieb klar. Der Arzt babe erklărt, daß eine Lungenentzündung bestanden habe. Der $P$. blieb bettlägerig krank und stand erst in der vorletzten Oktoberwoche einige Stunden täglich auf.

Am 24. November, also reichlich 3 Wochen später, erkrankte unser P. vormittags neuerdings und, wie es schien, unter anderen Symptomen.

Als man inn früh fragte, ob er nicht Kaffee trinken wollte, antwortete er kaum und bei genauerem Hinsehen fand man ihn im Bett bewuBtlos liegend. Die Augen waren verdreht, die Fäuste geballt, Schaum vor dem Mund, der Atem ging schwer und stöhnend. Von $1 / 29$ bis 9 Uhr morgens. sollen sich drei solcher "Schauer" wiederholt haben. Der gerufene Art erklärte diese Anfälle für epileptische. Nach bestimmter Versicherung des Kranken und seines Vaters hat der Patient bisher nie in seinem Leben an Krämpfen gelitten. Mittag $12 \mathrm{Uhr}$ ist $\mathbf{P}$. aufgewacht, hat seine Umgebung erkannt, einmal Wasser getrunken und dann weiter geschlafen bis $1 / 23$ Uhr. Während dieses Schlafes zuckte der Mund mebrmals nach der rechten Seite: Dann schlief der Kranke mit kleiner Unterbrechung, während welcher er auf Fragen nur mit Kopfnicken an.wortete, bis $6 \mathrm{Uhr}$ abends. Von da an lag er unruhig, schlief kurze Zeit, wälzte sich im Bett, sprach fû̉r sich hin und sang auffälligerweise Kirchenlieder. Gegen $8 \mathrm{Uhr}$ abends gab er auf die Frage nach seinem Befinden die Antwort: „Ich weiß von nichts, ich mache gar nichts." Die Nacht war in gleicher Weise unrubig. Am 25. 11. 0s war der $P$. etwas ruhiger, doch klagte er jetzt über Schwindel, als er sich im Bett aufrichtete. Dies wiederholte sich öfter. Die năchsten Tage blieb P. noch im Bett; als er dann aber versuchte, das Bett zu verlassen, war ihm dies wegen Schwindels unmöglich.

Am 1. 12. 08 befand er sich auffallend wohl, doch stellten sich dann in der Nacht außerordentliche Kopfschmerzen ein, die das Schlafen verhinderten; das Gleiche war in der năchsten Nacht der Fall. Der Arzt verordnete Pulver, worauf der Kranke schlief.

Seit jenem Tage (1. 12.) fiel dem Kranken selbst die starke Vergeß lichkeit auf. Er meinte, er hätte es beim Lesen ausprobiert, er wüßte den Inhalt des soeben Gelesenen nicht mehr. Ferner war ibm die Abnahme der Sehschärfe aufgefallen, bei längerem Lesen verschwömme die Schrift. Appetit war immer vorhanden, Stuhl angehalten.

Status praesens vom 3. 12. 08: Grober, kräftiger Mann, von bleicher Gesichtsfarbe und blassen Schleimhäuten, noch guten Ernährungs- und Kräftezustand. Reflexe normal. Innere Organe obne Krankheitsbefund. Urin eiweiß= und zuckerfrei. Sensorium vollkommen klar. Objektiv Schwindel nachweisbar, beim Blick nach oben Schwanken und stark taumelnder Gang beim Gehen mit geschlossenen Augen.

A ugenbefund: Keine Augenmuskellähmung, kein spontaner Nystagmus. Pupillenreaktion beiderseits obne Unterschied und normal. Augenhintergrund: Papilla optica rechts zeigt eine leichte Prominenz in der nasalen Hälfte (ca. 2 Dioptrien Niveaudifferenz). Grenzen hier verwaschen, temporale Papillengrenze ziemlich scbarf. Die auffälligste Veränderung sind einige streifenförmige Retinalblutungen in unmittelbarer Nähe der Papille, sich an die Venenang liedernd. Die Stauung in den Retinalvenen ist im allgemeinen nicht sehr auffällig. Arterien obne nachweisbare Verănderungen. In der Peripherie keine Blutungen usw., ebenso wenig in der Macula lutea Veränderungen.

Links: Prominenz der nasalen Papillenbälfte, Abknickung einer dicken Vene am unteren Papillenrande. (Niveaudifferenz ca. 2 Dioptrien). Grenzen verwaschen wie rechts. Am unteren Papillenrande eine kleine Hämorrhagie, die zum Teil auf der Papille liegt, aber nicht so ausgedehnt wie rechts ist. Peripherio frei. (Also Stau ngspapilleim Beginn).

T em p erat u r: 37,5 , Puls 100 kräftig, aber unregelmäßig; Respiration 24. 
Umgebung des Ohres: Beiderseits ohne wesentlichen Befund; die rechte Spitze des Processus mastoidens nicht so deutlich abzutasten, wie links und auf Druck etwas emptindlich.

Gehörgang: Im rechten Gehörgang ist ein großer obturierender Polyp, der von Eiter und Blut umspült ist und bis fast in die Concha reicht. Bei Ausspülung entleert sich stark stinkender Ausfluß, der zum Teil bröckelig und griesartig ist und im Spülwasser zu Boden sinkt.

Linker Gehörgang weit, trocken. Das Trommelfell ist sichtbar verdickt, ohne Reflex, hinten halbmondförmige Verkalkung.

Hörprüfung rechts: Flüstersprache überhaupt nicbt, Konversationssprache ad concham; links: Flüstersprache $2 \mathrm{~m}$.

Stimmgabelprüfung: rechts Fis $^{4}$ nur auf Metallanschlag, links auf stärkeren Fingeranstrich; $C_{1}$ vom Scheitel und 3 Finger breit über die Mitte hinaus nach rechts. Tiefe Stimmgabeltöne werden nur rechts noch gehört. Rinne rechts negativ, links positiv.

Therapie 3. 12. 08: Ausspülung des rechten Gehörgangs, Abschnürung des Polypen. Einfacher Verband. Abends Bad. T. 37,5, P. 100. Abends 37,2.

4. 12. 08. Nicht ruhig durchgeschlafen. Beim Aufrichten schwindelig, kein spontaner Nystagmus. Morgens $36,7, \mathrm{P}$. unregelmäßig $88-96$. Abends 36,6 .

5. 12. 08. P. hat nicht gnt geschlafen, wurde fast stündlich wach, unruhig. Die Schmerzen waren nicht sehr stark, doch bestand Klopfen in der rechten Schläfê. P. zeigt etwas ikterische Färbung. Stuhl nach Rizinusöl normal. T. 37,0, P. 76 regelmäßiger; abends 37,1 .

11 Uhr vormittags: Lumbalpun $\mathrm{k}$ ti on, dieselbe ergibt klaren Liquor; darauf Totalaufmeißelung rechts.

Operationsbefund:

Die Weichteile sind ohne Befund. In der hinteren, knöehernen Gehörgangswand ist ein großer Defekt, der mit Granulationen ansgefüllt ist. Breite Freilegung aller Mittelohrräume durch Fortnahme der ganzen knöchernen, hinteren Gehörgangswand. Hierbei quillt plötzlich von hinten her dieker, rahmiger Eiter. A-su gedehnte Karies namentlich im Antrum. Die Sinusgegend wird eingenommen von einem buchtigen, eitrigibelegten, grauschwarzen Granulationspolster. Diese Gegend wird in tuber Markstïekgröße freigelegt, ohne daß man von dem Sinus etwas zu sehen bekommt. Im horizontalen Bogengang ist eine große mit Granulationen ausgefüllte Fistel. Ambof fehlt, Hammer vorhanden, am Kopf kariös. Mehrfache Zuckungen des Fazialis bei Berührung oberhalb des Steigbïgels. Plastik, Tamponade Naht, Verband.

Verlauf: P. nach der Operation unregelmäßrg, 88-92, T. abends 6 Uhr 37,1 , R. 24-28, geschlafen bis abends 9 Uhr: 39,5. P. ist ruhig, Gesicht mit leichtem Scbweiß bedeckt. Nur einmal nach der Narkose gebrochen mittags, dann nach 9 Uhr nochmals Erbrechen. Sensorium vollkommen frei. 6. 12. 08. P. hat während der Nacht gut geschlafen. Kopf ist Jeichter Stuhl auf Klysma; 'T. 39,1, 39,5, 39,4, P. 100, 108, R. 24-26. Zunge feucht. Im Laufe des Tages Schlaf. Klage über Hitzegefühl. Antworten sind prompt und richtig.

7. 12. 08. Nacht gut geschlafen. T. 37,6 morgens, P. 92-100, R. 26. 39,4 abends, kein Frösteln.

8. 12. 08. Nachts schlecht geschlafen. T. 40,4, P. 104, R. 32, keine Beschwerden beim Atmen, spärliches Sputum, klar. Links hinten handbreite Dämpfung, Abschwächung des Atemgeräusches, Bronchialatmen (entferntes 
Klingen), deutliches Lederknarren vereinzelt. Probepunktion auf Pleuraexsudat fällt negativ aus. T. mittags $39, ; 37,3$ abends, P. 76, R. 17. P. fühlt sich seit Mittags leichter. Schmerzen in der Schläfe sind vorhanden. Appetit mittags und abends gut.

9. 12. 08. T. 36,9 , P. 70 , R. 24 morgens.

Patient hat die Nacht gut geschlafen, fühlt sich freier im Kopfe, subjektives Befinden besser. Appetit gut, Zunge rein, Stuhl auf Klysma.

10. 12. 08. P. hat gute Nacht gehabt; aber Mitternacht setzte hohe Temperatur 39,7 ein. Morgens $37,5, \stackrel{P}{P} .64, \mathrm{R} .22$. Morgens Milch erbrochen. T. mittags 36,8 . Abends 37,7 P. 68, R. 28.

$P$. schläft heute viel, ist aber nicht soporös, sondern geistig rege, aber fühlt sich matter. Sputum reichlich, grau, geballt.

11. 12. 08. Nachts guter Schlaf. 'T. 38,3 , P. $56-58-72$, R. 28. Verbandwechsel, Wunde sieht gut aus. Mittags 37,5, P. 58-62.

12. 12. 08. Gut geschlafen, mit Appetit gefrühstückt T. 83,0, P. 60, R. 28, kein Frösteln. T. 37,0, P. 60, R. 28-30. Stuhl auf Klysma.

13. 12. 08. Nacht war unruhig, öfteres Stöhnen. T. 38,5, P. 68, R, 28. Mittags keinen Appetit, schläft viel, stöhnt laut auf. Abends $39,6, \mathbf{P} .64$. R. 30. Cheyne-Stokesches Atmen, mittags zweimal Erbrechen. Schläft viel, erkennt aber beim Aufwachen seine Zimmergenossen. Klage über Kopf-
schmerzen. Verbandwechsel.

14. 12. 08. Nacht wieder sehr unruhig. T. 38,3, P. 62, R. 24-26.

Abends 37,7. Patient fühlt sich leichter im Kopfe.

16. 12. 08. Nachts ruhiger Schlaf. Aussehen besser. T. 37,8, P. 62-58 R. 22. Appetit besser. Abends T. 37,5, P. 64-62, R. 26 .

16. 12. 08. Nachts ruhiger Schlaf, am Tage weniger Schlaf. Morgens 37,6 , P. 52-55, R. 24.

P. fühlt sich heute tagsüber viel frischer, zeigte guten Appetit. Abends rührte er jedoch das Essen nicht an. Klage über starken Stirnkopfschmerz.

17. 12. 08. P. schlief die Nacht unruhiger, drehte sich viel im Bett herum und richtete sich sehr oft hoch. T. 37,4, P. 60, R. 22. Tagsüber viel Schlaf. Nach dem Frühstück Erbrechen. Mittags und abends nichts gegessen. Kein Durst, Zunge gut. Stuhl auf Klysma. T. 37,5, P. 54, R. 20.

18. 12. 08. Nachts ruhiger Schlaf. Früh Klage über starke Stirnkopfschmerzen, so ,daB er mit den Kopf gegen die Wandrennen möchte“. T. 37,3, P. $50-52$, R. 22.

Früh aß P. nichts, das Mittagbrot verzehrte er vollständig mit Appetit, aber es erfolgte sofortiges Erbrechen. Dann nicht wieder Erbrechen anf Getränke.

T. 37,6, P. $46-44$, R. 24-22. erbrochen.

13. 12. 08. P. schlief die ganze Nacht. Der Morgenkaffee wurde sofort

T. 36,8, P. 44, R. 24. Sensorium vollkommen frei, Klage über sehr starke Stirnkopfschmerzen. P. 40.

Lumbalpunktion: Klarer Liquor unter stărkerem Drack stebend.

Mittags 1 Uhr Operation: Trepanation auf das Kleinhirn und Punktion desselben, es wird kein $A b s z e B$ gefunden. Wunde primärgeschlossen. Darauf sofort die Trepanation des rechten Schläfenlappens. Beim Einstechenmitdem Skalpel entleertsich reichlich ein EBlöftel dünnflüsiger, fötider Eiter. Drains, Verband.

Puls unmittelbar nach der Operation: 66. P. liegt bis 5 Uhr nachmittags ruhig und schlummert, erwacht alsdann und klagt über unerträgliche Schmerzen in der Stirn.

Abends T. 36,8, P. 52-56.

Im I.aufe des Tages Klage über Stirnkopfschmerzen: „es sei nicht mehr auszuhalten". Eisblase, abends Klysma von Chloralhydrat mit
Codein.

20. 12. 07. Der P. hat ziemlich ruhig geschlafen. T. 37,5, P. 50-52, R. 22. 
Verbandwechsel, bei Entfernung des Drains aus der Abszeßhöhle entleert sich nicht von neuem Eiter. Klage über die gleichen K op fsch merzen besteht fort. Sensorium klar.

T. 38, P. 54, R. 28 . Abends Klysma wie tags zuvor.

21. 12. 09. Schlaf gut. Kopfschmerzen bestehen in gleicher Stärke fort. Morgens T. 37, P. 52, R. 20-24. Abends T. 37,3 P. 54, R. 20-22.

22. 12. 08. Nacht wie vorher. T. 37,5, P. 56, R. 18.

Verbandwechsel, wallnußgroßes Stück prolabierter Gehirnmasse bröckelt ab. Abends 37,6 .

23. 12.07. T. 38 ; nach dem Verbandwechsel T. 39,4, P. 98-100 R. 38

Durch den Verband sickert heute Liquor cerebrospinalis, so daß der Verband mehrere Male gewechselt werden muß. P. ist hente hinfälliger, antwortet nicht mehr; zuckende Bewegungen in der oberen und unteren Extremität. T. 38,7, P. $112-116$. R. 36 .

24. 12. 08. Der Kranke hat die Nacht apathisch, teils in leichtem Schlummer da gelegen. T. 38,5, P. klein und flatternd 148-152, Sensorium benommen. Vormittags $11 \mathrm{Uhr}$ Exitus.

Sektionsprotokoll. Schlanker Körper. Starre, Leichenflecke in den abhängigen Partien. Schädel symmetrisch von normaler Dicke. Diploe vorhanden, mäßig injiziert. Dura etwas gespannt, die feinen Gefăße etwas stärker, die größeren etwa stark gefüllt. Im Sinus longitudinalis eine ziemlich reichliche Menge flüssigen, dunkeln Cruors. Innenflache der Dura trocken, ebenso die Oberfläche des Gehirns. Gyri auferordentlich stark abgeplattet und in den Sulcis allenthalben etwas Eiter. Große Gefäße besonders links stärker injiziert, die feineren weniger. Bei Herausnahme des Gehirns stößt man an der Basis auf eine große Menge dünnflüssigen Eiter des Subduralraumes. In den Subarachnoidealräumen des Chiasma, an der Unterfläche des Kleinhirn und in dem verlängerten Mark eine reichliche Menge grünen Eiters. In dem Mittellappen, entsprechend einer fingerdicken Trepanationöffnung über dem rechten Uhr, findet sich ein entsprechend großer Defekt, ausgefüllt mit dunkelroter, weicher Gehirnmasse. In der ganzen Umgebung fehlt jegliche Eiterung. Bei Herausnahme des Gehirns stößt man auf einige Verwachsungen zwischen Kleinhirn und Dura, zugleich entleert sich eine große Menge dicker Eiter aus der Seite des Hinterhauptlappens. Der Balken ist etwas nach links verschoben und nach oben vorgewölbt. Nach Eröffnung des Seitenventrikels, der stark erweitert ist und dessen Ependym erweicht erscheint, entleert sich eine große Menge grünlichen Eiters. Die linke Hemispbäre sebr feucht, die weiche Substanz durch ausgedehnte Kapillarhyperämie von leicht rosa Schimmer; Rinde graurot. Der recbte Seitenventrikel wie links, nur ist das Ependym in größrer Ausdehnung erweicht, ebenso die Hirnmasse. Unter dem rechten Hinterhorn befiudet sich ein etwas platter, von oben nach unten ca. $1 \frac{1}{2} \mathrm{~cm}$ von vorn nach hinten ca. $4 \mathrm{~cm}$ messender, mit dicklichem Eiter gefüllter, ziemlich stark umschriebener, von mißfarbener Hirnmasse begrenzter Herd, der nach hinten zu ca. $2 \mathrm{~cm}$ von der Spitze des Hinterhauptlappens entfernt, endigt. Nach sorgfältiger Entfernung des Eiters zeigt sich der Eiterherd scharf gegen die Umgebung abgesetzt, wie durch eine, wenn auch nicht vollkommen entwickelte, zum Teil schiefergraue Membran abgegrenzt. Nach unten und hinten, besonders nach unten grenzt an den AbszeB ein ansgedebnter Bezirk erweichter Hirnmasse. Die erweichte Partie erstreckt sich über den Ventrikel weit nach vorn bis über die Mitte der Hemisphăre hinaus und nach hinten bis in den Hinterlappen der entsprechenden Hemisphäre hinein. Die Hemisphäre rechts ist stark ödematös, weich und sehr anämisch. Auch der dritte Ventrikel ist mit Eiter gefüllt. Die Subarachnoidealräume an der Konvexität des Kleinhirns sind mit Eiter gefüllt, die Rantengrube stebt voll Eiter. Das rechte Kleinhirn ist feucht, blah, ohne entztindliche Veränderungen, auch auf dem. Durchschnitt ist die Ungebung der hämorrhagisch erweiterten Trepanationshöhle frei von jeglicher Eiterung. Die Brücke ist frei, ebenso das verlängerte Mark. Der Sinus transversus eng, im linken Sinus transversus frisches Cruor- und Fibringerinnsel. Die übrigen Sinus sind von ungewöbnlicher Enge, frei. 
Zwerchfellstand rechts im 4 . links im 5. Interkostalraum. Lungen stark zurückgesunken. Herz liegt in Ausdehnung eines Daumenballens frei. Beide Lungen frei, Pleurasäcke ebenfalls.

Im Herzbeutel etwas Serum. Her z entsprechend groß, mäßig kontrahiert, enthält geringe Menge flüssiges Blut und Cruor. Arterielle Klappen schlußfähig; das rechte Ostium bequem für 3 , das linke für 2 Finger durchgängig. Klappen intakt. Aorta elastisch. Innenfläche glatt. Linker Ventrikel $1,5 \mathrm{~cm}$ stark, Herzmuskel lebhaft rot, von guter Konsistenz.

Linke Lunge von mäßiger Größe, etwas erhöhtem Gewicht, überall nachgiebig, aus den linken Bronchus entleert sich viel Schleim. Bronchialschleimhaut blaurot injiziert. Lungenarterien frei, Luftgehalt reduziert. Ganze Lunge, besonders unten blutreich. Schnittfäche überall glatt und glänzend.

Rech te obere und nittlere Lappen in den Randpartien etwas gebläht. Lunge überall nachgiebig, Luftgehalt reduziert, aber auch in den tieferen Partien nicht aufgehoben,

Kehlk op feingang frei. Tonsillen von mittlerer Größe, Ränder der Stimmbänder scharf, Schleimhaut blaß, Schilddrü se nieht vergrößert.

$\mathrm{M}$ ilz nicht vergrößert, $12: 7: 2 \mathrm{~cm}$, glatte Oberfläche, Parenchym derb, blaßrot, Zeichnung undeutlich.

Leber $26: 18: 7 \mathrm{~cm}$. Oberfläche platt, graublau, unterbrochen durch einige blaue, grangelbe Stellen, Lāppchen undeutlich brau, Stellenweise lichtere gelbbraune Partien. Braune Galle in mäßiger Menge in der gesunden Blase.

Im Magen viel dünner, brăunlicher Inhalt. Scheimhaut stark gefältet, blaß, Größe normal.

Pankreas normal körnig.

Li nke Niere normal groß, Kapsel mäßig fettreich, fibröse löst sich leicht, Oberfläche glatt, von hell violetter Farbe, ebenso der Durchschnitt; Rinde etwas lichter, $6 \mathrm{~mm}$ breit.

Rechte Niere ebenso.

Diagnosis post mortem: Eitrige Meningitis, ausgedehnte Abszedierung der rechten Hemisphäre mit hochgradigem Pyocephalus internus aller Ventrikel, hochgradige Kompression und Anämie des Gehirns. Hyperämie der Lungen, anvollkommene Atelektase.

Sehläfenbeinsektion: Nach Entfernung der reichlichen Granulationen aus der Operationshöhle sieht man eine ca. $4 \mathrm{~mm}$ lange Fistel im horizontalen Bogengange, deren Grund mit schwärzlich-schmieriger Flüssigkeit ausgefüllt ist. Der Nervus facialis ist an der darunter liegenden Spitze des Fazialissporns etwa $2 \mathrm{~mm}$ von Knochen entblößt; die Nervensubstanz ist jedoch nicht erweicht und sieht gesund aus. In der Paukenhöhle ist eingedickte Eiterschmiere. Der Steigbügel ist in seiner natürlichen Lage; bei der versuchten Extraktion brechen die Sehenkel $a b$ und es bleibt die Platte in der Fenestra ovalis zurïck. $O b$ das ovale Fenster völlig unversehrt ist, läßt sich bei der bereits eingetretenen Erweichung nicht feststellen. Jedoch enthalten das Vestibulum, die Bogengänge und die Schnecke bereits schwärzliche, nicht mehr klare Flïssigkeit. Der obere Teil der medialen Antrumswand ist durch Karies zerstört, eine der Granulations- 
membranen überzieht den Defekt des Knochens, der dieht oberhalb des Sinus transversus in die mittlere Schäde]grube fuibrt, Die den Defekt umgebende Knochensubstanz ist erweicht, die bedeckende Dura eitrig belegt. Die Dura der hinteren Pyramidenfläche liegt dem Knochen an, ist nirgends verfärbt.

Epikrise: Die ausführliche Anamnese gibt uns einen genauen Überblick über die Entstehung dieses sohweren Ohrenleidens mit all seinen Komplikationen.

Die ersten Anfänge der Ohrerkrankung liegen bei dem 20jährigen P. 14 Jahre zurück. Im 6 . Lebensjahre ist das erste Mal ein Ohrleiden aufgetreten und zwar ohne bekannte Veranlassung. Es begann mit Ohrenschmerzen und Ohreiterung. Zwei Jahre später sollen wegen kopiöser Eiterung Ohrausspülungen gemacht sein. Im 12. Lebensjahre, als dringlichere Symptome ärtliche Hilfe notwendig machten, soll ein Ohrpolyp entfernt sein. Man darf wohl annehmen, daß die Ohreiterung, überhaupt. seit dem 6 . Lebensjahre fortdanernd bestanden hat und nur zeitweise zu reichlicherer Absonderung und zu Schmerzen geführt. hat bis endlich im 20. Lebensjahre bedrohliche Symptome einsetzten. Ungefähr bis 8 Wochen vor der Aufnalime in die Klinik hat der P. noch als Bergarbeiter gearbeitet.

Plötzlich (am 29. Sept. 07) konnte er wegen Mattigkeit, "reißender Sohmerzen im rechten Ohr und Schläfe*6. und wegen hohen Fiebers das Bett nicht verlassen. Nach achttägigem Krankenlager traten dann Sehüttelfröste, gefolgt von Schweißausbruch ein und nach wieder acht Tagen danach Erbrechen und Schwindelanfälle. Die Erkrankung ist als schwere Influenza mit Lungenentzündung angesehen worden. Nach vier Wochen besserte sich der Zustand so, daB. der P. stundenweise das Bett verlassen konnte, bis nach acht Wochen (also etwa zehn Tage vor der Aufnahme) die zweite schwere Attacke einsetzte, von der der Kranke sich nicht mehr erholen konnte. Am 28. November nämlich traten plötzlich epileptiforme Krampfanfälle auf, sowie Zuckungen im rechten Fazialisgebiet (kranke Seite), starker Schwindel $P$. konnte das Bett nicht verlassen - und rechtseitige reißende Kopfsehmerzen, die den Schlaf verseheuchten. Dazu gesellten sich "Vergeßlichleit" und Abnahme der Sehschärfe ohne objektiven Befund.

Bei der nunmehr erfolgten Aufnahme in die Klinik machte: der Kranke einen schwerleidenden Eindruck. 
Der Schwindel und der starke stechende Kopfschmerz vom rechten $\mathrm{Ohr}$ nach der Schläfe traten in den Vordergrund der Symptome. Der Befund des rechten Augenhintergrundes ergab Stauungspapille und Retinalblutungen. Sie ließen in Verbindung mit den anderen Symptomen auf bereits eingetretene cerebrale Komplikation des Ohrleidens sohließen. Daß es sich etwa nur um Erseheinungen, die von der Eiterretention (obturierender Polyp) veranlaBt seien, handeln konnte, war nach den voraufgegangenen, in der Anamnese erwähnten Krankheitsanfällen nicht anzunehmen. Nach sofortiger Entfernung des Polypen besserten sich die Beschwerden nicht. Da die Lumbalpunktion klaren, unter mäßigem Drucke stehenden Liquor ergab, wurde Totalaufmeißelung vorgenommen. Bei der Operation zeigte sich kein Cholesteatom, sondern ausgiebige Zerstörung der Wände des Antrum mast. durch Karies. Der Sinus transv. war mit derbem Granulationspolster bedeckt und es wurde ein perisinuöser, größerer Abszeß entleert. Der horizontale Bogengang zeigte eine größere, mit Granulationen bedeckte Fistel. Der Kopfschmerz, der Schwindel, die früheren Schüttelfröste, das Erbrechen und die sonstigen cerebralen Erscheinungen sehienen bei diesem Operationsbefunde ihre Erklärung gefunden zu hahen. Es war zu hoffen, daß nach der reichlichen Eiteréntleerung ein Rückgang der Erscheinungen eintreten würde. Im Gegenteil! Am Abend nach der Operation schnellte die Temperatur, die vorher normal gewesen war, bis auf 39,5 in die Höhe und blieb tn den nächsten Tagen mit Ausnahme einiger Remissionen gleich hoch. Die Pulszahl folgte der Fieberkurve nieht, sondern blieb lmmer niedrig, bis sie am 6. Tage nach der Operation in deutiichem Mißverhältnis stand. Es waren bei einer Temperatur von 38,8 nur 56-58 Pulsschläge vorhanden und diese Zahl hat sich über 68 bei 38,5 Fieber nicht wieder erhoben. Diese Pulsverlangsamung sprach für Hirnabszeh, zumal da noch der unerträgliche Kopfschmerz, die Staungspapille das Erbrechen, der Schwindel, die Abnahme der Geisteskräfte, die Vergeßlichkeit und die Schläfrigkeit als wichtige Momente hinzu kamen. Dieses Bild war nur die ersten Tage undeutlich, als einigemale bei hohem Fieber jäher Abfall der 'Temperatur anftrat und auf dem rechten unteren Lungenlappen Schallverkürzung und deutliches Lederknarren sich einstellten. Da mußte man bei den Schüttelfrösten vor der Aufnahme an pyämische Metastasen denken. War doch der Sinus 
sigmoideus bei der Operation mit derben Auflagerungen gefunden worden, so daß an Sinusthrombose zu denken war. Die Lungenerscheinungen gingen aber zurück, Schüttelfröste wurden nicht mebr beobachtet und die Temperatur blieb niedriger; die Pulszahl blieb wie gesagt, subnormal.

Bei der Diagnose Hirnabszeß war nun aber die Frage, die eruster Erwägung bedurfte, die, ob es sich um Kleinbirnoder Schläfenlappenabszeß handelte.

Bei der Operation hatte man im horizontalen Bogengange eine Fistel und einen extraduralen Abszeß gefunden. Die Dura der mittleren und der hinteren Schädelgrube, rechterseits wurde in größerer Ausdehnung frei gelegt, da die Zerstörungsprozesse bis an diese heranreichten. Ein Hirnabszeß konnte demnach sich sowohl im Schläfenlappen, als im Kleinhirn entwickelt haben. Für die Annahme des Kleinhirnabszesses kam hinzu, daß ein zweiter Weg nach dem Kleinhirn noch durch die größere Bogengangsfistel gegeben war. Von hier aus konute sich zunächst die Eiter rung einen Weg in das Labyrinth gebahnt haben. Ist bier eine Eiterung vorhanden, so geht dieselbe leicht dureh den Aquaeductus vestibnli oder cochleae weiter in die Schädelhöhle. Den Weg durch den Fazialiskanal konnte man hier wohl ausschließen Denn obschon bei der Operation einigemal Spasmen im Fazialisgebiet beobachtet waren, folgte keine Fazialislähmung nach, die sicher gefolgt wäre, wenn sich die Eiterung durch den Fazialiskanal und dann durch den Meatus auditorius internus weiter fortgesetzt hätte. Ferner sprachen aber noch für Kleinhirnabszeß zwei Momente: der starke Schwindel, der den P. vier Wochen vor der Aufnahme befallen und nicht mehr verlassen hatte. Ein Aufrichten im Bett war unmöglich geworden. Dieser hohe Grad von Sehwindel konnte sehr wohl für Kleinhirnschwindel gedeutet werden.

Wenn nun auch als Symptom von Schläfenlappenabszeß oft genug Schwindel beobachtet ist - auch aus unserer Klinik sind verschiedene, derartige Fälle beschrieben - so ist doch der Schwindel bei Großhirnabszeß nicht die Regel. Hier kam nun noch dazu, daß schon bei der Aufnahme das Schwanken und der taumelnde Gang so stark war, daß man sie für Cerebellarataxie ansehen konnte. Hätte man nach der Ohroperation eine Wegleitung nach dem Kleinhirn ausschließen können, wäre man trotz Schwindels und taumelnden Ganges auf die Diagnose Schläfenlappenabszeß gekommen. Hier war aber der perisinuöse 
Abszeß, die granulierende Bogengangsfistel manifest. Vergessen darf man auch nicht, daß auf der erkrankten Seite Labyrinthtaubheit bestand.

Nun könnte man noch einwerfen, daß der Kopfschmerz nicht konstant nach dem Hinterhaupte verlegt wurde. Man muß zugeben, daß der Kopfschmerz, oft genug das einzige sichere Krankheitssymptom für Hirnabszeß ist. Auch hier war er in so außerordentlich heftiger Weise aufgetreten, daß der $P$. ihn kaum ertragen konnte, so, „daß er mit dem Kopfe hätte gegen die Wand rennen mögen". Aber der Kopfschmerz ist eben nur ein Symptom für den Hirnabszeß; einen entscheidenden Wert für die Lokalisation des Abszesses wird man ihm selten beimessen können. Unser P. hatte den Kopfschmerz als kaum erträglich, im rechten $\mathrm{Ohr}$ und $\mathrm{S}$ chläfe geschildert; der sonst für Kleinhirnabszeß typische Hinterhaupt- und Genickschmerz fehlte.

Noch ein Symptom soll nicht unerwähnt bleiben, das freilich für die Stellung der präziseren Diagnose nicht zu verwerten war; es war eine rechtsseitige Stauungspapille sehon bei der Aufnahme vorhanden. Bei otitischen Gehirnabszessen pflegt die Stauungspapille nur in $15-20 \%$ der Fälle vorzukommen.

Man kann das Fehlen von Neuritis optica oder Staungspapille bei sonst deutlichen Abszeßssymptomen wohl für die Diagnose, nicht aber das Bestehen derselben gegen die Diagnose verwerten. Meist tritt sie dann im zweiten Stadium des Abszesses auf und gewöbnlich nur bei größeren Abszessen, die eine Raumbeschränkung verursachen, wie sie bei Hirntumoren eine konstante Begleiterscheinung ist.

Die Diagnose Kleinhirnabszeß war also, obwohl versohiedene Momente dafür sprachen, falseh, es wurde bei der Operation kein Kleinhirn-, wohl aber ein größerer Schläfenlappenabszeß gefunden. Leider kam aber der operative Eingriff zu spät, es hatte sich bereits Meningitis entwickelt.

Wie bei der Autopsie sich herausstellte, war neben der operativ eröffneten Abszeßhöhle noch ein zweiter Abszeß vorhanden und beide zusammen hatten allerdings eine nicht unbedeutende intrakranielle Raumbeschränkung bedingt. Daraus erklärte sich dann auch die vorhandene Stauungspapille zur Genüge.

Von einigem Interesse ist an diesem Falle, wenn man die Anamnese und den Krankheitsverlauf in der Klinik verfolgt, 
daß man deutlich die von Macew en beschriebenen drei Stadien des Hirnabszesses zu erkennen vermag.

Das Initialstadium spielt sich daheim ab; dumpfer quälender Kopfschmerz,Erbrechen,Temperatursteigerung,Pulsbeschleunigung, Gliederschmerz und Prostration, alle diese Erscheinungen waren unter dem Bilde einer schweren Influenza aufgetreten und behandelt. Nach etwa 3 Wochen trat scheinbar eine Besserung auf, die ungefähr 4 Wochen anhielt, dann setzten aber stürmische Anzeichen als zweites Stadium ein: Krämpfe epileptiformer Art, Schwindel, Kopfschmerz, Schläfrigkeit und geistige Stumpfheit. Die Temperatur wurde normal, der Puls subnormal und mehr und mehr stellte sich verlangsamte Hirntätigkeit, Vergeßlichkeit, Abnahme der Sehschärfe ein. In dieser Zeit fand der P. Aufnahme in der Klinik. Das Endstadium setzte wenige Tage nach der Trepanation auf dem Schläfenlappen ein und verlief unter dem Bilde der Meningitis.

Auch in diesem Falle von Hirnabszeb kam, wie so oft, wenn auf ganz zweifellose Symptome gewartet wird, die Operation zu spät. Aber nach dem Autopsiebefunde zu urteilen, wäre eine Operation auch am ersten Tage der Pulsverlangsamung nicht mehr lebensrettend gewesen.

Da tibrigens die Pulsbeschleunigung nach Eröffnung des Abszesses nicht von Dauer war, sondern wiederum anf die niedrige Zahl zurück verfiel, so war es klar, daß es sich noch weiter um intrakranielle Drucksteigerung handeln müsse, daß vielleicht ein zweiter Abszeß vorhanden sei, dessen Lokalisation jedoch nicht zu bestimmen war.

\section{$X V$.}

Johanna Schröder, Gastwirtsfran, $37 \mathrm{Jahr}$, aus Palditz bei Bad Dürrenberg. Aufgenommen am 22. Febr. 08, gestorben am 24. Febr. 08.

Vom Arzte der Klinik überwiesen mit der Diagnose Otitis mit Gehirnsymptomen.

A namnestisch konnte beỉ der Aufnahme nichts Näheres eruiert werden, weil die $\mathrm{P}$. soporös war und die begleitende Krankenschwester nichts wußte. Später post mortem wurde mitgeteilt, daß die Frau 14 Tage vor der Aufnahme mit Ohrenschmerzen erkrankt sei. Sie hat deshalb ärztliche Hilfe in Anspruch genommen, doch soll sie nie bettlägerig gewesen sein. Zwei Tage vor der Aufnahme in die Klinik habe sie noch mit ihrem Manne Karten gespielt. Am nächsten und dem folgenden Tage hătten die Kopfschmerzen jedoch in solcher Weise zugenommen, daB sie sich entschlossen habe, die Klinik aufzusuchen. Ob Schwindel, Erbrechen, stärkere Ohreiterung vorhanden gewesen seien, konnte nicht angegeben werden. 
Status praesens vom 22. 2. 98: Große kräftige Frau mit stark ent. wickeltem Fettpolster, guter Muskulatur. Leib stark gespannt, kein Ascites, keine Gravidität, keine Ödeme. Das Gesicht ist gedunsen, cynanotisch. Das Sensorium vollständig benommen, Nackensteifigkeit, Druckempfindlichkeit im Genick. Keine Parese der Extremitäten, allgemeine Hauthyperästhesie, Reflexe undeutlich. Die Pupillen sind ungleich und zwar ist die rechte etwas weiter als die linke; beide reagieren prompt auf Lichtreiz, Nystagmus, Déviation conjugée. Augenhintergrund normal.

Der Urin entbält grobe Mengen von Ei weiß, keinen Zucker, Brust- und Bauchorgane sonst ohne Befund.

P. voll und kräftig, regelmäßig, etwas hart, $96-100$ schläge in der Minute. Temp. bei der Aufnahme $40,1^{\circ}$.

Die $\mathrm{Omgebung}$ des Ohres ist beiderseits ohne Besonderheiten. Insbesondere besteht auf der ohrkranken, rechten Seite keine Schwellung oder Druckempfindlichkeit. Insertionslinie der Muschel ist deutlich.

Der linke Gehörgang ist weit, frei von Sekret, das Trommelfell ist leicht getrübt.

Der rechte Gehörgang ist weit, das rechte Trommelfell in der vorderen Hălfte ist blaß. Die Cutis etwas aufgelockert. Vorn unten im Winkel des Trommelfells und Gehörgangs steht etwas gelblich-weißes, geruchloses Sekret. Weder Perforation noch ein pulsierender Reflex sichtbar, ebenso wenig ein Nachquellen des Sekretes nach dem Abtupfen. Der Pr. brevis sowie der Hammergriff deutlich sichtbar mit stark injizierten Gefäßen. Die hintere Partie des Trommelfel]s diffus gerötet; die Rötung setzt sich auf die hintere obere Gehörgangswand fort, so daß hier die Trommelfellgehörgangsgrenze nicht zu erkennen ist. Über dem Processus brevis keine Fistel, auch keine randständige Perforation in der oberen Hälfte des Trommelfells zu finden, auch keine Vorwölbung hier.

Abends wird zunächst Parazentese gemacht; es klafft der Schnitt, es quillt aber kein Sekret nach. Eisblase, Klysma mit Chloralbydrat 2,0.

Nachts große Unruhe, fortwährendes Stöhnen.

23. 2. 08. Status idem. Unruhe, die Temper. bewegte sich zwischen $39,5-40,3^{\circ}$. Da bei der mangelnden Anamnese, dem geringen Obrbefunde, und dem starken Eiweißgehalte des Urins an die Möglichkeit eines Coma uraemicum gedacht werden konnte, wurden bei dem vollen und harten Pulse 400 Gramm Blut abgelassen.

24. 2. 08. Die Nacht war eben so schlecht als die vorige. Das Fieber blieb auf gleicher Höhe. P. ließ Urin und Kot unter sich gehen, Abends 9 Uhr trat unter den Zeichen größter Unrube und unter Schweißausbruch der Tod ein. Die Kranke hatte seit Einlieferung in die Klinik das BewuBtsein nicht wieder erlangt.

Diagnosis intra vitam: Otitis dextra. Nephritis. Coma uraemicum.

\section{Sek tionsprotokoll.}

Mittelgroße Leiche in gutem Ernährungszustand, Hautdecken und sichtbare Schleimhänte blaß, Totenstarre und -Flecke vorhanden. Brust- und Bauchdecken braunrot, trocken. Das mäBig fettreiche Netz ist kurz, herabgeschlagen. Serosa des Darmes etwas injiziert, spiegelnd, kein fremder Inbalt im Abdomen. Zwerchfell rechts 4, links 5. Interkostalraum. Nach Herausnahme des Brustbeines sinken die Lungen beiderseits nur wenig zurück, sind nicht verwachsen, kein fremder Inhalt in den Pleurahöhlen.

Herzbeutel: Innenfläche spiegelnd, enthält einige Tropfen klaren Serums, liegt handtellergroß frei. Herz entsprechend groß. Linker Ventrikel gut kontrahiert. Rechtes Ostium für 3, linkes für 2 Finger durchgängig. Arterienklappen schlußfähig. In den Herzböhlen reichlich Cruor, Fibrin und flüssiges Blut. Klappen der Mitralis an den Rändern etwas verdickt. Dicke der Wand des rechten Ventrikels $1,8-2,0 \mathrm{~cm}$, Intima der Aorta fest. 
gut elastisch. Coronararterie o. B. Herzmuskel von mäßiger Konsistenz, braun, etwas trüb, von kleinen stibbchenförmigen, weißen Flecken durchsetzt.

Linke Lunge: Volumen und Gewicht etwas erhöht, Bronchialschleimhaut etwas injiziert. Pulmonalis frei. Oberlappen leichtgebläbt. An der Spitze narbige Verdickungen in der Pleura. Diese sonst spiegelnd bis auf die unteren Partien, wo sie etwas trüb ist und zarte fibrinöse Belege aufweist nebst zahlreichen, stecknadelkopf- bis hirsekorngroßen Blutungen. Schnittfäche des Oberlappens graurot, glatt, Blut- und Saftgehalt etwas ertöht. Luftgehalt überall vorhanden, Schnittfäche des Unterlappens dunkelrot. Blut- und Saftgehalt stärber als im Oberlappen. Luftgehalt überall erbalten.

Rechte Lunge: Volumen und Gewicht, Bronchien, Pulmonalis wie links. Pleura spiegelnd bis auf die hinteren Partien des Unterlappens, wo sich frische fibrinöse Auflagerungen befinden. Daselbst auch Ekchymosen wie links. Ober- und Mittellappen wie der linke Ober- und Unterlappen. Schnittfläche etwas gekörnt von dunkelroter Farbe, Blut- und Saftgehalt sehr stark erböht. Luftgehalt reduziert, aber nicht aufgehoben.

Linke Niere: Fettkapsel ziemlich reichlich, fibröse zart, leicht löslich, Oberflăche etwas gelappt. Maße: $121 / 2 \div 4 \frac{1}{2}$. Rinde blaßgrau bis graurot , $6-7 \mathrm{~mm}$ breit, sehr trüb, etwas injiziert, deutlich gegen die Pyramiden abgesetzt. Konsistenz ziemlich gut. Nierenbecken 0 . Befund.

Rech te Niere: Maße $12: 5: 21 / 2$, Fettkapsel und fibröse wie links, Oberfläche glatt, Rinde etwas breiter als links, leicht überquellend, Farbe und Zeichnung wie links. Konsistenz weicher. Nierenbecken o. B. Nebennieren $0 . B$.

U te ras: Kleinapfelgroß, fest kontrahiert, derb, äußerer Muttermund spaltförmig, Schleimhaut injiziert ekchymosiert, geschwollen. Im Cavum ein kleinhaselnußgroßes der Wand locker anliegendes Blutgerinnsel. Adnexe $0 . B$. Im rechten Ovarium findet sich ein haselnußgroßes cystisches Corpus luteum.

Milz: Masse: $11: 7^{1 / 2}: 2^{1 / 2}$; Kapsel graublau spiegelnd, Parenchym von guter Konsistenz. Schnittfläche blaurot, von deutlicher Trabekel- und Follikelzeichnung.

Leber: $24: 23: 7^{1 / 2}$. Kapsel an der Konvexität des rechten Lappens etwas fibrös verdickt. Parenchym derb, graugelb, etwas undeutlich gezeichnet. Gallenblase 0. B.

Magen nicht vergrößert, Schleimhautfalten teils verstrichen. Im Fundus reichlich Hämorrhagien. Pankreas, Mesenterium, Darm o. B.

K op f: Schädeldach von mittlerer Dicke, symmetrisch, blaßgrau, durchscheinend. Diploë vorhanden, blaßgrau, rot.

Dura leicht gespannt, Außenfläche glatt, Gefäße derselben mittelstark gefüllt, Innenfläche spiegelnd, etwas trocken.

Weiche Häute: Namentlich an den Stirnhirnpolen und in der Umgebung der Fossae Sylvii finden sich längs der Gefäße in den Subarachnoidealräumen gelbliche Eiteransammlungen. In den übrigen Teilen sind die weichen Häute leicht getrübt, sonst ist nur wenig, leicht trübe, seröse Flüssigkeit in den Supraarachnoidealrăumen. Gyri nicht abgeplattet. Weiche Häute der Basis: In den Arachnoidealräumen findet sich ebenfalls reichlich Eiter auch besonders in der Fossa Sylvii. Ventrikel etwas dilatiert. Ependym zart. In den Ventrikeln einige Tropfen trüben, gelb. lichen Serums. Birnsubstanz von guter Konsistenz. Weiß̧e Substanz zeigt nur wenig Blutpunkte. Grane Substanz blaßgrau.

Kleinhirn: Von seiner oberen Fläche zieht in den Lobus quadrangularis eine keilförmige, an der Basis etwa $3 \mathrm{~cm}$ breite, mit ihrer Spitze bis unter das Fastigium reichende Zone, die sich im Zustand beginnender roter Erweichung befindet.

Sinus der Basis: Entbalten Cruor und flüssiges Blut. Stirnhöblen und beide Orbitae sind frei. Großhirnganglien, Medulla oblongata o. B. 
Diagnosis post mortem: Meningitis purulenta basalis et convexitatis. Anänie und leichtes Ödem des Gehirns. Encephalitis hämorrhagica purulenta cerebelli. Braune Atrophie des Herzmuskels. Hyperämie und Ödem beider Lungen. Pleuritis fibrosa recens duplex. Beginnende pneumonische Infiltration des rechten Unterlappens. Anaemie und parenehymatöse Degeneration der Rinde beider Nieren. Byperämie der Milz. Trübe Schwellung der Leber. Gastritis acuta.

Schläfenbeinsektion (25. 2. 08): Im rechten Gehörgang wenig eitriges Sekret, Trommelfell erhalten; unten hinten und vorn lappenförmiger Schnitt von der Parazentese herrührend. Im unteren, vorderen $Q u$ adranten parallel dem Hammergriff eine kleine schlitzförmige Perforation. Bei Wegnahme des Tegmen antri et tympani erscheint der Knochen morsch, man sieht das Antrum und den Atticus mit dickem Eiter und Granulationen angefüllt. Die Zellen des Proc. mastoid. sind bis in die Spitze mit Eiter angefüllt, ohne daß die Septen schon eingeschmolzen wären. Hammer und Amboß, in dicken Granulationen eingebettet, werden extrahiert; vom Steigbügel ist nichts zu finden; das Foramen ovale und rotundum stehen nach Entfernung der üppigen Granulationen offen, doch ist das Vestibulum, Sehnecke und die Bogengänge frei von Eiter, der Liquor darin hat jedoch einen trüben Schimmer. Der Fazialis erscheint in seinem Verlaufe vom horizontalem Bogengang bis zum M. acusticus int. erweicht und von Eiter umspiult, der periphere Teil ist gesund. Die ganze Spongiosa des Felsenbeines ist weich, blutigeitrig durchsetzt, ea. $1 \mathrm{~cm}$ unterhalb des Aquaeduetus vestibuli ist ein Knochenulcus, grauschmierig von der Größe eines Hanfkornes, an dieser Stelle ist auch die Dura grau-grünlich, mißfarben.

Epikrise: Obwohl uns die P. mit der richtigen Diagnose: "Otitis mit Geh irnsymptomen" zugesandt wurde, mußte doch der geringe objektive Befund im Ohr bei der Aufnahme auffallen. Links war Gehörgang und Trommelfell vollständig normal, rechts war der Gehörgang an seiner hinteren und oberen Wand leicht gerötet etwas infiltriert, aber keine Senkung vorbanden. Das rechte Trommelfell war erhalten, die vordere Hälfte blaß; vorn unten auf derselben etwas weißgelbes Sekret. Eine Perforation, oder pulsierender Lichtreflex war nicht siehtbar, ebenso wenig wurde nach dem Abtupfen ein Nachquellen von Eiter beobachtet. Der Hammer und Processus brevis gut sichtbar, die Hammergriff- 
gefäße injiziert, ebenso die hintere Trommelfellhälfte diffus gerötet, desgleichen die Gehörgangswand, so daß der Übergang vom Trommelfell in den Gehörgang nicht erkennbar war. Aus-, drücklich ist bemerkt, daß keine Fistel oder Perforation sichtbar ist.

Freilich sind zur Genüge Fälle beobachtet, in denen nach einer akuten Mittelohreiterung eine scheinbar schnelle Heilung erfolgt ist, die spontane oder artifizielle Perforation des Trommelfelles verklebt rasch und das Trommelfell hat nach wenigen Tagen ein normales Aussehen. Eine solche Heilung ist jedoch nur eine Scheinheilung und nach kurzer Zeit setzen die stürmischen Erscheinungen der Warzenfortsatzeiterung ein. Immerhin muß man doch zugeben, daß diese Erkrankungsform ziemlich selten ist. Wenn sie auftritt, handelt es sich in der Regel um Infektion mit Diplokokken. Man findet dann aber meist starke Druckempfindlichkeit auf dem Planum mastoideum oder an der Spitze. Oft ist auch dann ödematöse Schwellung vorhanden. An eine derartige Krankheitsform konnte auch hier gedacht werden. Erschwerend für die Diagnose kam hinzu, daß die Kranke in vollkommen soporösen Zustand zugeführt wurde. Anamnestische Anhaltspunkte waren so gut wie nicht vorhanden. Es sollte seit etwa 14 Tagen ein Ohrenleiden bestehen, aber nicht von solcher Bedeutung, daß die Kranke das Bett aufsuchen mußte; ja, es war erzählt worden, daß sie noch 2 Tage vor der Einlieferung mit ihrem Manne abends Karten gespielt habe. Bei der Aufnahme lag sicher ein schweres cerebrales Leiden vor; da der Ohrbefund aber keinen sicheren Anbaltspunkt. gab, suchte man nach einer anderen Ursache.

Der Urin zeigte beim Kochen einen derartig starken Ejweißniederschlag, daß kaum der zehnte Teil der Harnmenge flüssig: blieb. Die Blase war stark gefüllt, Urin mußte durch Katheterismus gewonnen werden. Sehwangerschaft bestand nicht. Man dachte zunächst auf Grund ähnlicher schon früher in unserer Klinik vorgekommener Fälle an Urämie, wenn auch hier keine Ödeme der Extremitäten oder Aseites vorhanden waren. Diese Annahme stellte sich im Verlauf und durch die Sektion als irrig heraus. Tatsächlich handelte es sich um eine schwere akute Otitis, die auf das Gehirn tubergegriffen und Meningitis veranlaßt hatte. Die Diagnose wäre wahrscheinlich durch Lumbalpunktion gestellt worden; sie ist hier aber leider unterlassen 
worden, da das Bild der Urämie die Situation bei dem erwäh nten Fehlen eines charakteristischen Ohrbefundes beherrsohte.

Auffallend bei dem Falle war die Beschaffenheit des Eit ers Die bakteriologische Untersuchung (Hygienisehes Institut) ergab Bacterium coli in Reinkultur.

Der Weg, den der Eiter genommen hatte, ist vielleicht der Verlauf des Nervus facialis gewesen, da der Nerv erweicht er. schien und von Eiter umspïlt war, allerdings konnte dabei a uffallen, daß keine Fazialislähmung beobachtet war. Indessen kann solehe sehr wohl bei dem Coma unbemerkt geblieben sein.

Der Stapes ist vermutlich bei der Beseitigung der Granuationen ans der Paukenhöhle unbemerkt mit entfernt worden. Die Zerstörung der Membran des runden Fensters bei dem akut verlaufenden Prozel ist vielleicht Folge und Zeichen der starken Virulenz der bakteriellen Infektion.

Die-Patientin ist nicht operiert worden und die Sektion hat zur Genige bewiesen, daß die Meningitis bereits so weit vorgeschritten war, daß jeder operative Eingriff doch umsonst gewesen wäre.

\section{XVI.}

Otto Koch, 7 Jahre, Schlosserskind ans Giebichenstein. Aufgenommen am 20. Februar 08. Gestorben 6. März 08.

Anamnese: Das schwächliche Kind stammt von gesunden Eltern und soll im 1. and 2. Lebensjahre Masern und Scharlach durchgemacht haben. Ob damals die Ohren erkrankt waren, können die Eltern nicht angeben.

Am 14. 2.08 erkrankte es an "Influenza", unter großer Hinfälligkeit, Fieber, Kopfschmerz und Frost. Tags darauf' wurde eine Schwellung hinter dem rechten $\mathrm{Ohr}$ bemerkt, ohne daß zuvor Ohrenschmerzen oder Ohreiterung bestanden hatte. In der nächstfolgenden Nacht profise Ohr-Eiterung, Anfangs von gelber, dann von braunroter Farbe. Tägliches Erbrechen und starke Frostscbauer, zuweilen eineinhalb Stunden lang.

Status praesens vom 21. 2. 1908. Anämisches Kind in schlechtem Ernäbrungs- und Kräftezustand. Sensorium frei, ängstliche Gesichtszüge. Lippen mit trockenen Borken belegt, Zunge mit fuligininösem Belag, Foetor ex ore. Keine Lāhmungserscheinungen, Reflexe normal. Leib eingefa en. Urin frei von Eiweiß und Zucker.

A u g en b e fund: Pupillen mittelweit, gleich, reagieren prompt auf Lichtreiz. Keine Augenmuskelstörungen. Die Papilla optica links erscheint durch Mitbeteiligung des peripapillären Gewebes etwas vergrößert, die nasale Grenze ist vollkommen. verwaschen. Die Prominenz der masalen Hälfte entspricht einer Höhe von ca. 2 Dioptr, die temporale liegt noch annähernd im Niveau der Netzhaut. Zentrale fovea verschwunden. Im äußeren oberen Quadranten erkennt man zwei leicht gebogene neben einander liegende Exsudatanbäufungen von weißgrauer Farbe. Die Venen sind durchweg sehr stark gefüllt, geschlängelt, knicken am Rande der Papille deutlich ab. Die Arterien von normaler Füllung, aber auch geschlängelt. Am unteren Papillenrande ein paar kleine strichförmige Blutungen entsprechend der Richtung der Müllerschen Stützfasern. Die Netzhaut in der Umgebung der Papille zeigt die gewohnte ödematöse Durchtränkung bezw. Verfärbung. Keine Plaques (ausgesprochene Staungspapille). 
Rechts: Papilla optica ist bis auf eine leichte Verwaschenheit an der nasalen Grenze vollkommen scharf begrenzt, keine nennenswerte Hyperämie im Papillenrot, zentrale Fovea gut ausgesprochen. Am auffälligsten aber ist die starke Füllung und Schlängelung der Venen, aber etwas weniger als links. Am oberen Papillenrande knickt die Vene deutlich ab. (Stau ungspapille im ersten Ânfang).

Um gebung des rechten Ohres: Starke periostitische Auftreibung auf dem Planum, kein Ödem. Dicht hinter der Insertionslinie der Concha fühlt man eine fingerkuppengroße Vertiefung im Knochen, einen Durchbruch, auf Druck dieser Stelle entleert sich aus dem Gehörgang eine dunkelbraune Jauche, wie eingedickte Pflaumenbrühe.

Starke Druckempfindlichkeit auf Planum, Spitze und Jugularisverlauf vorhanden. Die Umgebung des linken Ohres ist obne Befund.

Gehörgang und Trommelfellbefund: Der rechte Gehörgang ist schlitzförmig verengt durch Senkung der hinteren häutigen Gehörgangswand; in derselben, auch auf den knöchernen Teil übergreifend, ist ein ziemlich großer Durchbruch, der mit dicken Granulationen erfüllt ist Der Gehörgang steht voll von oben beschriebener braunroter Flüssigkeit. Das Trommelfell rechts nicht sichtbar wegen der Stenose des Gehörgangs; links ohne pathologischen Befund. stellen.

Hörprüfung: Läßt sich bei dem schwerkranken Kinde nicht an-

Nackensteifigkeit und Druckempfindlichkeit im Nacken.

Die inneren Organe sind gesund bis auf die rechte Lunge, die hinten unten eine handbreite Dämpfung, Rasseln und pleuritisches Schaben und Reiben beobachten läßt.

Bei der Aufnahme ist P. $38,5^{\circ}$, P. 112 , kräftig regelmäBig, R. 4\%, Stubl angehalten.

22.2.08. In der Nacht nach der Aufnahme ist ein deutlicher Schüttelfrost von 12 Minuten beobachtet, Temperatur stieg danach bis $40,1^{\circ}$.

Morgens Temp. $38,3^{\circ}$, P. 112 , R. $46-48$, auf der Lunge rechts hinten unten abgeschwächtes Atmen. Morgens $11 \mathrm{Uhr}$ erneuter Schüttelfrost von 15 Minuten T. $39,6^{\circ}$,

23. 2. 08. Temp. 38,3, vormittags Schüttelfrost, Temp. 40,1 ${ }^{\circ}$, abends 38,6 ; Klysma.

24. 2. 08 . $38,9^{\circ}$ vorm.

Operation: Lumbalpunktion ergab keine Flüssigkeit. Es wird zunăchst die rechte Jugularis unterbunden. Die Vene prominierte bei auseinander gehaltenen Fascienblättern als über bleistiftstarker, derber kompakter Strang, der teils dunkelmißfarhen, teils weiß, als ob Eiter durchschimmert, aussieht. Nach doppelter Unterbindung wird die Vene geschlitzt und schmierig bröckeliger Inbalt aus der derselben ausgelöffelt.

Darauf Totala fmeißelung rechts. Auf dem Planum, welches vom Periost entblöBt ist, zehnpfennigstuickgroßer Durchbruch mit Granulationen angeftillt. Ein zerfallenes Cholesteatom füllt das Antrum aus, desgleichen den Aditus, Atticus und Paukenhöhle. Das Tegmenantri ist kariös zerstört, die Dura liegt hier in Linsengröße frei, sieht aber gesund aus. Die laterale Sinuswand ist zerstört, der Sinus selbst stellt eine mit brauner Jauche angefüllte Rinne dar. Von unten her sickert aus dem Sinus schwarzes dickflüssiges Blut, so daß zunăchst das untere Sinusende tamponiert werden wuß. Nach Wegnahme der Brücke wird der kariöse Amboß, dessen langer Schenkel vollständig fehlt und dessen Körper gleichfalls ungefähr zur Hälfte abgenagt ist, sowie der Hammer, dessen Griff nur zur Hältte erhalten ist, entfernt. . Der obere Teil des Sinus wird fast bis zum Torkular freigelegt, von unten her gesehlitzt und mit dem Löffel das Gerinnsel entfernt, bis endlich eine ausgiebige Blutung erfolgt, dann mit Jodoformgaze tamponiert. Um den unteren Teil des Sinus frei zu legen, wird zunăchst die Spitze des Proc: mast. entfernt, dann der Sinus bis fast zum Bulbus freigelegt, ansgelöffelt und tamponiert. Plastik wird unterlassen, nur die hintere Gehörgangswand gespalten. Drei Nähte in den oberen Wundwinkel, Tamponade, Naht Verband. 
Nacb der Operation war P. bleich nnd fast pulslos, Ätherinjektion, Kochsalzinfusion, Sauerstoffeinatmungen.

Temperatur mittags $39,2^{\circ}$, abends 38,7 .

Nährklystier.

25. 2. 08. Die Nacht war gut, P. hat viel und ruhig geschlafen, T. 38,20 , P. 104 kräftig, regelmäßig. Viel Durst, Nährklysma, Pupillen ungleich, die rechte ist weiter als die linke. Abends T. $38.5^{\circ}$.

26. 2. 08. Nacht war sehr unrubig, schlaflos mit Phantasien. Morgens T. $39,0^{\circ}$, P. 124, Respiration 64, Hüsteln. R. hinten oben Rasseln; Perkusionsschall gedämpft unten.

27. 2. 08. T. $39,1^{\circ}$, morgens T. $39,3^{\circ}$ mittags. Verbandwechsel. Durch das Jugularisrohr wird durchgespült, dabei eine Menge Eiterflocken entleert. 3 dünne stinkende Stuhlgänge. Pat. läßt Urin unter sich.

29. 2. 08 . T. 38,5 morgens, P. 120 , T. 39,40 mittags $39,8^{\circ}$. Stuhlentleerung ins Bett, tympanistisch aufgetriebener Leib, druckempfindlich vor allem in der Ileveocäcalgegend, daselbst leichte Dämpfung. Nacht sehr unruhig, wenig Schlaf. $\mathbf{R}$. von der 3. Rippe abwärts Dämpfung, nach oben Knisterrasseln hörbar. Hüsteln, Nahrungsaufnahme noch genügend, Wein.

29. 2. 08. T. $39,7^{\circ}$, P. 134 . Verbandwechsel. Nacbt war ruhiger. Zunge rein, Appetit besser. Stuhl und Urin unter sich gelassen.

1. 3. 08 . T. $39,3^{\circ}$, P. 140 . Probepunktion ergab rechts und links trübes eitriges pleuritisches Exsudat. Wein. Nahrungsaufnahme genügend. Leichter Decubitus.

2. 3. 08. Nacht unruhig, wenig Schlaf. T. $39,2^{\circ}$, P. $120,39,6^{\circ}, 39,2$. Verbandwechsel.

3. 3. 08. T. $38,4^{\circ}$, P. $132,39,1^{\circ}, 39,4$ Verbandwechsel.

4. 3. 08. T. 38,4, P. $130,38,7^{\circ}, 39,7$. Verbandwechsel. Rippenresektion der linken zehnten Rippe. Es entleeren sich etwa 400 Gramm, stinkender mit großen Eiterflocken, vermischter Flüssigkeit. Ord. Wein.

5. 3. 08 . T. $38,8^{\circ}$, P. $134,39,4,39,6$ Dyspnoë geringe Nahrungsa ufnahme, Kräfteverfall, große Unruhe, ungleiche Pupillen, rechts weiter, wie links.

6. 3. 08. T. 39,4 , morgens P. $140,40,10$ mittags Dyspnoë hat zugenommen. Cyanose. Puls fliegend. Sensorium frei?, Angst und Unruhe. 3 Uhr Nachm. Exitus.

\section{Sektionsbefund:}

Mäßiger Ernährungszustand, Haut und sichtbare Schleimbäute blafi Bei der Lösung der linken Clavicula findet sich das Sternoclaviculargelenk mit schmierigem Eiter erfüllt, der zum Teil in die Muskulatur durchgebrochen ist. Die rechte Vena jugularis wird wie die Anonyma und der Anfangsteil der rechten Vena subclavia freigelegt. $3 \mathrm{~cm}$ oberhalb des Zusammenflusses der beiden Venen beginnt nach oben etwa $5 \mathrm{~cm}$ hinaufreichend sehr derbe Infiltration in der Umgebung der Vena jugularis. Die Vena jugularis ist hier eröff́net. Der eröffnete Teil der Vena jugularis zeigt etwas graubläuIich schmutzige Verfärbung. Oberbalb dieser Stelle ist die Vene leer, zeigt nichts Besonderes. Unterhalb davon liegt zunächst ein erbsengroßer grauweiser Thrombus, weiter abwärts frische postmortale Gerinnsel, die sich bis in den rechten Vorhof fortsetzen und mit einer geringen Menge schmutzig braunroter Blutflüssigkeit gemischt sind. Linke Pleurahöhle leer. Sie öffnet sich nach außen durch einen Defekt, der für drei Finger durchgängig ist.

Lin ke Lunge ist mit der Pleurawand leicht verklebt. In der rechten Pleurahöhle befinden sich etwa $200 \mathrm{ccm}$ einer blutig braunblau gefärbten stinkenden, trüben Flüssigkeit.

Herzbeutel: Innenfläche spiegelnd. Herz entsprechend groß. Arterienklappen schlußfähig. Rechtes Ostium für 3 linkes knapp für 2 Finger durchgängig. Aorta, Pulmonalis o. B. Herzmuskel blaß, braungelb, ziemlich weich, trüb. Li nke Lunge: Volumen und Gewicht stark erhöht, Bronchialschleimhaut leicht geschwollen, injiziert, Pulmonalis frei. Pleura im Bereich des Unterlappens von dicken fibrinösen, schmierig verfärbten $\mathrm{Be}$ - 
lägen bedeckt. Die Pleura ist hier an einzelnen Stellen durchlöchert. Löcher erbsen- bis haselnußgroß von schmierigem Eiter erfüllt, die in großer Anzahl auf dem ganzen Unterlappen zerstreut sind, frischere grauweiße bis rot gefärbte, auf der Schnittfläche prominente, gegen das äbrige Gewebe scharf abgesetzte, bis kirschkerngrobe Herde finden sich zerstreut, namentlich in Ober- und Unterlappen. Im Oberlappen findet sich an der Spitze. ein im Zentrum erweichter Infarkt, der im übrigen dem im Unterlappen beschriebenen gleicht. Außerdem findet sich noch eine taubeneigrobe, dicht unter der Pleura gelegene, von einer ziemlich glatten, etwas schunutzig graublau - gelb gefärbten Membran ausgekleidete Höhle. Das Lungengewebe des Ober- und Unterlappens lufthaltig, stark ödematös, von herabgesetztem Blutgehalt. Im Unterlappen ist das Gewebe teilweise atelektatisch.

Rechte Lunge: Volumen, Gewicht, Bronchien, Pulmonalis, Pleara. wie links. Auch die übrige Lunge zeigt im wesentlichen dieselbe Veränderung wie links. Die bronchialen Lymphdrüsen beiderseits stark geschwollen, weich, auf der Schnittfläche graugelblich verfärbt.

Milz: 12,6,3 cm, Kapsel etwas fibrinôs verdickt in Ausdehnung eines 5-Markstückes graublau. spiegelnd. Parenchym von mäßiger Konsistenz, Schnittfläche hellrot, Follikel deutlich geschwollen, Trabekelzeichnung undeutlich.

Le ber: Kapsel zart, spiegelnd, 19, 14, $7 \mathrm{~cm}$. Gallenblase o. B. Parenchym der Leber von guter Konsistenz, Schnittlläche blaß, graugelb, Läppchenzeichnung stellenweise undeutlich.

Magen: Schleimhaut blaßgraa und Falten zum Teil verstrichen. Im Fundus löst sich die Schleimhaut in Fetzen ab.

Pankreas von mäßiger Konsistenz, Schnittläche grauweiß, trüb. Mesenteriale Lymphdrüsen geschwollen, bis kirschgroß, teils weich und markig, teils verkäst.

Linke Ni e re: Fettkapsel spärlich, fibröse zart, spiegelnd, $9,3,2 \mathrm{~cm}$, Oberfläche glatt, Venensterne an einigen Stellen deutlich, an anderen ist die Oberfläche blaß und graugelb. Rinde $7--8 \mathrm{~mm}$ breit, überquellend, trüb, sehr deutlich von den Pyramiden, die dentlich rot gefärbt sind, abgesetzt. Mittlere Konsistenz. Nierenbecken o. B.

Rechte Niere wie die linke. Nebenniere beiderseits ohne Befund.

Blas e kontrahiert, leer. Scbleimhaut blaßgrau.

Darm o. B.

Kopf: Schädeldach von mäßiger Dicke, sehr blaß, durchscheinend, symmetrisch. Dura sehr blaß, leicht gespannt, Außen- und Innenflāche glatt, letztere spiegelnd. Weiche Hăute äußerst blaß, spiegelnd. In dem Subarachnoidealraum keine Flüssigkeit. Weiche Häute der Basis verhalten sich ehenso. Gefäße zartwandig. In den Ventrikeln, deren Ependym zart rot, befinden sich einige Tropfen klaren Liquors. Gehirnsubstanz von guter Konsistenz, sehr blaß, etwas feucht. Großhirnganglien klein. Medulla oblongata 0 . B. Im rechten Sinus transversus nahe dem Torkular ein $1 / 2 \mathrm{~cm}$ langer, der Wand nicht adhärenter, glatter, derber, grauroter Thrombus.

Diagnosis post mortem: Periphlebitis venae jugularis dextrae. Thrombus im rechten Sinus transfersus. Anämie und leichtes Ödem des Gehirns. Anämie und fettige Degeneration des Herzmuskels. Eitrig, jauchig, fibrinöse Pleuritis rechts und eitrige fibrinöse Pleuritis links. Metastatische Abszesse und infektiöse, teils erweichte Infarkte in beiden Lungen. Anämie und parenchymatöse Degeneration in den übrigen Organen. Entzỉndliche Hyperplasie der Milz.

Schläfenbeinsektion: Die Untersuchung des. Sinus ergab, daß der Thrombus in dex Nähe des Torkular von frisehem gesunden Aussehen war. Die ganze Sinus-Jugularisrinne war 
frei von eitrigem Inhalt. Die Operationshöble war von frischen Granulationen ausgekleidet, nur in der Tiefe der Paukenhöhle war noch etwas schwärzlich-schmieriges Sekret. Der Steigbügel war in situ, rings von Granulationen umgeben, das runde Fenster geschlossen. Im Vestibulum, in den Bogengängen und in der Schnecke war klarer Liquor. Die Dura war allenthalben intakt.

Epikrise: Wie aus dem Sektionsbericht hervorgeht, war die chronische Eiterung nicht nach den Hirnhäuten fortgeschritten. Aber die zerstörende Wirkung des Cholesteatoms hatte sich den Weg nach dem Sinus gebahnt und hatte das typische Bild einer Sinusthrombose mit Pyämie entrollt. Die teils von dicker Membran ausgekleideten metastatischen Lungenabszesse deuteten auf ein ziemlich langes Bestehen hin, ehe der Durchbruch in den Pleurasack erfolgt war. Die zahlreichen jüngeren, metastatischen Herde in den Lungen zeugten dafür, daß vielfach neue Nachsohübe aus dem zerfallenen Thrombus im reehten Sinus transv. erfolgt waren.

Schon bei der Einlieferung in die Klinik mußte für den Patienten eine ungtinstige Prognose gestellt werden, denn es bestanden damals bereits unzweifelhafte Symptome von Lungenmetastasen. Auch bei diesem Fall von typischer, otogener metastatischer Pyämie hätte bei frühzeitiger Operation dem Ausbruche derselbeu vorgebeugt werden können durch die Unterbindung der Jugularis. Zeigte doch die Jugularis unterhalb der Unterbindungsstelle keinen infizierten Thrombus, der nahe dem Torcular Herophili sitzende Thrombus sah gleichfalls gesund aus. Die Unterbindung hatte also ihrem Zweck entsprochen, nur hätte sie früher gemacht werden müssen, um noch lebensrettend wirken zu können.

\section{XVII.}

Lebrecht Backhaus, 27 Jahr alt, Bergmann aus Bemelde, Kreis Kalbe, wurde aufgenommen am 6. März 1908. Gestorben 8. März 1908.

A namnese: P. will keine Kinderkrankheiten, wohl aber als vierzebnjähriger Knabe eine schwere Lungenentzündung durchgemacht haben, dabei aber bisher nie ohrenkrank gewesen sein. Vor fünf bis sechs Wochen ist der $P$. angeblich an Influenza erkrankt. Im Verlauf derselben schmerzte 
das linke Ohr sehr stark, so daß deshalb ärztliche Hilfe in Anspruch genommen werden mußte. Es wurden zunächst nach seiner Angabe Lufteinblasungen gemacht, später das Ohr ansgespält, Eiter ausgetupft und Öleinträufelungen gemacht. Starke Ohr- und Kopfschmerzen dauerten fort, mit Schwerhörigkeit geringen Grades; aber kein Schwindel, kein Erbrechen. Der P. wurde der Klinik vom Krankenhaus "Bergmannstrost" überwiesen. Dort hatte or die Nacht zuvor sehr unruhig verbracht, T. über 39,0 gezeigt, über starken Kopfschmerz geklagt und öfteres Erbrechen gehabt.

Status praesens: Großer, breitschultriger Mann in gutem Ernăhrungs- und Kräftezustand, von sehr blasser Gesichtsfarbe. Zunge stark belegt. Keine Läbmungserscheinungen. Pupillen sind gleichweit, reagieren prompt auf Lichtreiz und Akkomodation. Keine Augenmuskellähmung, kein Nystagmus. Augenhintergrund obne pathologischen Befund. Urin enthält $2 \%$ Zucker, ist frei von Eiweiß. Sonst innere Organe gesund. Sensorium frei.

Umgebung des Ohres: Auf dem linken Planum mastoideum und in der Gegend des Emissarium mastoideum, ist leichte Schwellung vorhanden; linke Spitze des Pr. mast. läßt sich nicht so frei abtasten wie rechts; beide Stellen leicht druckempfindlich.

Gehörgang und Trommelfell: Linker Gehörgang weit, frei von Sekret. Linkes Trommelfell gerötet, hinten oben vorgewölbt. Hammerkonturen noch erkennbar. Rechts normaler Befund.

Hörprüfung: Wird bei dem angegriffenen und über starke Kopfschmerzen klagenden Patienten bei der Aufnahme zunächst unterlassen. Temp. $38,2^{\circ}-38,3^{\circ}$, P. 100 , kräftig und regelmäßig, R. 40-44; starker Durst, angehaltener Stuhl. mel 0,3 .

Therapie: Nach der Aufnahme Bad, Eisblase auf den Kopf. Kalo-

7. 3. 08. Früh $38,4^{\circ}$, Abends $39,4^{\circ}$, P. 104 kräftig, aber unregelmäßig.

Die Nacht war schlecht, unruhig, schlaflos. Klage über starke Kreuzschmerzen. Stuhlgang zweimal. In der Nacht ging $\mathbf{P}$. trotz Verbotes noch zum Kloset, putzte sich $6 \frac{1}{2}$ Uhr noch selbst die Zähne und machte die vor geschriebene Mundspülung.

Plötzlich früh $7_{1 / 2}^{1 / 2}$ Uhr setzen vermehrte Unruhe, Iaktation, Stöhnen, Flockenlesen und Bewaßtlosigkeit ein.

Sehnen- und Muskelreflexe links erloschen. Sensibilität so herabgesetzt. daß Nadelstiche nicht mehr gefühlt werden. Cornealreflexe erloschen. Déviation conjugée.

Die Lumbalpunktion ergiebt unter sehr starkem Drucke stehenden, eitrig-trüben Liquor, in welchem kulturell Pyocyaneus im Hygienischen Institut nachgewiesen wurde.

Der Katheterismus der Blase lieferte 700 Gramm trüben Urin, der Eiterkörperchen und Blasenepithel entbält bei $2 \%$ Zucker.

Abends $40,1^{\circ}$ große Unrube, Schweißausbruch, anhaltendes Stöbnen beginnendes Trachealrasseln. Morphiuminjektion.

8. 3.08. Früh 7 Uhr Exitus.

\section{Sektionsprotokoll.}

Große mānnliche Leiche, in gutem Ernährungszustande, Bauchdecken blaß, Totenstarre-Flecke vorhanden; Fettpolster der Brust- und Bauchdecken gut entwickelt, von gelblicber Farbe; Muskulatur gut entwickelt, braunrot. Das mäBig fettreiche Netz bedeckt die geblähten Darmschlingen. Serosa blaß, spiegelnd. Im Abdomen kein fremder Inhalt. $\mathrm{Z}$ werchfellstand rechts 4. links 5. Rippe. Nach Eröffnung der Brust sinken die Lungen leicht zurück. In den P.eurahöhlen kein fremder Inhalt, Lungen nicht verwachsen. Herzbeatel in Handtellergröße freiliegend. Innenfläche spiegelnd, enthält etwa $50 \mathrm{ccm}$ klares Serum.

Herz entsprechend groß. Linker Ventrikel gut kontrahiert. Arterielle Klappen schlußtähig, rechtes Ostium für 3 , linkes für 2 Finger durchgängig. Klappenapparat intakt. Aorta gut elastisch. Intima zart, Coronararterien 
o. B. Wand des linken Ventrikels $1,7-1,8 \mathrm{~cm}$ dick, Muskel von guter Konsistenz, braunrot, leicht getrübt.

Lin ke Lunge: Volumen entsprechend, Gewicht leicht orhöht, Broncbialschleimbaut leicht injiziert und geschwollen, Pleura im ganzen von bläulich schiefriger Farbe spiegelnd, Oberlappen überall nachgiebig und knisternd, Schnittflăche glatt ebenfalls stark schiefrig pigmentiert. Blut- und Saftgehalt entsprechend: Unterlappen etwas blutreicher, sonst wie der Oberlappen. wie links.

Rechte Lunge, Volumen, Gewicht, Bronchus, Pulmonalis, Pleura

Leber, weist zahlreiche zarte, strangförmige Verwachsungen sowohl an der Konvexität wie an der Unterfläche auf, Kapsel zeigt dementsprechend die Residiuen der Verwachsung. Maße: 26, 20,8. Parenchym von mäßiger Konsistenz, Schnittfläche braun, Läppchenzeichnung deutlich. An der Unterfläche des linken Leberlappens findet sich ein linsengroßes, weißliches Gebilde innerhalb einer narbigen Verdickung der Kapsel, aus dem sich beim Durcbschneiden ein hirsekonrgroßer gelblicher Pfropf pressen läßt. Gallenblase enthält nur wenig schleimige schwărzliche Galle.

Milz ebenfalls ziemlich fest, fast in ganzer Ausdehnung mit der Umgebung verwachsen. Parenchym von guter Konsistenz, blaurot. Follikel geschwollen, Trabekelzeichnung undeutlich. Blase stark gefült mit gelblichem Urin. Schleimhaut blaß.

Niere, linke: Fettkapsel ziemlich reichlich, fibröse der Oberfläche ziemlich adbärent. Oberfläche zeigt einige flache Einziehungen. Venensterne deutlich, Rinde stark injiziert, $7 \mathrm{~mm}$ breit, von dunkelroter Farbe, trüb, Konsistenz gut, Nierenbecken o. B.

Rechte Niere wie links.

Magen nicht vergrößert, enthält reichlich braunschwarze, mit:schleimflocken gemischte Flässigkeit. Schleimhaut im Fundus mit zahlreichen, kleinen Hämorrhagien durchsetzt. Im übrigen ist sie blaß, von grauer Farbe. Falten vorhanden.

Pankreas ziemlich groß. Schnittfläche gelblich rot, Konsistenz mäßig, etwas trüb, mesenteriale Lymphdrüsen nicht vergrößert. Darm nicht seziert. Hals und Rachenorgane nicht seziert.

Kopf: Schädeldach von mittlerer Dicke, symmetrisch, blaßgrau durchscheinend, Diploë vorhanden. Außenfläche der Dura glatt, ziemlich stark gespannt, Gefäße wenig gefüllt. Im Sinus longitudinalis spärlicher Cruor und flüssiges Blut. Innenfläche der Dura trocken, sonst spiegelnd. Weiche Häute ebenfalls etwas trocken. In den Supraarachnoidealräumen namentlich über der rechten Hemisphäre finden sich entlang den Gefäßen reichliche Eiteransammlungen. Gyri stark abgeflacht. Weiche Häute und Subarach. noidealräume an der Basis sind durchsetzt mit reichlichem rahmigen, grünlichen Eiter. Derselbe geht auch noch in die Sylvischen Gruben, auch im Bereich der Medulla oblongata im oberen Teile des Rückenmarks. In den Ventrikeln namentlich deu Hinterhörnern beiderseits findet sich trübe, gelbliche Flïssigkeit zum Teil mit Eiterflocken untermischt. Derselbe Inhalt im 4. Ventrikel. Ependym der Ventrikel etwas matt, sonst o. B. Plexus chorioidei eitrig infiltriert. Gehirnsubstanz von mittlerer Konsistenz, die weiße Substanz zeigt nur wenig Blutpunkte. Die graue Substanz ist von grangelblicher Farbe. Kleinhirn, Großhirnganglien, Hirnstamm zeigen im übrigen nichts Besonderes. Im linken Sinus transversus und sigmoideus findet sich ein grauroter, der Wandziemlich fest adhärenter Thrombus. Nach Entfernung der Dura findet sich im linken Sinus sigmoideus ein Loch von $3-5 \mathrm{~mm}$ Durchmesser, aus welchem sich trüber, schmutziggelber Eiter entleert. Die Entleerung aus diesem Loch läßt sich noch steigern durch Druck auf die Gegend hinter dem linken Warzenfortsatz. Beim Herausnebmen des linken Schläfenbeins findet sich ein Abszeß etwa von der Größe einer Kirsche hinter- unter dem Processus mastoideus zwischen Periost und Muskulatur.

Im Ausstrichprāparat des Eiters von der Basis lassen sich spärlich Diplokokken nachweisen, díe zwischen den Zellen gelagert sind. 
Diagnosis post mortem: Meningitis purulenta basalis, ausgehend von einer Eiterung im /linken Schläfenbein, bezugsweise von einem Abszeß hinter dem linken Warzenfortsatz mit Perforation in den Suleus sigmoideus. Pyocephalus internus. Anämie des Gehirns. Thrombose des linken Sinus transversus und sigmoideus. Leichte Anthrakosis beider Lungen. Perihepatitis und Perisplenitis fibrosa chronica adhaesiva. Hyperämie und trübe Schwellung beider Nieren.

Sehläfenbeinsektion: Zunächst sieht man im inneren Gehörgang keinen fremden Inhalt, das Trommelfell ist erhalten, der Hammergriff und Processus brevis deutlich sichtbar, keine Perforation ist zu finden. Auf dem Planum mastoideum ist das Periost leicht abziehbar, die Cortikalis grtinlich mißfarben. Nach Wegnahme der obersten Knochensehicht sieht man die Zellen des Processus mastoideus teils mit hirsekorngroßen Eiterherden, mit Granulationen angefüllt und zwar reichen diese disseminierten Eiter- und Granulationsherde unten bis in die äußersten Zellen der Spitze und oben bis weit über die Linea temporalis. Mehrere in der Spitze liegende größere Zellen sind, ohne ihr Septum vollständig zerstört zu haben, in einander übergegangen und baben die Suleuswand etwa ein em unterhalb des Emissarinm mastoideum in Bohnengröße durchbrochen und hier umspült der Eiter den Sinns; die den Durchbruch umgebende Knochenmasse ist erweicht und brïchig. An dieser Stelle ist auch die Dura mibfarben und gelockert. Im Antrum, Atticus und Paukenhöhle sind reichliche Granulationen und trüber, fadenziehender Schleimeiter. Hammerkopf und Amboß sind nur mit Mühe aus dem Grannlationsbett zu lösen. Der Steigbügel ist gleichfalls von Granulationsmassen umgeben und in seiner richtigen Lage, das runde Fenster ist geschlossen. Die Bogengänge, Vestibulum und die Schneoke enthalten klaren Liquor. Der Meatus auditorius internus ist frei von Eiter, der Nervus acusticus und facialis sind nicht erweicht. Das Tegmen antri ist papierdünn nud erweicht, Dura aber hier intakt.

Epikrise: Dieser Fall ist ein Beispiel jener heimtückischen Diplokokkeneiterungen, bei denen eine akut einsetzende Mittelohreiterung nach einigen Tagen zu einer Scheinheilung fübrt, dann aber, wie das glimmende Feuer unter der Asche, die Mikrorganismen ihr Zerstörungswerk fortsetzen bis es zu einer explosiven Erkrankung schwerster Art kommt. Gerade die 
Diplokokken haben die Tendenz, ihre verheerende Wirkung in der Richtung nach der Dura und dem Sinus fortzusetzen.

Vor 5-6 Wochen hat unter dem Bilde einer angeblichen "Influenza" die erste akute Mittelohreiterung eingesetzt. Es sind Ausspülungen des Gehörganges gemacht und der Eiter ist ausgetupft worden. Nach kurzer Zeit hat die Eiterung aufgehört, die Spontanperforation des Trommelfelles ist verklebt. Die Kopf- und Ohrensehmerzen bestanden jedoch fort. Vermutlich ist, da die Ohreiterung aufgehört hatte, das Trommelfell auch keine akuten Entzündungserscheinungen mehr zeigte, die Ursache der Schmerzen nicht in dem erkrankt gewesenen Ohre gesucht worden, bis die Schmerzen unerträglich wurden und Druckempfindlichkeit am Planum mast. und an der Spitze des Warzenfortsatzes auf die Wahrscheinlichkeit der fortbestehenden Otitis hinwiesen.

Bei der Aufnahme sehien die Prognose noch nicht so ungünstig, wenn auch bereits Zeichen einer cerebralen Komplikation vorhanden waren. Ehe durch kurze Beobachtung das Krankheitsbild geklärt werden konnte, setzten schnell die schwersten Symptome ein: Somnolenz, Erbrechen, Unruhe, Flockenlesen machten die Diagnose Meningitis manifest. Die Lumbalpunktion bestätigte die Diagnose: eitrig-trüber Liquor unter starkem Drucke entleerte sich und ergab damit die Nutzlosigkeit einer etwaigen Operation. Die Autopsie erwies zur Gentige, daß eine solehe zu spät gekommen wäre; die Meningitis war bereits weit vorgesehritten. Der Eiter hatte den Weg durch die Sulcuswand genommen, hatte auch bereits das Tegmen antri zerstört und hätte in Kürze anch von hier aus das Endocranium infiziert, wenn nieht der Eiterdurchbruch nach den Ventrikeln dies schon zuvor herbeigeführt hätte.

\section{XVIII.}

Hugo Seibicke, 3 Jahre alt, Gastwirtssohn aus Braunsdorf bei Merseburg, aufgenommen 10. 9. 07, gestorben 14.3.08.

Seit $1 \mathrm{Jahr}$ soll das rechte $\mathrm{Ohr}$ eitern und Anschwellung hinter dem Ohr bestehen. Ein Jahr früher schon wurde die Lähmung der rechten vesichtshälfte bemerkt Das durch die Lähmung herbeigeführte Augenleiden veranlaBte zuerst die Aufnabme des Kindes in die Augenklinik. Von dort wurde es später verlegt nach der Ohrenklinik, nachdem in letzterer schon am 26. August am rechten Ohr die Totalaufmeißelung vorgenommen war. Dabei ergab sich (cf. Operationsbuch S. 41) folgender Operationsbefund:

Kleiner subperiostaler Abszeß über dem Planum mast; die hintere knöcherne Gehörgangswand mit einem Teil des Planum liegt als beweglicher Sequester vor und läßt sich mit der Kornzange herausnehmen. Ein zweiter großer schwarzer Sequester liegt in der Tiefe und wird ebenfalls leicht mit der Kornzange entfernt. Dieser enthălt einen großen Teil des Labyrinths. Glătten der Knochenwănde. Die hintere häutige Gehörgangswand ist zum 
größten Teil zerstört, so daß Plastik nicht möglich ist. Verband. - Über fortbestand, sich hartnäckige Diarrhoe hinzugesellte und schließlich der Tod unter den Zeichen tuberkulöser Meningitis erfolgte, nach voraufgegangenen allgemeinen Konvulsionen.

\section{Sektionsprotokoll.}

Kindliche, männliche Leiche im Zustande höchster Macies. Hautdecken und sichtbare Schleimhäute sehr blaß. Totenflecke und -Starre vorhanden. Schädeldach fest mit der Dura verwachsen. Schädeldach dünn, nach der rechten Seite etwas mehr ausgebuchtet wie links. Pia mater stark gespannt, diffus getrübt, subarachnoideale Flüssigkeit stark vermehrt. Über dem rechten Parietallappen finden sich in der Umgebung der gröheren Gefäße zahlreiche hirsekorngroße und miliare Tuberkelknötchen. Gefäße der Basis zart. In der rechten Fossa Sylvii findet sich ein ganzer Haufen hirsekorngroßer, gelblich weißer, froschlaichăhnlicher Tuberkelknötchen. Seitenventrikel enorm stark erweitert und mit klarer, leicht blutig gefärbter, seröser Flüssigkeit gefüllt. Desgleichen der 3. und 4. Ventrikel. In den Plexus des rechten Seitenventrikel findet sich eine kleinkirschgroße, mit klarem Serum gefüllte Cyste. Hirnmasse sonst o. B. Zwerchfellstand beiderseits Unterrand der 3 . Rippe. Das fettarme Netz ist herabgeschlagen, mit seinen Zipfeln dem Peritoneum parietale adbärent. Kein fremder Inhalt im Abdomen. Serosa der Därme blaß. Nach Herausnahme des. Brustbeins sinkt die rechte Lunge gut zurück. Sie ist nirgends mit der Brustwand verwachsen, die linke ist über der Spitze durch fibröse Stränge mit der Thoraxwand verwachsen. Herzbeutel liegt in Daumenballengröße frei. Er enthält einen EBlöffel klaren Serums. Seine Innenfläche ist spiegelnd. Herz größer als die Faust der Leiche, etwas schlaff. Rechtes Ostium für gut einen, linkes für einen Finger durchgängig. In beiden Herzhälften Cruor, Fibrin und flüssiges Blut. Arterielle Klappen schluBfähig. Klappenapparat des Herzens zart, intakt. Herzm uskel etwas trüb mit helleren gelblichen Stellen durchsetzt Linke Lunge, Volumen und Gewicht entsprechend. Aus den Bronchien deren Schleimbaut stark injiziert und geschwellt ist, dringt auf Druck eitrig-schaumige Flüssigkeit. Pulmonalis frei Pleura zeigt Residuen alter Verwachsungen, ist von grauroter bis dunkelblau-violetter Farbe. Schnittfläche des Oberlappens etwas blutreich; von ihr fließen bei Druck eitrige aus dem Bronchus quellende Massen ab, auf ihr selbst sieht man entsprechend dem Bau der Bronchien angeordnet kleinere und größere bis etwa kirschgroße Hohlräume, die mit eitriger Flüssigkeit erfüllt und von glatter Wand umgeben sind und deutlich mit den Bronchien in Verbindung stehen. Unterer Lappen etwas blut- und saftreicher, sonst 0 . B. Rechte Lunge zeigt dasselbe Bild wie die linke, nur $\mathrm{da} \beta$ hier die im Oberlappen der linken beschriebenen Bronchiektatischen Cavernen fehlen. Milz: etwas größer als normal, diffus mit der Umgebung. verwachsen, von guter Konsistenz und deutlicher Zeichnung. Leber: fast mit 'der Umgebung verwachsen. Parenchym von leidlich guter Konsistenz, auf der Schnittfläche ist die Zeichnung deutlich, stellenweise von helleren, gelben Partien unterbrochen. Gallenblase: enthält etwas Galle, sonst o. B. Magen: enthält wenig Speisereste, seine Schleimhaut ist blaß, gut gefaltet. Hie und da auf der Höhe der Falten etwas injiziert. Pankreas: von mäßliger Konsistenz, trüb, blaß. Drăsen des Mesenteriums stark vergrößert und in der Mitte verkäst. Linke $\mathrm{Niere:} \mathrm{entsprechend} \mathrm{groß,}$ Fettkapsel spärlich, fibröse, zart, leicht lösbar. Organ von guter Konsistenz, trüb und blaß. Rechte Niere wie links. Darm: Schleimhaut im allgem. etwas injiziert. Im oberen Dünndarm zeigen sich einzelne quergestellte lentikuläre Gesch w üre, die von der Klappe an gehăufter auftreten, zirkulär den ganzen Darm an mebreren Stellen umgeben. Blas e: enthält viel leichtgetrübten Urin.

Diagnosis post mortem. Hydrocephalus externus et internus, Meningitis tuberculosa baseos et convexitatis cerebri 
Jahresbericht der Kgl. Universitäts-Ohrenklinik zu Halle a. S. 279

Trübe Sehwellung des Herzmụskels, Hyperämie beider Lungen, bronchiektatische Cavernen im linken Oberlappen. Perisplenitis, Perihepatitis chronica. Fettige Degeneration der Leber. Trtibe Schwellung des Pankreas und der Nieren. Tuberkulöse Geschwüre in Dünnund Dickdarm.

Sobläfenbeinsektion: Bei der äuBeren Untersuehung. findet man die Operationshöhle in ihrem änßeren Teile bereits epidermisiert, während in der Tiefe der Paukenhöhle noch schlaffe Granulationen die Labyrinthwand und den Kuppelraum bedecken. Nach Entfernung der letzteren sieht man die äußere Labyrinthwand nekrotiseh verfärbt und in toto beweglich. Der innere Teil des Sebläfenbeins ist von Dura fest überzogen, die letztere ist allenthalben intakt. Im Meat. audit. int. ist sehmieriger Eiter, Fazialis und Akustikus erseheinen erweieht. In den Bogengängen ist klarer Liquor. Der bereits erwähnte Sequester wird heraus präpariert und zeigt, daß er außer den Bogengängen die ganze Schnecke enthält.

Epikrise. Der Tod des P. war durch allgemeinen Kräfteverfall, den die Tuberkulose verursacht hatte, erfolgt. Der Hydrocephalus internus und externus hat wahrscheinlich die in den letzten Lebenstagen beobaohteten Krampfanfälle und Atemstörungen verursacht. Die ausgiebigen tuberkulösen Gesehwüre im Darm mit dadureh bedingten diarrhoischen Stühlen erklären die schnell zunehmende Entkräftung. Die Aussaat der Tuberkulose war von den verkästen Mesenterialdrüsen aus erfolgt. Die Sequestrierung des Labyrinths war ohne vitale Sehädigung vor sich gegangen; die nekrotisch abgestoßenen Teile des inneren Ohres wären bei längerer Fortdaner des Lebens zur spontanen Lösung und Abstolung gekommen.

Von diesen 18 Todesfällen waren 4 unabhängig vom Ohrleiden erfolgt und zwar 2 mal dureh Meningitis tuberculosa, $1 \mathrm{mal}$ dureh Miliartuberkulose, $1 \mathrm{mal}$ dureh Bronehopneumonie. Die restierenden 14 Todesfälle waren verursacht duroh intrakranielle Komplikationen der Otitis, nämlieh:

5 mal dureh Meningitis purulenta;

2 mal dureh Sinusphlebitis mit Meningitis purulenta;

$2 \mathrm{mal}$ durch Sínusphlebitis allein;

3 mal durch Schläfenlappenabszeß;

$2 \mathrm{mal}$ dureh Kleinhirnabszeß: davon einmal kompliziert mit Sinusphlebitis und Meningitis. 


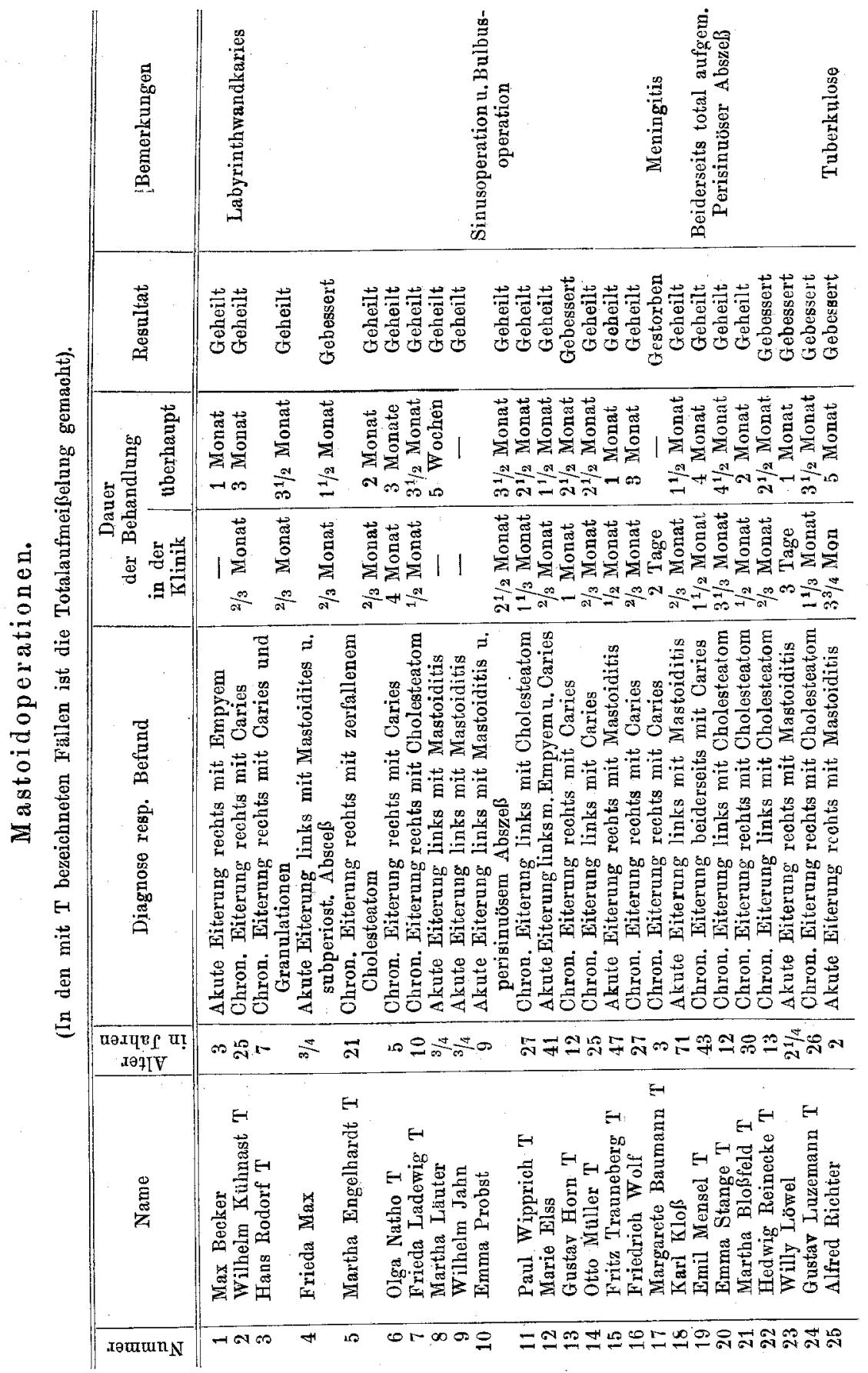


Jahresbericht der Kgl. Universitäts-Ohrenklinik zu Halle a. S. 281

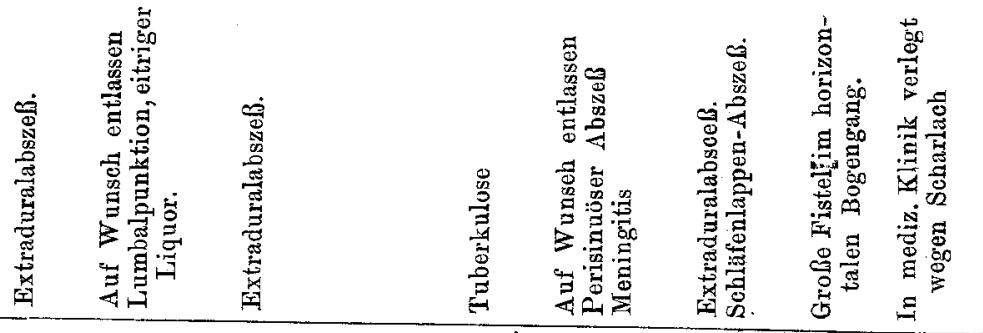

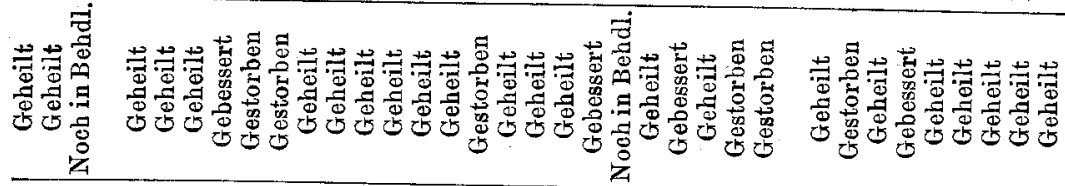

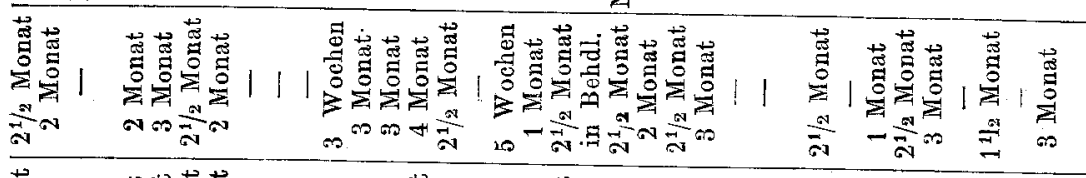

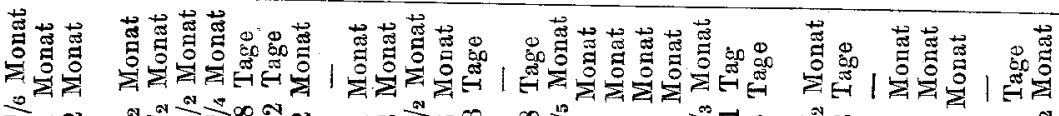

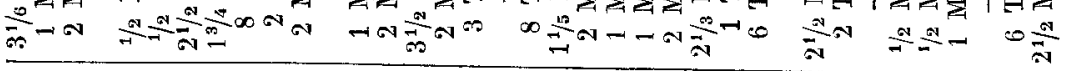

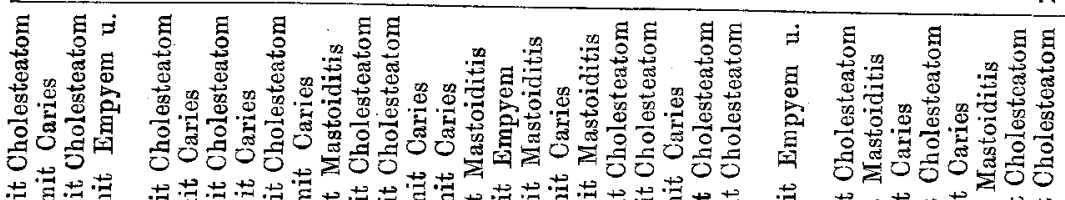

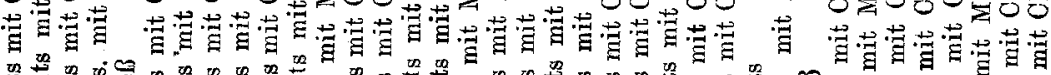

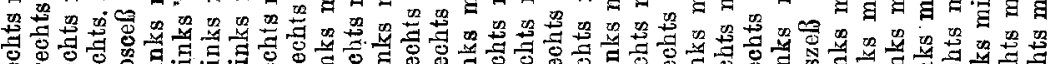

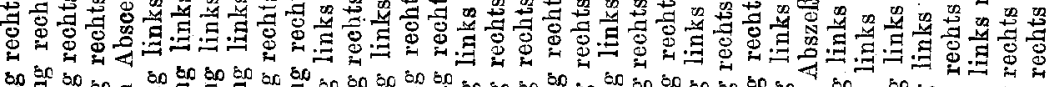

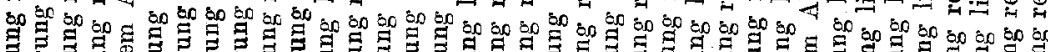

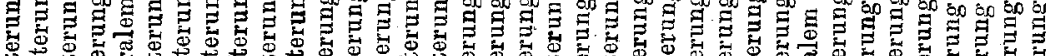

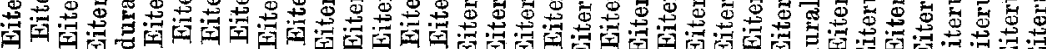

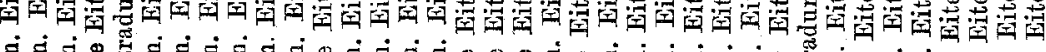

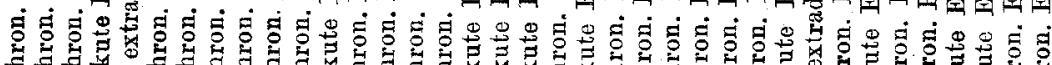

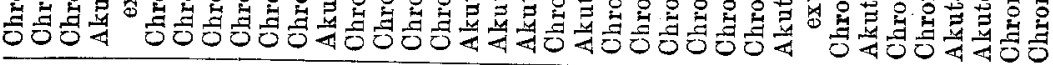

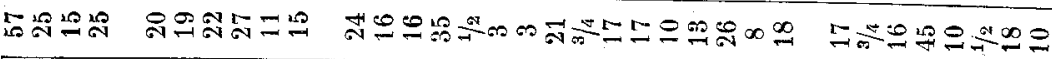

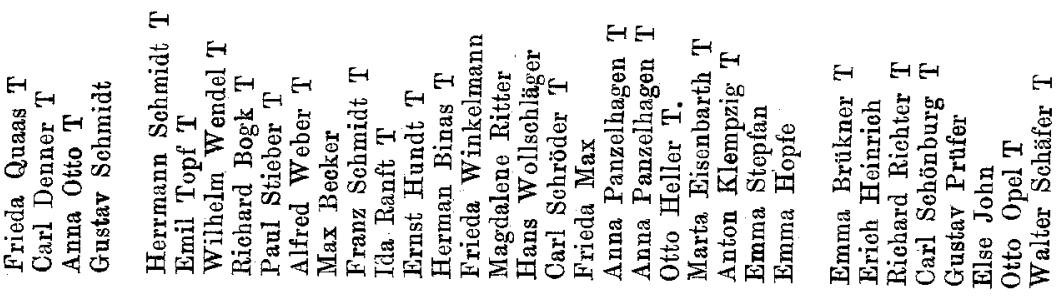

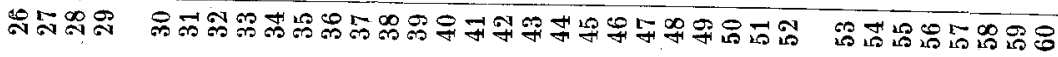




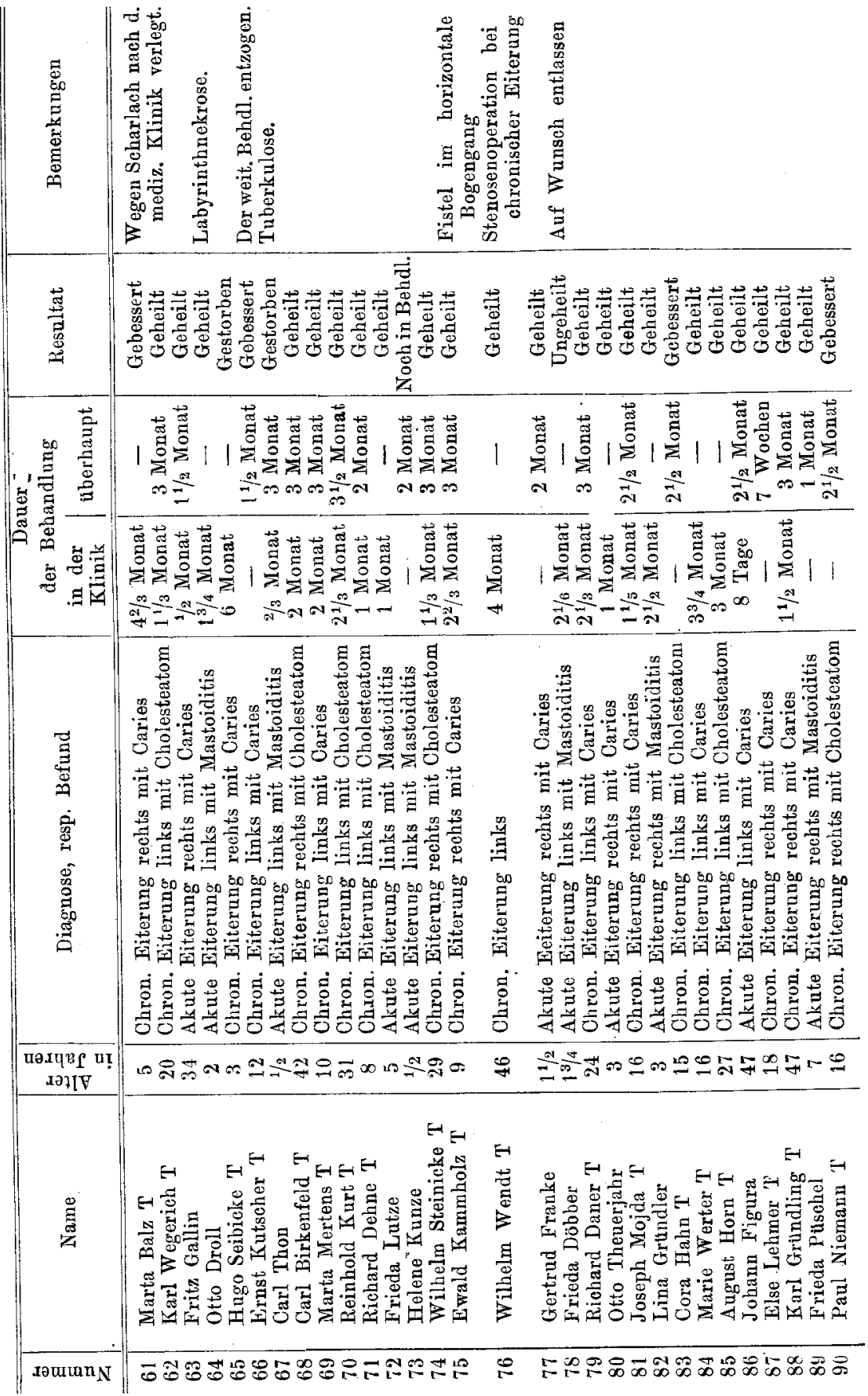


Jahreshericht der Kgl. Universitäts-Ohrenklinik zu Halle a. S. 283

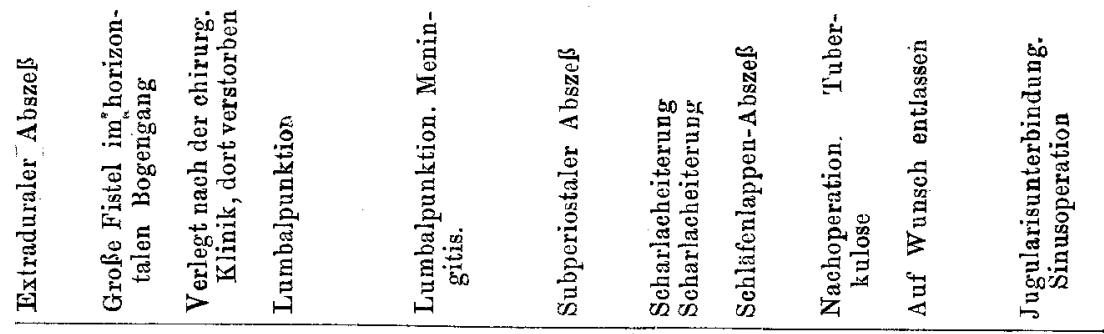

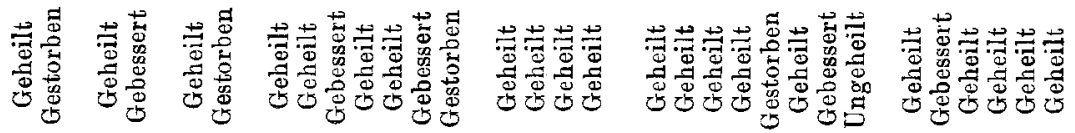

\begin{tabular}{|c|c|c|c|c|c|c|c|c|}
\hline ธี & 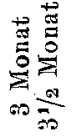 & 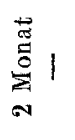 & 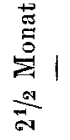 & 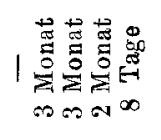 & 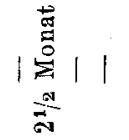 & 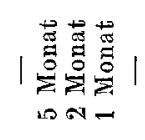 & 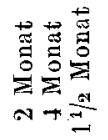 & 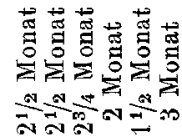 \\
\hline
\end{tabular}

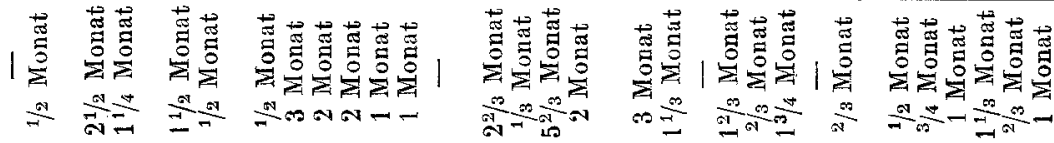

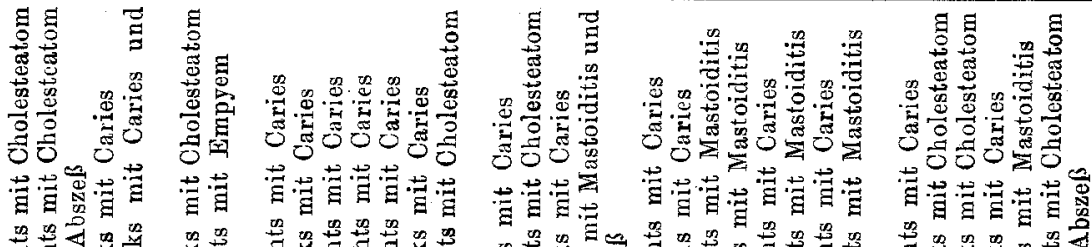

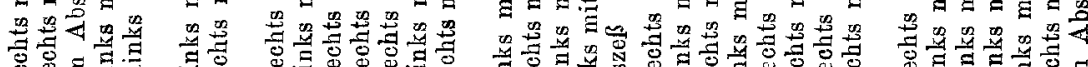

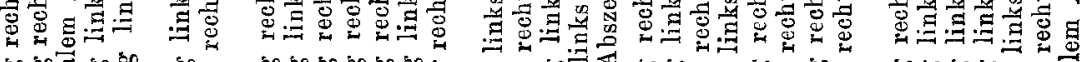

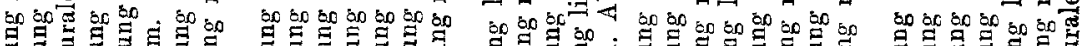

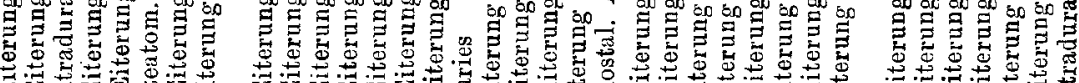

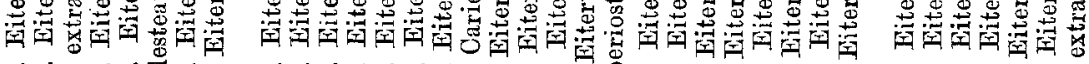

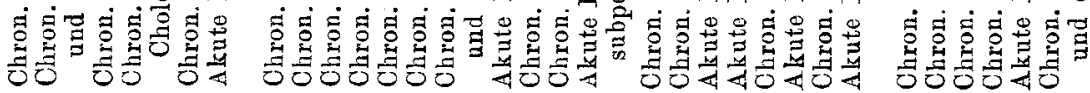

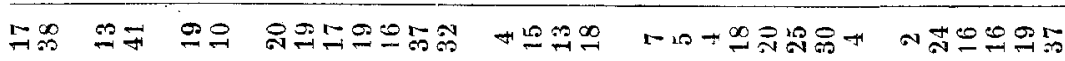

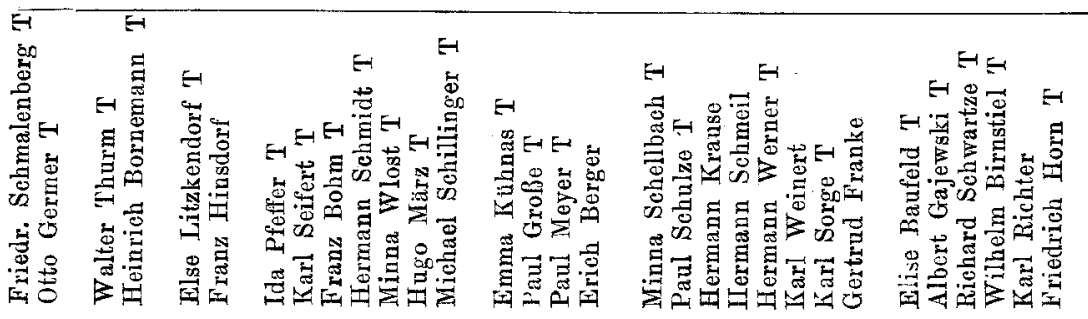

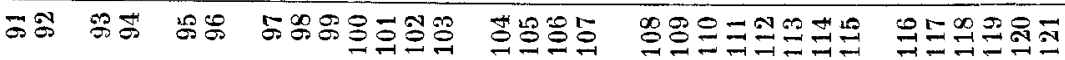




\begin{tabular}{|c|c|c|c|c|c|}
\hline 苛 & 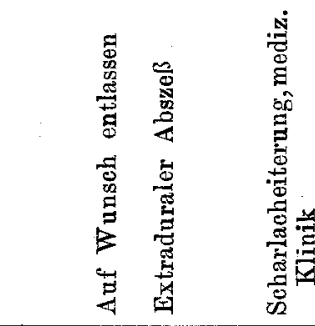 & 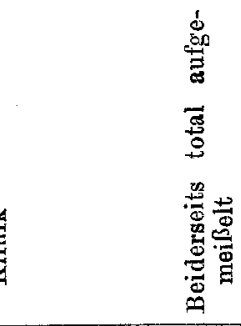 & 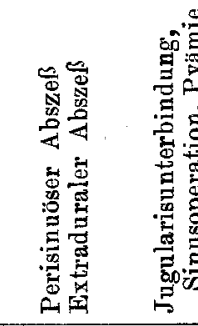 & 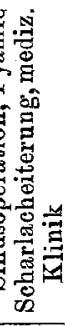 & \\
\hline 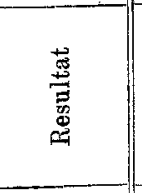 & 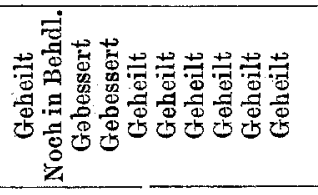 & 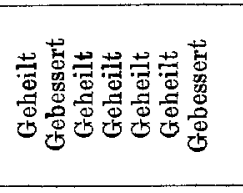 & 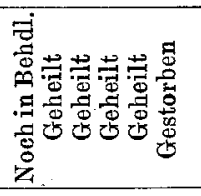 & 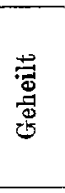 & 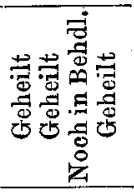 \\
\hline 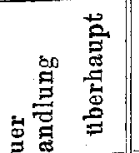 & 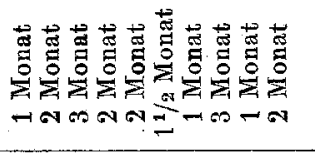 & 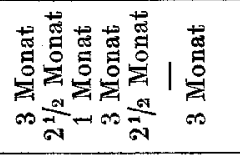 & 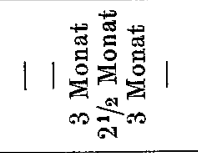 & 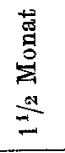 & 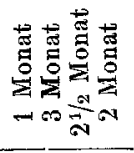 \\
\hline 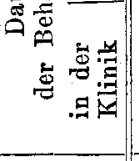 & 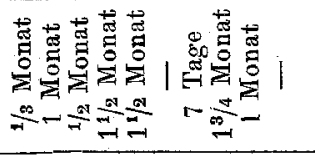 & 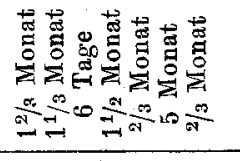 & 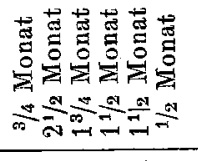 & 1 & 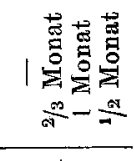 \\
\hline 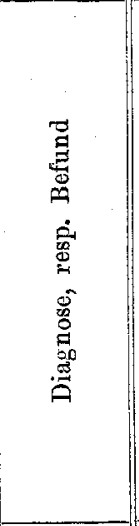 & 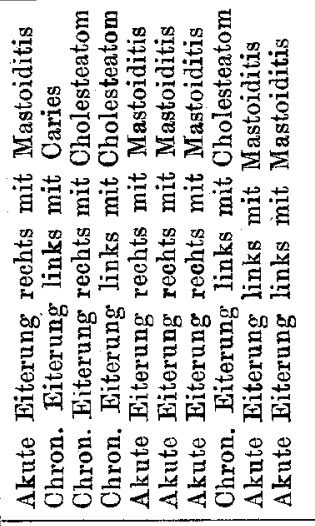 & 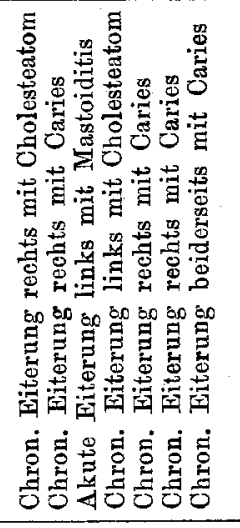 & 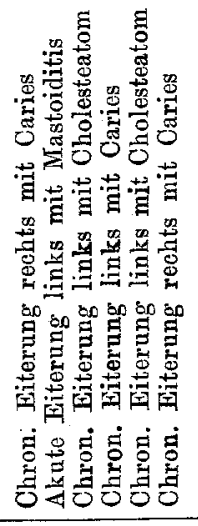 & 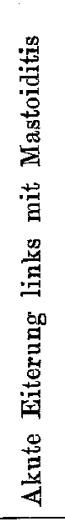 & 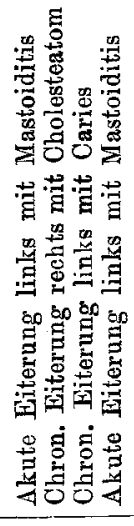 \\
\hline 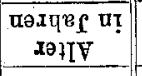 & 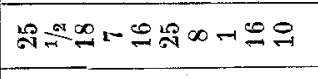 & $\varphi$ ตำ & 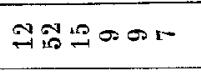 & $r$ & สีさむ゙ \\
\hline $\begin{array}{l}\stackrel{9}{g} \\
\stackrel{\mathbb{g}}{Z}\end{array}$ & 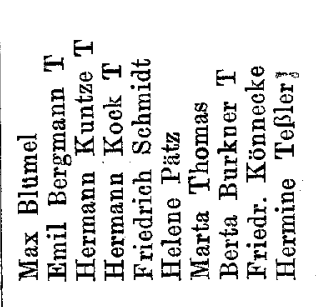 & 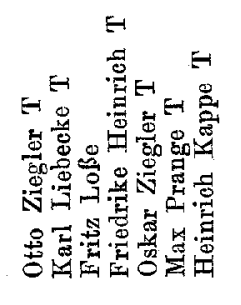 & 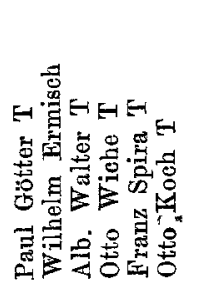 & 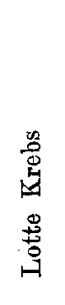 & 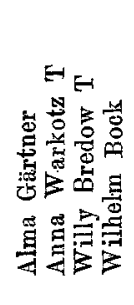 \\
\hline xau & 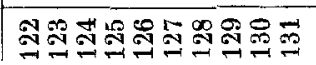 & 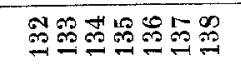 & 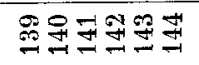 & $\stackrel{20}{=}$ & 导尔导䍜 \\
\hline
\end{tabular}


Jahresbericht der Kgl. Universităts-Ohrenklinik zu Halle a. S. 285

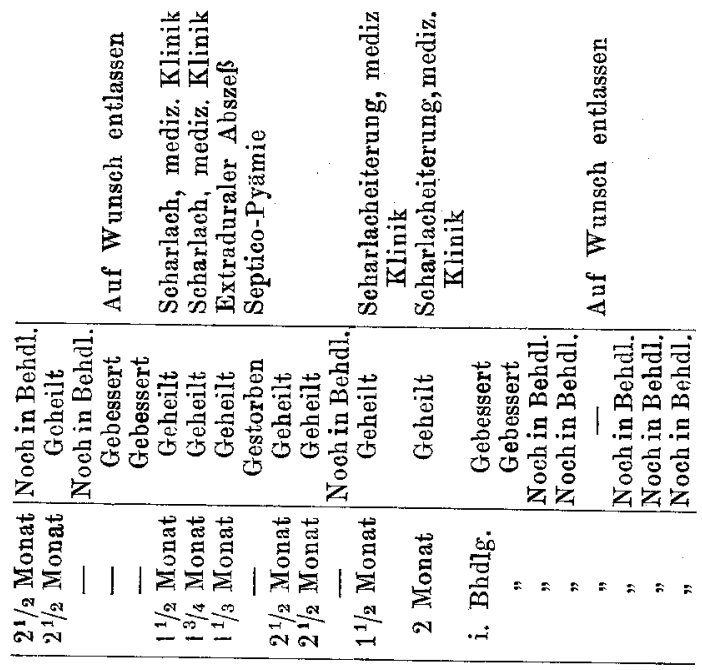

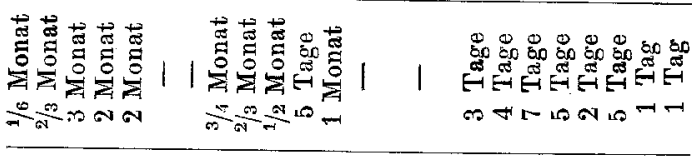

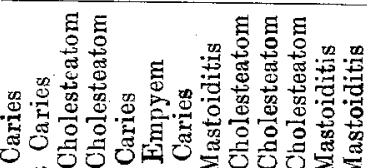

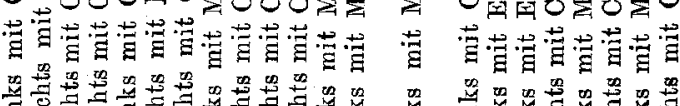

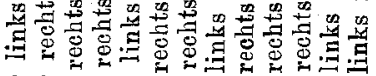
so so on o

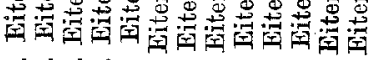

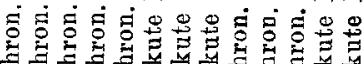

\section{咅}

尊

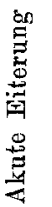

Ex

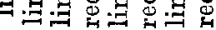

80 so bc 80 bo 00 so 50

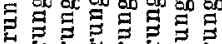

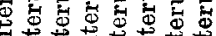

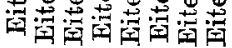

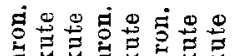

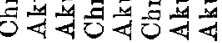

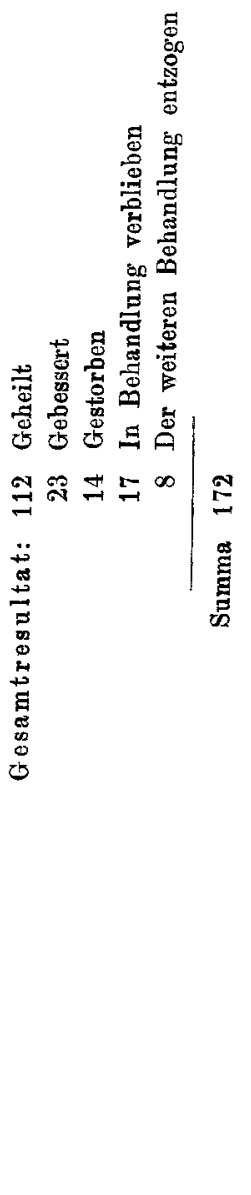

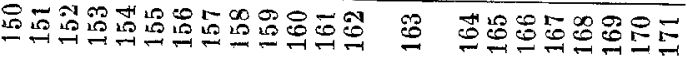


Das Erscheinen des Jahresberichtes pro 1907,08 hat sich diesmal außergewöhnlich verspätet. Schuld daran trägt die Verzögerung in der Anfertigung der Vorarbeiten und Platzmangel fitr den Abdruck. Bei den überaus zahlreich eingehenden Beiträgen für das Archiv glaubte ich den zur Verfügung stehenden Raum in erster Linie den Autoren dieser Beiträge gewähren zu müssen. Dabei möchte ich aber den geehrten Mitarbeitern den dringenden Wunsch wiederholen, die einzuliefernden Beiträge in möglichst knappe Form zu kleiden, Tabellen aber und Tafeln nur dann in Anspruch zu nehmen, wo sie zum Verständnis des Inhalts absolut unentbehrlich erscheinen. - 